\title{
Disseminated Intravascular Coagulation and Related Syndromes: A Clinical Review
}

\author{
RODGER L. BICK, M.D., F.A.C.P.
}

\begin{abstract}
Disseminated intravascular coagulation (DIC) is not an independent disease entity but rather an intermediary mechanism of disease and is usually seen in association with well-defined clinical entities. ${ }^{1,2}$ The pathophysiology of DIC serves as an intermediary mechanism of disease in many localized disease processes which, in some instances, remain organ specific. This catastrophic syndrome spans all areas of medicine and presents a wide clinical spectrum that remains confusing to many clinicians. The syndrome of DIC was referred to in the early literature as "consumptive coagulopathy"; $;, 4$ this is not an appropriate term because very little is consumed in DIC; most factors and plasma constituents are plasmin biodegraded. Terminology that followed this initial descriptive phrase was that of "defibrination syndrome"; 5,6 however, a more appropriate term would be a "defibrinogenation syndrome." The most common and current terminology "DIC" is a good descriptive pathophysiologic term if one accepts that coagulation represents hemorrhage plus thrombosis. ${ }^{7}$

Most consider DIC to be a systemic hemorrhagic syndrome; however, this is only because hemorrhage is obvious and often is impressive. What is less commonly appreciated is the significant amount of microvascular thrombosis and, in some instances, large vessel thrombosis that is also occurring. In fact, the hemorrhage is often easy to contend with in patients with fulminant DIC, and it is the small vessel and large vessel thrombosis with impairment of blood flow, ischemia, and associated end-organ damage that
\end{abstract}

Associate Clinical Professor, Department of Medicine, Division of Hematology/Oncology, and the Jonsson Comprehensive Cancer Center, University of California, Los Angeles, and the Regional Cancer and Blood Disease Center of Kern, Bakersfield, California.

Reprint requests: Dr. Bick, Regional Cancer and Blood Disease Center of Kern, 3550 Q Street, Bakersfield, CA 93301. usually leads to irreversible morbidity and mortality of the patient. Thus, DIC is a syndrome associated with hemorrhage, which is often clinically obvious, and with diffuse thromboses, which may lead to irreversible end-organ damage and death; it is this latter complication that is difficult to stop or reverse.

Throughout this text, acute versus chronic DIC and the attendant differences in clinical manifestations, laboratory findings, and treatment will be discussed. However, it should be realized that these are often pure and often theoretical clinical spectrums of a disease continuum, and patients may present anywhere in this continuum and, in fact, may lapse from one end of the spectrum to the other.

\section{HISTORICAL PERSPECTIVES}

The first description of DIC comes from a lecture delivered by Walter H. Seegers, then Professor and Chairman of the Department of Physiology at Wayne State University, to the Cincinnati Academy of Medicine on April 18, 1950, and subsequently published in that Academy's journal. ${ }^{8}$ This lecture gave special reference to Factor $V$, which had recently been discovered. During this presentation, it was postulated that "thromboplastin" may gain access to the maternal circulation and cause hemorrhagic problems. Several essential steps in developing this concept were discussed and thus served as the first logical pathologic thinking regarding DIC. Seegers recognized that thromboplastin was present in many tissues and could initiate the blood clotting mechanism directly by activating prothrombin. In addition, when thromboplastin was deliberately placed in the circulation of animals, a variety of pathologic responses were obtained. Seegers also recognized that in experimental animal models mechanical trauma of the placenta released material that was likely to be thromboplastin and induced a variety of pathologic changes in the 
animal. Also, a study of human cases revealed that many of the pathologic lesions corresponded to those produced by thromboplastin in animal models. Shortly before delivering this lecture, Seegers and his colleague Charles L. Schneider had been able to demonstrate that amniotic fluid and placenta contained a large amount of thromboplastin. Seegers also noted that, during observations in animal models, the injection of thromboplastin caused cessation of blood flow in small vessels altogether, and, if the animals were carefully examined, it was found that death was due to characteristic intravascular thrombotic lesions and that thromboembolism was present throughout the pulmonary vascular tree. It was also found that the central nervous system was damaged by perivascular hemorrhage and, additionally, liver necrosis was present. Thus, Seegers not only first described DIC and offered a pathophysiologic mechanism, but also recognized that hemorrhage plus thrombosis is the usual clinical result. These observations were extended to several patients who were discussed in this early lecture; three of these patients were instances of eclampsia. In addition, Seegers described a case of complete placental abruption with nearly complete "defibrination" in the patient; this was demonstrated by repeated laboratory assays for circulating fibrinogen.

These studies were expanded on and reported at the IVth American Congress on Obstetrics and Gynecology in $1951 . .^{9}$ During this presentation the investigators focused attention on thromboplastin and reviewed reasons why thromboplastin might be responsible for a group of "perplexing disorders" of late pregnancy, including the intracranial hemorrhagic diathesis of pregnancy, and toxemia of pregnancy. These investigators also recognized that thromboplastin led to an underlying disease process of intravascular coagulation, with thromboplastin presumably entering the bloodstream, and although this material initiates the blood clotting mechanism or procoagulant system, it may be carried some distance and mixed with a variable volume of blood before fibrin starts to form in the microcirculation. This process of coagulation then results in a depletion of fibrinogen and a resultant extensive defibrination, and following this blood was noted to be refractory to further injections of thromboplastin because of inadequate fibrinogen. They stated "by the same token, however, animals are subject to grave danger due to uncontrolled hemorrhage, for an important portion of the hemostatic mechanism has been depleted." They concluded by pointing out that the mechanism of thromboplastin introduction to the systemic maternal circulation needed to be considered a factor in several complications of late pregnancy and not simply as one type of compli- cation because the resultant foci of tissue destruction in different organs will cause differing clinical manifestations.

Also at this same meeting Seegers and Schneider ${ }^{9}$ documented and quantitated the degree of thromboplastin or procoagulant material that could be obtained from the placenta, decidua, and amniotic fluid. In addition, they presented a hypothetical mechanism by which intravascular coagulation might occur due to this thromboplastin material. It was proposed that maternal blood within a retroplacental hematoma became admixed with material fragmented from or leached out of the torn uterine decidua within which the hematoma was enclosed. This mixture, rich in thromboplastin material from the decidua, could then enter the circulation by one path or another, with the most likely path being into the maternal lake within the placenta. Once within the maternal lake, this admixture would be likely to be distributed throughout the maternal circulation. Thus, these are the first descriptions of clinical DIC.

In the same year in the Harvey Lectures Seegers ${ }^{10}$ further reported on decreases in Factor V as well as fibrinogen during the hemorrhagic complications of pregnancy. In 1952 this important work was further expanded and reported. ${ }^{11}$ In this report was described and incorporated the role of the accelerated conversion of prothrombin to thrombin, thus leading to subsequent defibrinogenation and hemorrhagic complications of pregnancy. ${ }^{11}$ In 1953, this original work was extended to the clinical field and published by Seegers and coworkers, ${ }^{12}$ who developed guidelines for early cesarean section to abort the hemorrhagic syndrome, which they called "defibrination." Major clinical extensions of this initial observation were shortly thereafter reported by Ratnoff and coworkers. ${ }^{13,14}$ In this two part article, many profound observations were described, including the following: the hemorrhagic syndromes of pregnancy included premature separation of the placenta, amniotic fluid embolism, the presence of a dead fetus in utero, and severe preeclampsia or frank toxemia of pregnancy. In addition, they recognized that a generalized bleeding tendency may occur as a sequel to "criminal abortion." It was also noted that the treatment of a patient with a hemorrhagic diathesis associated with premature separation of the placenta consisted, most importantly, of early evacuation of the uterus; it was pointed out that if labor did not occur promptly, it was difficult to keep a patient out of shock, or if laboratory tests revealed progressive hypofibrinogenemia, it was probably in the best interest of the patient to empty the uterus promptly by cesarean section. The reader will appreciate that this was profound thinking for 
1955. In addition, in the conclusion of this article it was recognized that more than simply hypofibrinogenemia was accounting for the hemorrhagic syndromes associated with pregnancy, and it was also noted that an "unexplained prolongation of the clotting time and associated severe thrombocytopenia" were present. Thus, it was again recognized that multiple hemostatic defects were present. In addition, Ratnoff and coworkers ${ }^{13,14}$ were the first to note that in patients with amniotic fluid embolism, hemorrhagic symptoms appeared even though the concentration of fibrinogen in the plasma did not seem to be sufficiently low to account adequately for ineffective hemostasis. This, then, was the first description of a multifaceted defect that accounted for the hemorrhage of DIC.

Additional observations were that: "fibrinolysin was thought to be present," thus also rendering the first description of secondary activation of the fibrinolytic system and probably the most important cause of hemorrhage in these patients. In these articles by Ratnoff and coworkers ${ }^{13,14}$ is to be found the first report of septicemia associated with DIC. Two patients were described who had undergone attempts at self-induced abortion and subsequently developed bacteremia with gram-negative coliform bacilli.

In 1962, Ratnoff and Nebehay ${ }^{15}$ published an article on the severe alterations in blood coagulation that may sometimes contribute to the bleeding tendency and shock in the Waterhouse-Friderichsen syndrome. Also reported was a case of DIC associated with incoagulable blood with prolonged clotting and bleeding times, thrombocytopenia, and low levels of fibrinogen, Factor V, and Factor VII in a patient with the Waterhouse-Friderichsen syndrome induced by infection with pneumococcus. Following this, additional reports of DIC began to appear in the literature and finally in the mid-1960s, DIC became a clinically accepted and readily recognized syndrome. However, we owe our basic understanding and appreciation of this syndrome to the astute clinical and laboratory observations of Seegers and Ratnoff and their coworkers; the reader is encouraged to peruse these early descriptions of DIC for a complete appreciation of the discoveries that may be made by careful biochemical observation and equally astute clinical observation.

\section{ETIOLOGY}

\section{Acute DIC}

DIC is usually seen in association with welldefined clinical entities and those clinical entities that are most commonly associated with acute DIC are summarized in Table 1.

Obstetric accidents are common events leading to DIC. Amniotic fluid embolism and associated DIC are the most catastrophic and common of the lifethreatening obstetrical accidents. ${ }^{16,17}$ The syndrome of amniotic fluid embolism is manifested by the acute onset of respiratory failure, circulatory collapse, shock, and a most serious thrombohemorrhagic syndrome of DIC. The first careful description of this syndrome was by Steiner and Lushbaugh in $1941 .{ }^{18}$ In this landmark description, these investigators describe the clinical histories of eight obstetric patients and demonstrated that these patients formed a distinct group with a unique pathophysiologic basis for the constellation of symptoms now associated with this syndrome. These eight patients came from 4000 consecutive autopsies performed over a period of 15 years, representing an incidence of $0.2 \%$ of deaths in their autopsy series. Also in this study, it was recognized that these eight patients were among a total of 24,200 deliveries, thus representing an incidence of 1 in 8000 of their obstetric cases. These investigators, when ana-

TABLE 1. Conditions Associated with Acute Disseminated Intravascular Coagulation

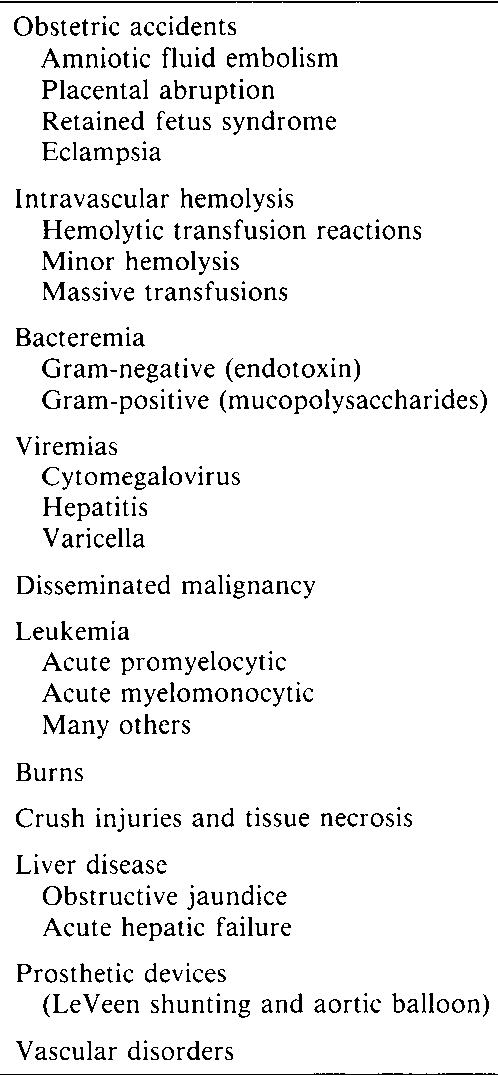


lyzing their data, were the first to show that amniotic fluid embolism was the most common cause of maternal death in the period between labor and the first 9 hours postpartum. The common etiologic factor in this syndrome of amniotic fluid embolism is the entrance, by various proposed mechanisms and routes, of amniotic fluid into the systemic maternal circulation followed by embolization of amniotic fluid and its contents to the lungs; subsequently, circulatory collapse and the development of DIC occurs almost uniformly. The incidence of this catastrophic syndrome has been reported to be between 1 and 8000 and 1 and 30,000 births. ${ }^{18,19}$ The syndrome is commonly fatal for both mother and child. Although the finding of amniotic fluid in maternal blood is not physiologic, there are rare instances when amniotic fluid may enter the systemic maternal circulation without significant manifestations of this catastrophic syndrome. ${ }^{20}$ In a 1970 study it was noted that the syndrome of amniotic fluid embolism represented $10 \%$ of all maternal deaths, and a study in Sweden from 1965 to 1974 demonstrated that the syndrome of amniotic fluid embolism accounted for $22 \%$ of all maternal deaths. ${ }^{21,22}$ The risk factors associated with the development of amniotic fluid embolism are depicted in Table 2, including marked exaggeration of uterine contraction following rupture of the uterine membranes or due to the use of oxytocin or other uterine stimulatory agents. ${ }^{18,23,24}$

The syndrome can, on rare occasions, occur late in pregnancy, but most commonly occurs during labor in $80 \%$ of patients; in only up to $20 \%$ of patients does the syndrome occur before labor begins and before rupture of the amniotic sac. ${ }^{25,26}$ Twentyfive percent of women will die within 1 hour of developing this syndrome and up to $80 \%$ of patients will die within the first 9 hours. ${ }^{27.28}$ It is of interest to note that in $10 \%$ of women the syndrome develops

TABLE 2. Amniotic Fluid Embolism: Risk Factors

Older age
Multiparity
Physiologic intense uterine contractions
Drug-induced intense uterine contractions
Cesarean section
Uterine rupture
High cervical tear
Premature placental separation
Intrauterine fetal death
$80 \%$ of cases develop during labor
$20 \%$ may develop before or after labor

without premonitory warning, usually during delivery, as amniotic fluid enters the systemic maternal circulation during an apparently normal labor.

There is generally rapid onset of signs and symptoms of pulmonary failure and circulatory collapse; in at least $50 \%$ of women this is followed by systemic bleeding. Fifty percent of fetuses die or develop intrauterine distress before the sudden maternal onset of acute respiratory failure and circulatory collapse. The cause of amniotic fluid embolism is only partially understood, but the common causative event is entrance into the systemic maternal circulation of amniotic fluid, which then causes extensive pulmonary microcirculatory occlusion and local pulmonary activation of the procoagulant system; in addition, there is systemic activation of the procoagulant system. This occurs in conjunction with intense induction of pulmonary fibrinolytic activity, presumably via release of pulmonary endothelial plasminogen activator activity in the lungs. Since this is a life-threatening and common syndrome, all clinicians involved with obstetrics and delivery should be familiar with the risk factors depicted in Table 2 and with the patient, immediately preceding, during, or immediately after delivery, who suddenly develops respiratory distress, shock, and uncontrolled bleeding. The general characteristics of amniotic fluid embolism are presented in Table 3. Amniotic fluid contains significant cellular material, including vernix caseosa, squamous epithelial cells, and other debris from the fetus. ${ }^{18,29}$ The lipid content, cellular content, fetal debris, procoagulant activity, and viscosity of amniotic fluid all increase with duration of pregnancy and are at a maximum at time of delivery. ${ }^{30,31}$ In most incidences the actual mechanism (or mechanisms) and site of entry of amniotic fluid into the uterine and, subsequently, systemic maternal circulation remain unclear.

The diagnosis of amniotic fluid embolism should be strongly suspected when there is sudden development of acute respiratory failure during an otherwise normal delivery. The acute respiratory failure occurs from occlusion of pulmonary vessels by amniotic fluid, and intense vasoconstriction of pulmonary ves-

\section{TABLE 3. Amniotic Fluid Embolism:} Incidence and Statistics

1 in 8000 to 1 in 30,000 deliveries

$10 \%$ of all maternal deaths in the United States

$22 \%$ of all maternal deaths in Sweden

$80 \%$ overall mortality

$25 \%$ will die within 1 hour

$50 \%$ fetal death or distress before symptoms 
sels and then further occlusion by platelet-fibrin thrombi. This initial event is usually followed by cardiogenic shock and systemic cardiovascular collapse. The usual clinical findings of acute pulmonary insufficiency are the sudden onset of tachypnea, dyspnea, and peripheral cyanosis due to the abrupt development of abnormal perfusion and diffusion. These findings are usually accompanied by acute cor pulmonale with resultant right-sided failure with subsequent decreased filling of the left ventricle and resultant low output failure and peripheral end organ hypoxia, ischemia, and metabolic acidosis. Abnormal diffusion capacity, metabolic acidosis, and elevated central venous pressure are also noted. Figure 1 demonstrates a fetal squamous cell in a maternal pulmonary capillary.

The approach to management of acute respiratory failure in these patients is straightforward and consists of immediate establishment of an airway, use of oxygen, and a mechanical ventilator if needed. Circulatory collapse must be managed immediately with the use of vasoconstrictive agents, usually dopamine. Other cardiovascular and respiratory modalities may also be needed. Circulatory collapse is further managed by volume replacement. Management of DIC, as will be discussed subsequently, should be via immediate use of heparin to stop quickly further deposition of platelet-fibrin thrombi and further generation of activated coagulation factors.

In instances of placental abruption, placental enzymes or tissues, including thromboplastin-like material, may be released into the uterine and subsequently the systemic maternal circulation and likewise lead to activation of the coagulation system.

In the retained fetus syndrome the incidence of DIC approaches $50 \%$ if the woman retains a dead

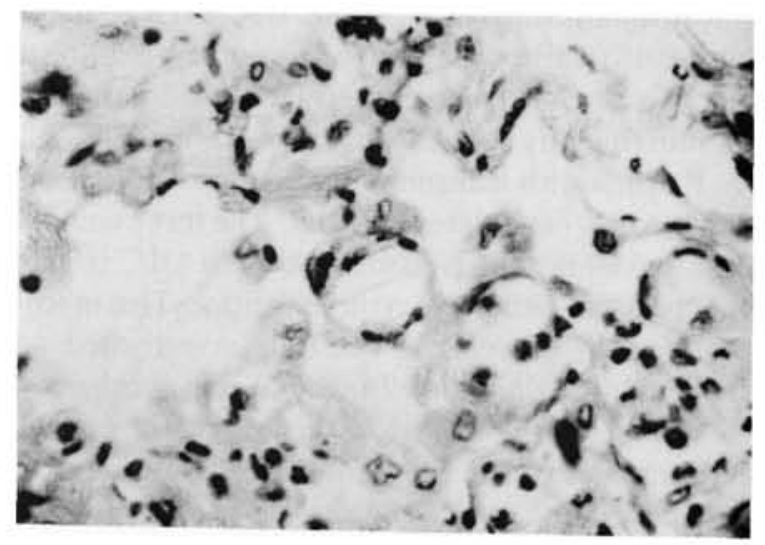

FIG. 1. A fetal squamous cell shown in a capillary of the mother. fetus in utero for greater than 5 weeks. The first findings are usually those of a chronic compensated DIC, which then amplify into a more fulminant hemorrhagic-thrombotic DIC. In this instance necrotic fetal tissue as well as enzymes derived from necrotic fetal tissue are released into the uterine and then the systemic maternal circulation and at various points activate the procoagulant system and trigger an episode of acute DIC. ${ }^{32,33}$

Intravascular hemolysis of any cause is a common triggering event for DIC. A frank hemolytic transfusion reaction is certainly a triggering event for DIC; however, hemolysis of any cause, even minimal, may provide a trigger. During hemolysis, the release of red cell adenosine diphosphate (ADP) or red cell membrane phospholipoproteins may activate the procoagulant system and in clinical practice a combination of these may account for episodes of DIC associated with major or minor hemolysis. ${ }^{34-38}$ An example of this is the use of multiple transfusions with banked whole blood over a short period of time. For example, the use of 5 to $10 \mathrm{U}$ of banked whole blood within a 24-hour period will provide a significant trigger for DIC via the aforementioned mechanisms. Thus, hemolysis due to a frank hemolytic transfusion reaction or even to a minor hemolytic reaction with release of red cell ADP or red cell membrane phospholipoproteins is capable of providing a trigger for activation of the procoagulant system and a subsequent episode of acute DIC.

Septicemia is often associated with DIC. An early organism to be associated with DIC was the meningococcus. ${ }^{39-41}$ Later, other gram-negative organisms were also noted to provide a triggering event for DIC. ${ }^{42,43}$ The triggering mechanisms have been well described and consist of the initiation of coagulation by endotoxin: bacterial coat lipopolysaccharides. ${ }^{44,45}$ Endotoxin has the ability to activate Factor XII to Factor XIIa, to induce a platelet release reaction, to cause endothelial sloughing with subsequent activation of Factor XII to XIIa or Factor XI to XIa, or to initiate a release of granulocyte procoagulant materials; any one of these might independently trigger DIC. However, what is most likely commonly seen is a clinical summation of several or all of these activation sequences. Following these observations, numerous gram-positive organisms were also noted to be associated with DIC and, likewise, the mechanisms have been aptly described. ${ }^{46,67}$ Bacterial coat mucopolysaccharides may demonstrate exactly the same activity as endotoxin, namely, the activation of Factor XII to Factor XIIa, a platelet release reaction, endothelial sloughing, or the release of granulocyte procoagulant materials, any one of which may initiate DIC. How- 
ever, as with gram-negative endotoxemia, what is most likely seen is a clinical summation of several or all of these activation events.

Numerous viremias have been reported to be associated with DIC and the most common are varicella, hepatitis, or cytomegalovirus infections. ${ }^{48,49}$ However, many other acute viremias may also induce DIC. ${ }^{2}$ The exact triggering mechanisms are poorly documented; however, the most likely mechanism is that of antigen-antibody associated activation of Factor XII, a platelet release reaction, or endothelial sloughing with subsequent exposure of subendothelial collagen and basement membrane. ${ }^{50-52}$ Severe viral hepatitis and hepatic failure can lead to DIC. In addition, intrahepatic or extrahepatic cholestasis may be accompanied by acute DIC.

Cancer is often associated with DIC and most persons with disseminated solid malignancy will have at least laboratory evidence of DIC, which may or may not become clinically manifested. If one therefore looks for laboratory evidence of DIC in patients with disseminated solid malignancy, it is almost always found..$^{53-56}$ There are many mechanisms by which malignancy may provide a trigger for initiation of DIC. One such mechanism is simply neovascularization of tumor; the "new vasculature" is comprised of abnormal endothelial lining, which may activate the procoagulant system by several mechanisms. ${ }^{57,58}$ In addition, solid tumors may release necrotic tumor tissue or tumor cell enzymes into the systemic circulation and activate the coagulation sequence. ${ }^{59,60}$ Other mechanisms may also be operative in malignancy; for example, the sialic acid moiety of mucin in mucinous adenocarcinoma tissue is capable of the nonenzymatic activation of Factor $\mathrm{X}$ to Factor $\mathrm{Xa}$, which may then lead to an acute or chronic compensated DIC and this may be manifested in the usual manner or as multiple or single thrombosis. ${ }^{61,62}$

It has long been debated whether prostatic carcinoma is associated with a primary hyperfibrino(geno)lytic syndrome or DIC. Rapaport and Chapman ${ }^{63}$ have clearly shown that malignant prostatic tissue secretes enzyme-type materials that are capable of activating the coagulation system and are associated with the usual secondary fibrinolytic response, which represents a typical DIC syndrome. ${ }^{64,65}$ In addition, these investigations have demonstrated that malignant prostatic tissue may secrete materials that independently activate the fibrinolytic system, converting plasminogen to plasmin. Thus, patients with prostatic carcinoma develop a typical DIC syndrome with secondary fibrinolysis and, in addition, develop primary activation of the fibrinolytic system. Thus, an overwhelming fibrinolytic response is seen in these pa- tients. This accounts for the clinical observation that these patients far more commonly present with hemorrhage rather than thrombosis. Studies done at the Mayo Clinic have revealed that there is a direct correlation between laboratory findings of DIC before transurethral prostatectomy and degree of postprostatectomy blood loss, suggesting that it is prudent to look for evidence of DIC, as defined by elevated fibrin(ogen) degradation products (FDP) and circulating soluble fibrin monomers, because these findings may predict those patients who will bleed following surgery and may predict the need for postoperative blood replacement. ${ }^{66}$

Pancreatic carcinoma has been classically associated with "migratory thrombophlebitis" and the mechanisms have been carefully studied and described. ${ }^{67,68}$ In this instance, the "migratory thrombophlebitis" is nothing more than a clinical manifestation of DIC. The incidence of thrombophlebitis in carcinoma of the pancreas is much higher in patients with carcinoma of the body or tail as opposed to those with carcinoma of the head of the pancreas. When a carcinoma is present in the body or tail of the pancreas, there is minimal ductal obstruction and thus large amounts of trypsin are released into the systemic circulation. Trypsin, a serine protease, possesses activity much like thrombin or Factor $\mathrm{Xa}$ and thus may activate the coagulation system, and a typical DIC-type syndrome results. The clinical manifestation is more commonly thrombosis rather than hemorrhage, in contrast to that seen in prostatic carcinoma. Alternatively, if the carcinoma is located in the head of the pancreas, ductal obstruction is pronounced and only minimal trypsin release occurs and disseminated thromboses are much less commonly seen.

In summary, many patients with disseminated solid malignancy demonstrate laboratory evidence of DIC. However, many patients never develop overt clinical manifestations of acute DIC even though a significant number may have laboratory manifestations of a chronic compensated DIC if it is suspected and subsequently looked for and documented.

Patients with leukemias of either acute or chronic types are also candidates for DIC. The most common acute leukemia that is associated with DIC is acute hypergranular promyelocytic leukemia. The mechanisms for this have been carefully investigated and described by Gralnick and $\operatorname{Tan}^{69,70}$ as well as others ${ }^{71-73}$ and consist of the release of procoagulant material from granules of the progranulocytes. Furthermore, Gralnick et $\mathrm{al}^{74}$ and Bennett ${ }^{75}$ have demonstrated that the use of heparin or miniheparin before the initiation of cytotoxic chemotherapy may ward off the development of DIC and may significantly prolong 
survival. It has certainly been my experience that if a patient with acute promyelocytic leukemia does not actually present with findings of DIC, the patient will almost always develop acute DIC when cytotoxic chemotherapy is initiated; this is initiated by a large population cell "kill" and resultant release of granule procoagulant material into the systemic circulation and subsequent DIC. ${ }^{2,76}$

The next most common leukemia to be associated with acute DIC is acute myelomonocytic leukemia. ${ }^{77}$ However, any acute leukemia or, less commonly, chronic leukemia, may be associated with DIC and may significantly alter the prognosis of patients. ${ }^{2,71,72,76,77}$ Any of the chronic leukemias can be associated with DIC, although much less commonly than the acute leukemias. ${ }^{76}$ Malignancies commonly associated with DIC are listed in Table 4.

Acidosis, and less commonly alkalosis, may also provide triggers for DIC. ${ }^{2,78-80}$ In acidosis the triggering event is most likely due to endothelial sloughing with the attendant activation of Factor XII to XIIa and/or Factor XI to XIa and platelet release with a subsequent activation of the procoagulant system. However, the mechanisms that are potentially operative in cases of alkalosis remain unclear.

Patients with extensive burns are common candidates for DIC and several mechanisms may be operative. ${ }^{81,82}$ Microhemolysis with the attendant release of red cell membrane phospholipids and red cell ADP may provide the trigger. In addition, necrotic burn tissue may be associated with the release of tissue materials and cellular enzymes into the systemic circulation to initiate a DIC-type process. Any patient with a large crush injury and attendant tissue necrosis may also develop DIC by the release of tissue enzymes or phospholipoprotein-like materials into the systemic circulation. . $^{2,76,79}$

Selected vascular disorders and other miscellaneous types of disorders may also be associated with acute DIC; however, these are more commonly associated with a chronic form of this syndrome. ${ }^{2,83,84}$ In particular, all are familiar with the Kasabach-Merritt syndrome, the association of giant cavernous heman-

TABLE 4. Disseminated Intravascular Coagulation and Common Malignancies

\begin{tabular}{ll}
\hline \hline Gastrointestinal & Ovary \\
Pancreas & Melanoma \\
Prostate & Acute leukemia \\
Lung & Myeloma \\
Breast & Mycloproliferative syndromes \\
\hline
\end{tabular}

giomas and DIC. ${ }^{85,86} \mathrm{Up}$ to $25 \%$ of patients with giant cavernous hemangiomas will develop a chronic low-grade "compensated" DIC that may or may not progress into an acute DIC. The progression into an acute from a chronic compensated DIC may occur with or without any particular identifiable reason. Approximately $50 \%$ of patients with hereditary hemorrhagic telangiectasia will also have a chronic DIC syndrome and many of these patients may develop an acute DIC process for unexplained reasons. ${ }^{87,88}$ Patients with small vessel disease, such as vasospastic phenomena, including Raynaud's disease or severe diabetic angiopathy, or angiopathy associated with autoimmune disorders, may also develop chronic DIC, which may or may not become acute. ${ }^{89}$ Vascular disorders associated with DIC are given in Table 5. Many chronic inflammatory disorders, including sarcoidosis, Crohn's disease, and ulcerative colitis, may also be associated with compensated DIC.

Selected prosthetic devices may also provide a triggering event for DIC. Exposure of the blood to foreign surfaces is often linked with activation of the procoagulant system and this may provide a major obstacle in the use of certain prosthetic devices. The use of prosthetic devices has become extremely commonplace in the management of patients with vascular disease, cardiac disease, renal disease, angiographic studies, and ascites. The hemostatic complications that accompany the insertion of prosthetic devices include activation of coagulation factors, "consumption" of coagulation factors as well as other plasma proteins and platelets, and the generation of microthrombi, which may or may not be of clinical consequence. In addition, thrombosis or thromboembolism

TABLE 5. Disseminated Intravascular Coagulation and Vascular Disorders or Defects
Kasabach-Merritt syndrome
Hereditary hemorrhagic telangiectasia
Raynaud's disease
Leriche's syndrome
Vascular prostheses
Autoimmune disorders with vasculitis
Microangiopathic hemolytic anemia
Hemolytic uremic syndrome
Thrombotic thrombocytopenic purpura (rare)
Malignant hypertension
Glomerulonephritis
Angiosarcoma
Arteriovenous fistulas 
may also give rise to serious life-threatening problems with prosthetic devices..$^{90}$ Intra-aortic balloon assist is a widely utilized clinical maneuver to control postmyocardial infarction cardiogenic shock, and to stabilize selected patients after bypass surgery. Activation of the coagulation system with an attendant low-grade DIC, which may become fulminant and acute, may accompany the use of these devices..$^{90}$ LeVeen valve shunting for peritoneovenous shunting has become a common palliative procedure for the treatment of intractable ascites associated with severe liver disease or malignant ascites. A generalized DIC-type syndrome is frequently seen with the use of the LeVeen shunt. ${ }^{90}$ It has been noted that the removal of ascitic fluid at the time of valve implantation, as well as the use of selected anticoagulants, may abort DIC in these patients. ${ }^{76,90}$ In an acute situation, simply placing the patient with a LeVeen shunt and DIC in a sitting position will usually stop the shunt function and, at least temporarily, abort the DIC process.

\section{Chronic Disseminated Intravascular Coagulation}

Chronic DIC is a compensated event and represents the pure end of a clinical spectrum that may not always represent reality. ${ }^{91}$ Those conditions that are most commonly associated with a chronic DIC-type process are depicted in Table 6. Obstetrical accidents are common causes of chronic DIC. The retained fetus syndrome usually represents an acute DIC process; however, many women with a retained dead fetus may develop a chronic-type DIC syndrome that then slowly amplifies into a more fulminant acute process. ${ }^{92}$ Likewise, eclampsia represents the straightforward pathophysiologic features of DIC that often remain chronic and often remain organ specific, remaining localized to the renal and placental microcirculation; however, in approximately $10 \%$ of women the process may become systemic and may become acute and fulminant. ${ }^{93,94}$ Many patients undergoing hypertonic saline-induced abortion develop a chronic DIC-type process that in some becomes acute and in others remains chronic and compensated until the abortion is completed. ${ }^{95}$

Cardiovascular diseases may likewise be associated with chronic DIC and on rare occasions patients with acute myocardial infarction may develop a chronic compensated or, alternatively, acute fulminant DICtype process. ${ }^{96}$ The mechanisms remain unclear but may simply be due to shock, hypoxia, and acidosis, with resultant endothelial sloughing or activation of the contact activation system via stasis. Peripheral vascular diseases, such as giant cavernous hemangiomas, hereditary hemorrhagic telangiectasia, Leriche's
TABLE 6. Conditions Associated with Chronic Disseminated Intravascular Coagulation

Obstetric accidents
Eclampsia
Retained fetus syndrome
Saline-induced abortion
Cardiovascular diseases
Acute myocardial infarction
Peripheral vascular disease
Leriche's syndrome
Metastatic malignancy
Hematologic diseases
Paroxysmal nocturnal hemoglobinuria
Polycythemia vera
Agnogenic myeloid metaplasia
Collagen vascular disorders
(especially if a microvascular component)
Renal disorders
Glomerulonephritis
Renal microangiopathies
Hemolytic uremic syndrome
Miscellaneous disorders
Allergic vasculitis
Sarcoidosis
Amyloidosis
Chronic inflammatory disorders
Diabetes mellitus
Hyperlipoproteinemias

syndrome, and selected small vessel diseases, may lead to a chronic compensated DIC process that may remain chronic or may progress to a more acute phase. ${ }^{97,98}$

The vast majority of patients with disseminated malignancy have laboratory findings of a chronic DIC-type process, although many of them never develop specific clinical signs and symptoms of DIC. Pulmonary hemorrhage is a very early and prominent sign of chronic DIC in the patient with cancer. ${ }^{54,99}$ Approximately $75 \%$ of patients with cancer and chronic DIC will eventually develop clinical evidence of this syndrome and $25 \%$ will develop some type of significant thrombotic event. ${ }^{1,2}$ As will be discussed under "Therapy," many patients with chronic DIC and cancer may show marked correction of both the clinical hemorrhage or thrombosis as well as laboratory findings of DIC when aggressive antineoplastic therapy is instituted..$^{2,54,100-102}$ Many hematologic disorders have also been associated with DIC. Agnogenic myeloid metaplasia has been associated with DIC and likewise a significant number of patients with polycythemia rubra vera have clinical and laboratory findings of an underlying chronic compensated DIC-type process. ${ }^{53,54,103,104}$ There is an increased tendency for thrombosis or thromboembolism in patients with paroxysmal nocturnal hemoglobinuria, and this represents a DIC-type process that is clinically manifested primarily as thrombosis. ${ }^{105,106}$ 
Collagen vascular diseases may also be associated with DIC, and any patient with a collagen vascular disorder, especially when associated with significant small vessel involvement, may develop DIC. This DIC, usually in a chronic compensated form, may be seen in patients with severe rheumatoid arthritis, systemic lupus erythematosus, Sjögren's syndrome, dermatomyositis, and scleroderma. Again, this is most commonly seen when these disorders are associated with a severe microvascular component. ${ }^{1,2,107}$

Hemolytic uremic syndrome (HUS) like eclampsia, shares similar pathophysiologic features with DIC. However, HUS often remains organ specific and localized to the renal microcirculation. ${ }^{108,109}$ In approximately $10 \%$ of patients with HUS the syndrome becomes systemic. ${ }^{2,76}$ It should be appreciated that when patients with HUS are seen, it is often clinically impossible to know whether the disease started as a primary insult to the renal vasculature and subsequent activation of the coagulation system or whether there was a primary activation of the coagulation system that initiated a localized or systemic DIC process that then subsequently induced local damage to the renal microcirculation secondary to fibrin deposition. No matter where the process started, the clinical manifestations may be quite similar; more importantly, when a patient with HUS is seen, it is often impossible to know where the cycle was initiated.

Numerous miscellaneous disorders have been reported to be associated with DIC, including the allergic vasculitides, such as Henoch-Schönlein purpura and the other allergic purpuras, sarcoidosis, amyloidosis, chronic ulcerative or inflammatory conditions, including Crohn's disease, acquired immune deficiency syndrome, ulcerative colitis, and severe dia- betes mellitus, especially when associated with a significant microvascular component. ${ }^{110-112}$ In addition, a chronic compensated DIC-type syndrome may occur in patients who have hyperlipoproteinemias types II and IV. ${ }^{113}$ On rare occasions, patients may develop a chronic DIC-type process in which no cause can be found. ${ }^{1,2,76}$

Figure 2 exemplifies how a wide variety of seemingly unrelated pathophysiologic insults can give rise to the same common final pathway, the syndrome referred to as DIC. There are many disorders associated with endothelial damage, circulating antigenantibody complex, endotoxemia, tissue damage of any type (with resultant release of tissue procoagulant materials or tissue procoagulant enzymes), platelet damage and release, or red cell damage. ${ }^{114-116}$ When one of these insults occurs, there are many potential activation pathways that may eventually give rise to systemically circulating plasmin plus systemically circulating thrombin. When these two enzymes are circulating systemically, DIC is the usual result. ${ }^{1,2,117-119}$ In many instances, the pathways leading from the initial pathophysiologic insult to the generation of systemic thrombin and plasmin are different; regardless of the activation pathway. Once triggered, the resultant DIC-type pathophysiology remains the same.

\section{PATHOPHYSIOLOGY}

The pathophysiologic changes in DIC, once a triggering event has been provided, are summarized in Figure 3. After the coagulation system has been activated and both thrombin and plasmin circulate systemically, the pathophysiologic changes of DIC are

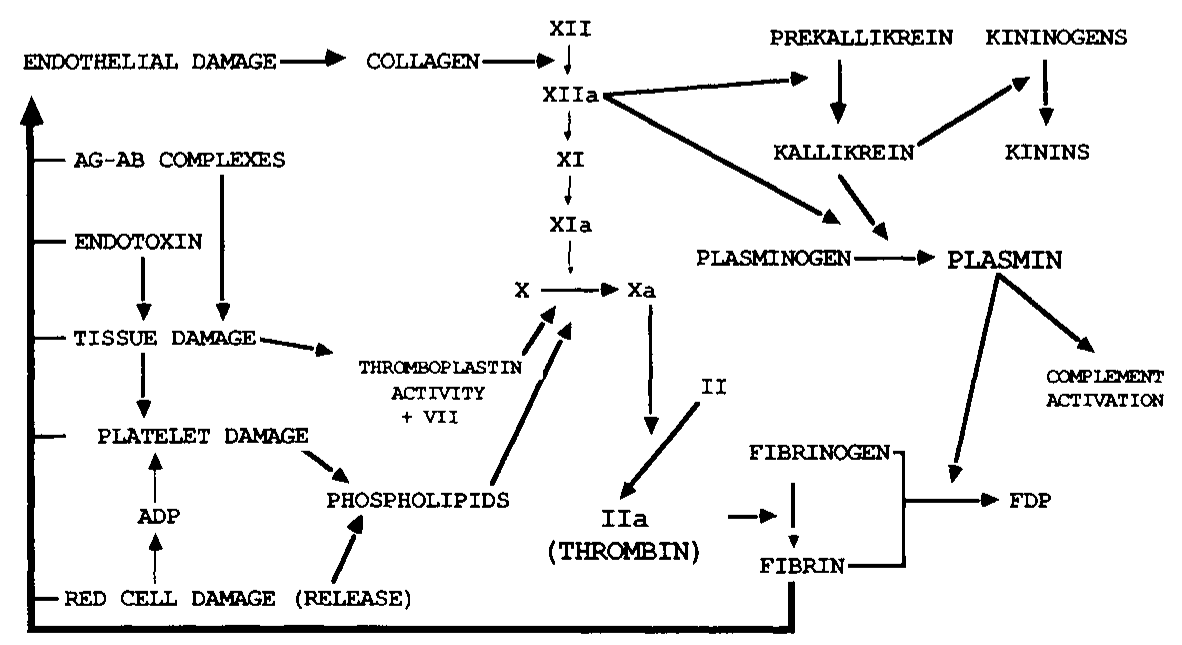

FIG. 2. A schema of the triggering mechanisms in disseminated intravascular coagulation. $A G-A B$ : antigen-antibody. 


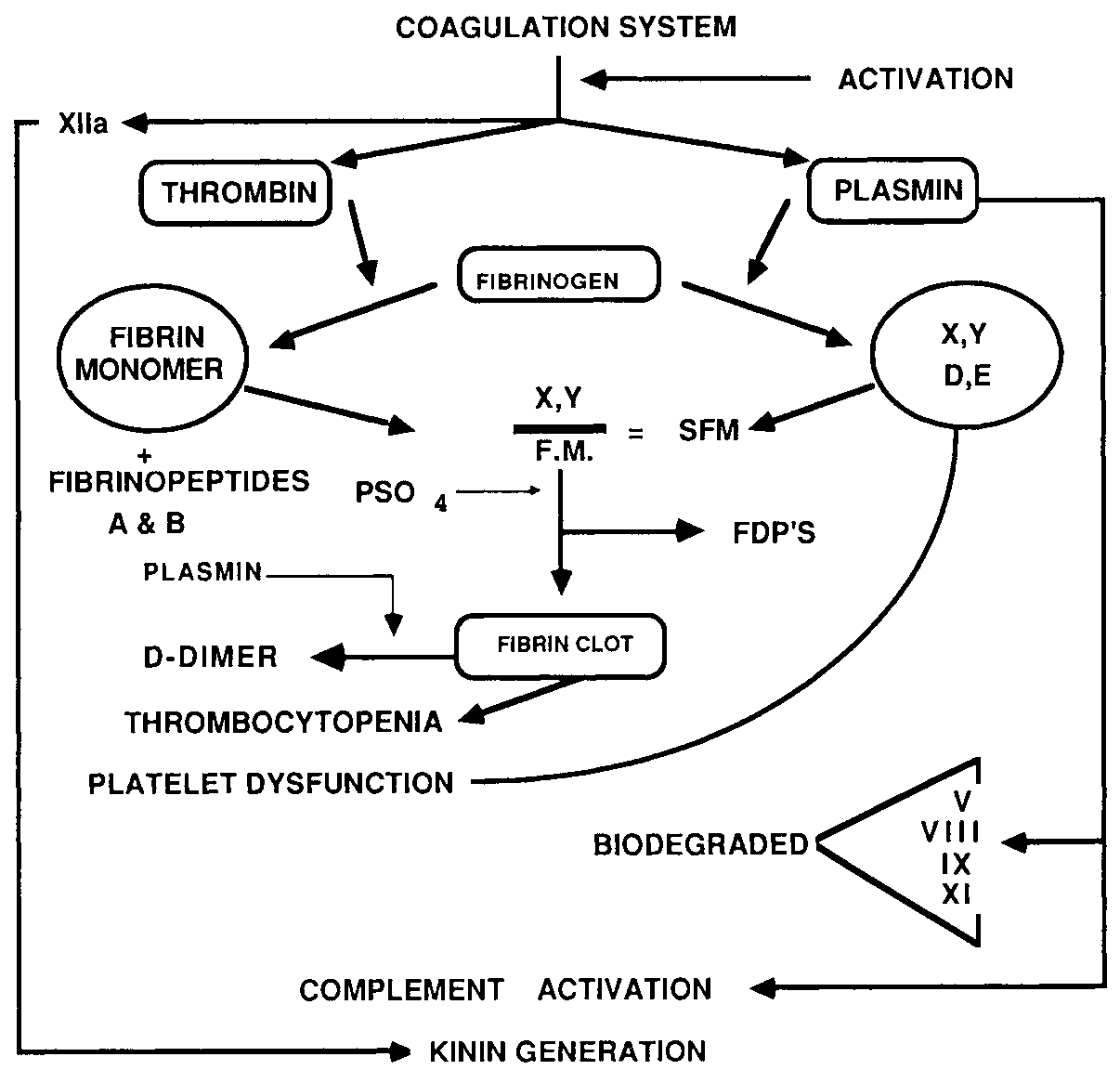

FIG. 3. A schema of the pathophysiologic changes in disseminated intravascular coagulation.

relatively constant in all disorders. When thrombin circulates systemically, it behaves as it would locally and begins to cleave fibrinopeptides $\mathrm{A}$ and $\mathrm{B}$ from fibrinogen, thus leaving behind fibrin monomers. Most of the fibrin monomers will then polymerize into fibrin (clot) in the microcirculation, leading to microvascular and macrovascular thrombosis, interference with blood flow, peripheral ischemia, end-organ damage, and other attendant findings. ${ }^{1,2,76,120-122}$ As fibrin is deposited in the microcirculation, platelets become trapped and the usual attendant thrombocytopenia, typical of DIC, follows. ${ }^{123,124}$ On the other side of the "circle" depicted in Figure 3 it is noted that plasmin also now circulates systemically and behaves as it normally would locally and begins to cleave the carboxy-terminal end of fibrinogen into FDP systemically, thus creating the clinically recognized X, Y, D, and $E$ fragments. ${ }^{125-128}$ It should be noted that plasmin also rapidly releases specific peptides, the $\mathrm{B} \beta$ 15-42 and related peptides, which also serve as diagnostic molecular markers and will be discussed subsequently. FDP may combine with circulating fibrin monomers before fibrin monomers have polymerized into fibrin.
When these degradation products complex with fibrin monomer, fibrin monomer cannot polymerize and therefore becomes solubilized. This complex of degradation products and fibrin monomer is referred to as soluble fibrin monomer, which is a significant aid in the diagnosis of DIC. The presence of soluble fibrin monomer forms the basis of the paracoagulation reactions, the ethanol gelation test, or the protamine sulfate test. ${ }^{129-132}$ If one adds protamine sulfate or ethanol to a citrated tube of patient plasma containing soluble fibrin monomer, the ethanol or protamine sulfate will clear the FDP from fibrin monomer, fibrin monomer will then complex with other fibrin monomer and polymerize. As a result fibrin strands are formed in the test tube and this is interpreted as a positive protamine sulfate or ethanol gelation test. ${ }^{133-135}$ Thus, systemically circulating FDP interfere with fibrin monomer polymerization. This, of course, further impairs hemostasis and leads to hemorrhage. An additional biologic activity of degradation products is that the later fragments have a high affinity for platelet membranes and coat their surfaces. This often creates a very clinically significant 
platelet function defect. ${ }^{136-138}$ Thus, when seeing a patient with DIC who has a reasonable platelet count and is only mildly to moderately thrombocytopenic, the clinician should not mistakenly harbor a false sense of security because it must be appreciated that those platelets remaining in the circulation are usually significantly dysfunctional and may lead to, or contribute to, clinically significant hemorrhage.

Plasmin, unlike thrombin, is a general proteolytic enzyme that has equal affinity for fibrinogen and fibrin. ${ }^{139,140}$ In addition, plasmin also effectively biodegrades many clotting factors, including Factors V, VIII, IX, and XI, and other plasma proteins, including growth hormone, adrenocorticotropic hormone, $(\mathrm{ACTH})$, and insulin. ${ }^{141-144}$ As plasmin degrades cross-linked fibrin, specific FDP appear in the circulation; one of these is D-dimer, which will be discussed subsequently. Additionally, as plasmin circulates systemically, it often activates both $\mathrm{C} 1$ and $\mathrm{C} 3$ systemically with the attendant activation of the entire complement sequence leading to $\mathrm{C} 8,9$ activation and subsequent cell and platelet lysis. ${ }^{145-147}$ This is of significance clinically in DIC and related syndromes associated with circulating plasmin because the attendant red cell lysis will release red cell ADP and red cell membrane phospholipid, thus providing more procoagulant material. In addition, complement-induced platelet lysis will not only cause further thrombocytopenia, but also will provide more platelet procoagulant material. Of additional clinical concern, activation of the complement system will increase vascular permeability, thus leading to hypotension and shock.

Activation of the kinin system is also an important pathophysiologic event with serious clinical consequences in DIC and related syndromes. With early activation of the coagulation system, as commonly occurs in DIC, there is usually generation of Factor XIla, with the subsequent conversion of prekallikrein to kallikrein and subsequent conversion of high molecular weight kininogen into circulating kinins. ${ }^{148-151}$ This, of course, also leads to increased vascular permeability, hypotension, and shock.

In summary, as thrombin circulates systemically, the consequences are primarily thrombosis with deposition of fibrin monomer and polymerized (crosslinked) fibrin in the microcirculation and, at times, large vessels. Concomitantly, plasmin also circulates systemically. This enzyme primarily accounts for the hemorrhage seen in DIC because of the creation of FDP and the interference of these degradation products with fibrin monomer polymerization and platelet function. Additionally, plasmin-induced lysis of numerous aforementioned clotting factors also leads to hemorrhage. By appreciating these circular types of pathophysiologic events, it is easy to appreciate why the vast majority of patients with DIC are sustaining hemorrhage plus thrombosis. Clinicians are often misguided by appreciating only the hemorrhage that occurs in these patients, because this is the most obvious physical finding noted during clinical examination. However, less often appreciated, but of equal or more importance, is the marked degree of microvascular thrombosis and, at times, large vessel thrombosis occurring and leading to end-organ damage, which may be extremely difficult to reverse. Thus, microvascular thrombosis and subsequent interference with blood flow and end-organ damage are usually not appreciated until laboratory parameters provide a clue to their presence, for example, impending renal failure, pulmonary failure, elevated muscle-derived enzymes, liver enzymes, bone enzymes, and severely compromised pulmonary function. Therefore it is important to realize that the majority of patients with DIC are not only undergoing significant hemorrhage, but also significant and often diffuse thrombosis. ${ }^{152-155}$ It should again be emphasized that it is usually thrombosis that is the more irreversible insult and more commonly leads to altered morbidity and mortality due to ischemic changes, end-organ damage, and potential death of the patient.

Figure 4 represents selected pathocybernetic events in DIC. These events are depicted for illustrative purposes; only several events in a DIC episode have been selected. Many others could have been selected to exemplify the all-important point that once a DIC process is initiated, the cybernetic nature of the coagulation system and the DIC process itself is such that the process will continue to self-perpetuate until something is done medically to intervene with the procoagulant drive. ${ }^{156}$ For example, if starting with a clinical insult resulting in damaged endothelium, damaged endothelium will subsequently convert Fac-

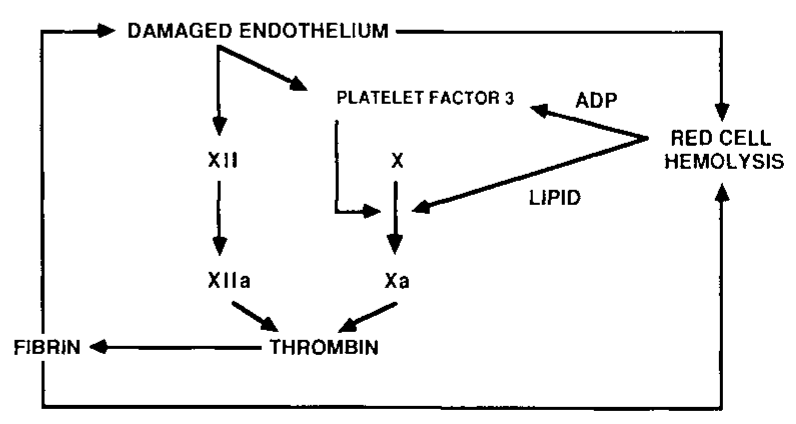

FIG. 4. A schema of the pathocybernetic events in disseminated intravascular coagulation. 
tor XII to Factor XIIa with the eventual generation of thrombin and the subsequent generation of fibrin; deposition of fibrin on the endothelium will cause more damaged endothelium. Thus, a self-perpetuating cycle is initiated, until stopped. In this selected instance the damaged endothelium will also lead to platelet release with eventual availability of platelet factor 3, leading to the conversion of Factor $\mathrm{X}$ to Factor Xa with the eventual generation of thrombin, more fibrin deposited on the endothelium, and more endothelial damage and more platelet release. Also in this selected instance the damaged endothelium will likely give rise to red cell hemolysis, as may the deposited fibrin, thus giving rise to release of red cell ADP causing more platelet release, more thrombin generation, further fibrin deposition, further endothelial damage, and further red cell hemolysis. Red cell hemolysis will, of course, also release red cell membrane phospholipid, which may also give rise to eventual Factor Xa generation, thrombin generation, and fibrin deposition, which, likewise, is associated with more red cell hemolysis and damaged endothelium with attendant red cell hemolysis. Thus, the nature of the process is circular and self-perpetuating; until something is done medically to intervene, the pathophysiologic process will continue. Table 7 depicts those clinical situations that may give rise to platelet factor 3 release to possibly initiate or, more importantly, perpetuate a DIC-type episode. The presence of subendothelial collagen, epinephrine, circulating antigen-antibody complexes, endotoxin, thrombin, or complement activation (possible through previous plasmin generation) will all cause a platelet factor 3 release and continue to augment a DIC process. ${ }^{157-160}$ In addition, but less likely, any one of these may independently cause a platelet factor 3 release that may initiate rather than simply perpetuate a process of DIC. However, it is likely that the availability of platelet factor 3, by any of the aforementioned potential mechanisms, is probably more important as an accelerating and self-perpetuating process rather than

TABLE 7. Potential Inducers of Platelet Factor 3 Release in Disseminated Intravascular Coagulation

Exposed collagen (subendothelial)

Elevated epinephrine levels

Circulating antigen-antibody complexes

Complement activation

Endotoxin

Thrombin a strictly etiologic singular mechanism in the initiation of DIC.

Table 8 depicts the consequences of endotoxemia in initiating DIC. Endotoxin (bacterial coat lipopolysaccharide) is capable of inducing a granulocyte release of procoagulant or coagulation-activating enzymes, of directly converting Factor XII to Factor XIIa, may induce a platelet release reaction, and may cause endothelial sloughing with subsequent exposure of subendothelial collagen. ${ }^{161-166}$ Any one of these insults may independently initiate an episode of acute DIC; however, what is most likely clinically seen is a summation of several or all of these events in patients with endotoxemia and DIC.

Table 9 depicts the clinical consequences of activating Factor XII to Factor XIIa in an episode of DIC. When Factor XIIa is circulating, there may be activation of the fibrinolytic system via mechanisms previously discussed. Subsequent to this there will be plasmin-induced biodegradation of numerous coagulation factors and the clinical manifestations of this will be hemorrhage. Secondly, the generation of Factor XIla may lead to kinin activation with attendant vasodilation and the resultant clinical manifestations of hypotension and shock. ${ }^{167-171}$ Thirdly, as Factor XIIa circulates and activates the fibrinolytic system, there will be subsequent activation of the complement system with cell lysis, vascular changes, and a platelet release reaction. ${ }^{172,173}$ Platelet release will likewise provide more coagulant material to self-perpetuate the intravascular clotting process; the vascular changes of

TABLE 8. Endotoxin and Induction of Disseminated Intravascular Coagulation

Granulocyte release

Activation of Factor XII to XIIa

Platelet release

Endothelial damage

TABLE 9. Clinical Consequences of Factor XIla Generation in Disseminated Intravascular Coagulation

Activation of fibrinolysis

Biodegradation $\rightarrow$ hemorrhage

Kinin activation

Vasodilatation $\rightarrow$ hypotension and shock

Complement activation

Vascular changes

Cell lysis and release

Platelet lysis and release 
complement activation are comprised of increased vascular permeability, again leading to hypotension and shock.

Clinical situations that may give rise to endothelial damage, endothelial sloughing with exposure of subendothelial collagen and subendothelial basement membrane, and the subsequent activation of Factor XII to Factor XIIa and possibly XI to XIa are: viremias (presumably the mechanism is circulating antigen-antibody complex), heat stroke, patients with hyperacute renal allograft rejection, circulating antigen-antibody complexes of any origin, shock with attendant hypoxia and acidosis, endotoxemia, and very importantly ongoing DIC with subsequent vascular damage. ${ }^{174-178}$ Many of the pathophysiologic events in DIC, as previously discussed, will give rise to significant endothelial damage with endothelial sloughing and the exposure of subendothelial collagen and basement membrane and subsequent activation of Factor XII to Factor XIIa and possibly Factor XI to Factor XIa, thus, again, self-perpetuating the DICtype process.

\section{CLINICAL FINDINGS}

The general signs and symptoms of DIC can be highly variable and generally consist of fever, hypotension, acidosis, proteinuria, and hypoxia. ${ }^{1,2,76,179}$ These findings are rather general signs and symptoms and may be found in many disorders and are not particularly helpful from the diagnostic standpoint. However, more specific signs found in patients with DIC that should immediately alert one to the possibility of DIC in the appropriate clinical settings are depicted in Table 10 and consist of petechiae and purpura, which are found in the vast majority of patients with DIC, hemorrhagic bullae, acryl cyanosis and, at times, frank gangrene. ${ }^{1,2,76,179-185}$ In addition, wound bleeding, especially oozing from a surgical or traumatic wound, is an extremely common finding in patients with DIC. ${ }^{1,2}$ Oozing from venipuncture sites or intra-

TABLE 10. Specific Signs in Disseminated Intravascular Coagulation

\begin{tabular}{ll}
\hline Petechiae & Surgical wound bleeding \\
Purpura & Traumatic wound bleeding \\
Hemorrhagic bullae & Venipuncture site bleeding \\
Acral cyanosis & Arterial line oozing \\
Gangrene & Subcutaneous hematomas \\
\hline
\end{tabular}

arterial lines is an additional common finding. ${ }^{2}$ Large subcutaneous hematomas, as well as deep tissue bleeding are also frequently seen., ${ }^{2,76}$ The average patient with acute DIC usually bleeds from at least three unrelated sites. ${ }^{1,2,76,179}$ For example, the patient may have petechiae and purpura, oozing from intravenous sites, and massive gastrointestinal blood loss or may have petechiae and purpura, massive hemoptysis, and hematuria. At times, other types of bleeding may also occur in deep tissues, including intracranial bleeding and intramuscular hemorrhage with compartmental compression syndromes. Any combination of bleeding sites can be seen, and it is unclear as to why different patients will bleed from differing sites. A significant amount of microvascular thrombosis and, at times, large vessel thrombosis may occur in DIC and may not be clinically obvious unless and until looked for. ${ }^{2,76,179,186,187}$ Table 11 depicts the incidence of end-organ dysfunction in DIC, these findings representing microvascular thrombosis of tissues with resultant ischemia and hypoxia rather than end-organ hemorrhage. Those organ systems that have a high incidence of microvascular thrombosis associated with subsequent end-organ dysfunction include cardiac, pulmonary, renal, and central nervous system dysfunction. ${ }^{2,188}$ Thrombotic thrombocytopenic purpura (TTP) is commonly associated with central nervous system dysfunction; however, it should be realized that this clinical finding can be seen just as commonly in acute disseminated intravascular coagulation. ${ }^{189}$

\section{MORPHOLOGIC FINDINGS}

Morphologic findings in DIC are summarized in Table 12 and consist of characteristic but not pathognomonic peripheral smear findings as well as hemorrhage in any organ or combination of organs. ${ }^{190,191}$ Any organ may be associated with severe hemorrhage

TABLE 11. End-Organ Dysfunction from Microthrombi in Disseminated Intravascular Coagulation

\begin{tabular}{cc}
\hline \hline Organ System & Percent Involved \\
\hline Skin & 70 \\
Lungs & 50 \\
Kidneys & 50 \\
Pituitary & 50 \\
Liver & 35 \\
Adrenals & 30 \\
Heart & 20 \\
\hline
\end{tabular}


TABLE 12. Typical Morphologic Findings in Disseminated Intravascular Coagulation

Peripheral smear alterations

Hemorrhage in various organs

Platelet-rich microthrombi: early (usually with vasoconstriction)

Fibrin monomer and fibrin oligomer: early

Fibrin-rich hyaline microthrombi: late

Pulmonary "hyaline membranes" in patients with acute or chronic DIC. Early morphologic findings are platelet-rich microthrombi. ${ }^{190,191}$ These are usually seen in association with intense vasoconstriction, presumably due to compounds released from platelets, including biogenic amines, adenine nucleotides, and kinins. ${ }^{192}$ These are later replaced by hyaline-rich microthrombi. ${ }^{190,191}$ In addition, another early finding is that of fibrin monomer deposition, primarily in the reticuloendothelial system; these findings require special staining. ${ }^{193}$ Later findings in patients with acute DIC are the typical fibrin-rich hyaline microthrombi that are thought to replace earlier deposited platelet-rich microthrombi and fibrin monomer deposits. ${ }^{194,195}$ In addition, many patients with acute DIC develop typical pulmonary hyaline membranes that account, in part, for the significant degree of pulmonary dysfunction and hypoxemia seen in these patients. ${ }^{76,196,197}$ In this regard it should be noted that pure adult shock lung syndrome is most likely an organ-specific DIC-type pathophysiologic event that usually remains localized to the pulmonary bed. ${ }^{2} \mathrm{Pe}-$ ripheral smear alterations typically seen in DIC are depicted in Table 13. Schistocytes are red cell fragments, including typical so-called Heilmeyer helmet cells, which are seen in approximately $50 \%$ of patients with acute DIC. ${ }^{112,113,198,199}$ Schistocytes are shown in Figure 5. The mechanisms for the formation of schistocytes in acute DIC have been elegantly demonstrated by Bull and associates, ${ }^{200,201}$ who described fibrin-red cell interactions. It is to be emphasized that the absence of schistocytes can certainly not be used to rule out a diagnosis of acute DIC, since they only occur in $50 \%$ of patients. The majority of patients with acute DIC will also present with a mild reticulocytosis and a mild leukocytosis, usually associated with a mild to moderate shift to immature forms. The degree of thrombocytopenia that is usually present in most instances of acute DIC is often obvious by examination of the peripheral blood smear. ${ }^{202,203}$ In addition, many so-called large bizarre platelets representing young platelets are usually seen on the peripheral
TABLE 13. Typical Peripheral Smear Alterations in Disseminated Intravascular Coagulation

Schistocytes (red cell fragments)

Reticulocytosis

Polychromatophilia

Leukocytosis with mild shift

Thrombocytopenia

Large young platelets

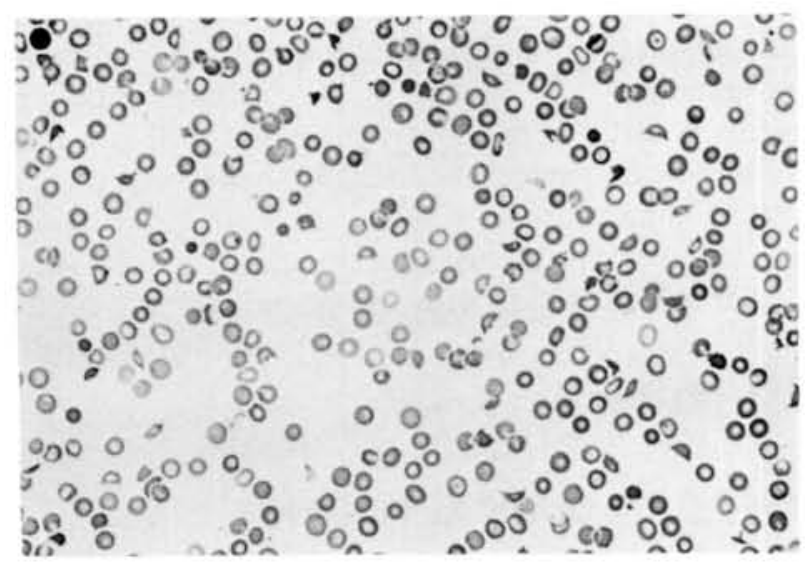

FIG. 5. Schistocytes found in the blood of a woman with disseminated intravascular coagulation.

smear in patients with DIC; this finding most likely simply represents an increased population of young platelets due to increased platelet turnover and decreased platelet survival due to platelet entrapment in microthrombi. ${ }^{204,205}$

Platelet-rich microthrombi are early findings in patients with DIC and are often easily demonstrated in the pulmonary microcirculation where they are usually seen in association with intense vasoconstriction due to vasoconstrictive compounds released from platelets. It is thought that these platelet-rich microthrombi are later replaced by more typical hyalinerich microthrombi. ${ }^{190,191,206}$ Fibrin monomer may also be precipitated early in DIC, but this is not commonly appreciated, since fibrin monomer is not demonstrated with usual staining techniques and requires periodic acid-Schiff (PAS) staining after ethanol fixation of appropriate tissue. Fibrin monomer is most commonly precipitated in the reticuloendothelial system. The precipitation of fibrin monomer may cause significant end-organ damage due to primary cellular or tissue damage as well as to microvascular occlusion. In addition, with this precipitation will come 
impaired reticuloendothelial clearance of FDP, activated clotting factors, and circulating soluble fibrin monomers.

Typical hyaline microthrombi occurring later in an episode of DIC and commonly accounting for significant end-organ damage are of three types. First, globular hyaline microthrombi may be seen on the peripheral blood smear and comprised of highly polymerized complexes of FDP and many intermediates. ${ }^{190,207}$ These may be from 4 to $60 \mu^{3}$ in volume and may occur singly or in mass and may be noted on a peripheral smear stained with PAS. They are also seen intravascularly but rarely appear to occlude the microcirculation. Another type is the typical intravascular hyaline microthrombus so typically seen by pathologists at postmortem examination in patients with DIC. ${ }^{190,208,209}$ It should be pointed out, however, that these microthrombi are not pathognomonic for DIC and may be seen in other related disorders, including TTP. ${ }^{189,210}$ These intravascular hyaline microthrombi are homogeneous, compact, intravascular hyaline structures that are oriented parallel to the blood flow and occasionally are noted to contain platelets or white cell fragments. They are easily seen by PAS, trichrome, tryptophan, and fluorescein-labeled antifibrinogen antiserum staining and are readily seen by electron microscopy. ${ }^{211-213}$ Third, pulmonary hyaline membranes are also a form of hyaline microthrombus and consist of highly polymerized complexes of FDP and all types of intermediates. ${ }^{214,215}$ They are usually seen to cover the alveolar epithelium with a preference of areas that have been denuded of epithelial cells. In addition, the interalveolar capillaries beneath these hyaline membranes often show abnormal vascular permeability with the circulation of endothelial cells, plasma protein precipitation between endothelial borders, and the formation of interstitial edema.

It should be appreciated that many patients with DIC develop these pulmonary hyaline membranes, which may account for significant pulmonary failure, abnormal arterial blood gases, and pulmonary function tests, including markedly altered diffusion capacity. In addition, it should be emphasized that so-called pure adult shock-lung syndrome shares similar pathophysiologic features with acute DIC and in this particular instance the pathophysiologic events appear to remain localized to the pulmonary microcirculation rather than becoming a systemic process. ${ }^{216,217}$ However, the pulmonary hyaline membranes of adult shock-lung syndrome and those seen in DIC are identical. For that matter, the pulmonary hyaline membranes seen in pediatric respiratory distress syndrome are also comprised of the same material, highly polymerized complexes of fibrin(ogen) and FDP. In this particular clinical situation the pathophysiologic process also remains much the same as in systemic DIC. This phenomenon has recently been carefully studied and reviewed by Ambrus and coworkers ${ }^{218-220}$ and it appears that in the normal infant during normal delivery a short period of hypoxia occurs and concomitant with this is endothelial sloughing with the usual precipitation of fibrin, which is then removed by subsequent activation of the fibrinolytic system. However, in patients with pediatric respiratory distress syndrome this physiologic event may be altered. In infants born of diabetic mothers the same process occurs, with deposition of polymerized complexes of fibrinogen and fibrin; however, in these infants there are elevated levels of alpha2-macroglobulin, which appear to inhibit the ability of the fibrinolytic system to degrade these deposits and hence a resultant "hyaline membrane."221 A similar pathophysiologic state appears to exist in the premature infant, and in this case there is hypoplasminogenemia and thus a hypoactive fibrinolytic system available for activation and therefore fibrin(ogen) deposition continues unchecked with no ability to resolve this and a pulmonary "hyaline membrane" results. ${ }^{222,223}$ Understanding the pathophysiologic changes of pediatric respiratory distress syndrome has led to the relatively successful use of plasminogen concentrates in infants with pediatric respiratory distress syndrome. Figure 6 depicts hyaline membranes as well as pulmonary edema in an infant dying with DIC secondary to meningococcemia.

As previously emphasized, DIC is a process associated with hemorrhage and thrombosis, although thrombosis is less clinically evident and less commonly appreciated by the clinician until late in a course of DIC or until autopsy is performed. However, hemor-

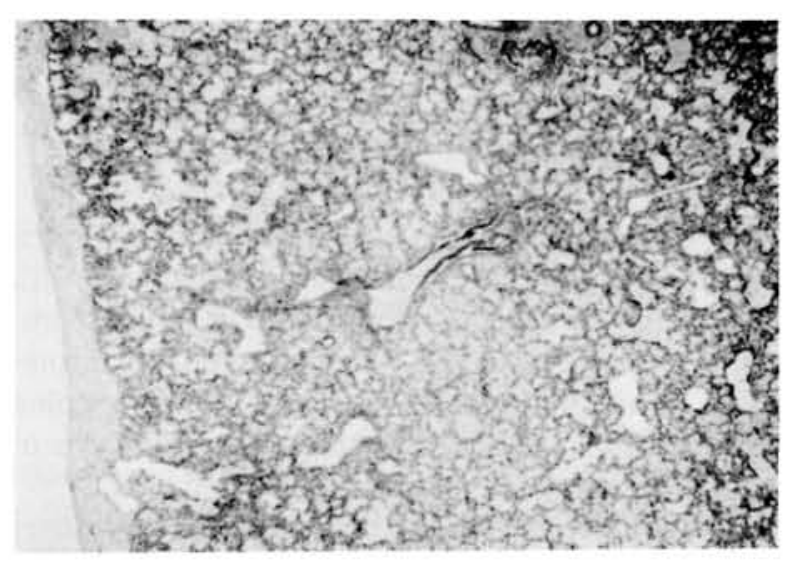

FIG. 6. Hyaline membranes and pulmonary edema are present in the lungs of an infant dying of disseminated intravascular coagulation secondary to meningococcemia. 
rhage may often be successfully contended with in patients with DIC, whereas thrombosis in the microcirculation and macrocirculation often leads to endorgan damage with irreversible ischemic changes that may result in death of a patient. It is therefore useful to examine those parameters that may accelerate or, indeed, cause precipitation of microthrombi and macrothrombi in patients with DIC. Identifiable precipitating causes for acceleration or induction of microthrombi are depicted in Table 14. It will be noticed that an important cause of acceleration of or precipitation of thrombi in the circulation are vasomotor reactions, including elevated catecholamines and progressive acidosis. ${ }^{224,225}$ In addition, glucocorticoids or ACTH elevation may also contribute to the precipitation of microthrombi in patients with DIC, and thus careful thought must be given to the use of steroids in these patients, although in many instances steroid use is indeed warranted. ${ }^{2,76,226}$ In addition, if there is impaired reticuloendothelial clearance, due to fibrin monomer precipitation or the use of steroids, of FDP, circulating soluble fibrin monomers, or activated coagulation factors (especially Factor Xa or thrombin), this could also markedly enhance the precipitation of microthrombi. ${ }^{2,227}$ Additionally, if there is impaired fibrinolytic system activation, this may also lead to accelerated fibrin deposition throughout the circulation. ${ }^{2,228}$ All of these mechanisms, as well as many interplays between them, may lead to accelerated fibrin monomer precipitation in the micro- and macrocirculation with attendant end-organ damage that may be irreversible and lead to significant morbidity and mortality. ${ }^{2,76}$ When seeing a patient with DIC, it should be appreciated that these potential mechanisms and their interplays may be operative and should be kept in mind.

\section{CLINICAL FINDINGS OF CHRONIC DISSEMINATED INTRAVASCULAR COAGULATION}

The clinical findings of chronic DIC are often significantly different from those in patients with acute DIC. Patients with chronic DIC more commonly have bothersome bleedings and diffuse thromboses rather than acute fulminant life-threatening hemorrhages. ${ }^{189,229}$ These patients have been appropriately described as having "compensated DIC."230,231 In this instance there is usually an increased turnover and decreased survival of many components of the hemostasis system, including the platelets, fibrinogen, and Factors V and VIII. Because of this, most coag-
TABLE 14. Factors Leading to Precipitation of Microthrombi in Disseminated Intravascular Coagulation

Release of platelet factor 4
Granulocytes (release)
Vasomotor reactions
Elevated catecholamines
Acidosis
Elevated ACTH
Glucocorticoid use
Poor or impaired reticulothelial clearance
Activated clotting factors
Soluble fibrin monomers
Fibrin(ogen) degradation products
Impaired fibrinolytic activity

ulation laboratory parameters are near normal or normal. ${ }^{2,76,230,231}$

However, patients with chronic DIC almost uniformly have significantly elevated FDP leading to impairment of fibrin monomer polymerization and a clinically significant platelet function defect resulting from the coating of platelet membranes by FDP. Thus, patients with chronic DIC commonly present with findings of gingival bleeding, easy and spontaneous bruising, large cutaneous ecchymoses, and mild to moderate mucosal membrane bleeding often manifested as genitourinary or gastrointestinal hemorrhages. However, patients may also present with diffuse or singular thromboses, which are quite taxing with respect to clinical management.

\section{LABORATORY ABNORMALITIES IN DISSEMINATED INTRAVASCULAR COAGULATION}

With the complex pathophysiologic changes depicted previously, the laboratory findings of DIC may be highly variable, complex, and difficult to interpret unless the pathophysiologic mechanisms of this disorder are clearly understood. Likewise, the evaluation of patients with DIC, especially with respect to significant laboratory tests that are useful for aiding in a diagnosis, as well as for monitoring efficacy of therapy, remain highly confusing and in some instances controversial. To complicate the situation further, many newer modalities have become available for assessing the patient with DIC; however, many of these modalities are as yet without enough experience to determine how clinically applicable they may be. ${ }^{76,110,232-235}$ 
The prothrombin time should be abnormal in the vast majority of patients with DIC for multiple reasons. Firstly, the prothrombin time depends on the ultimate conversion of fibrinogen to fibrin and in DIC there is usually hypofibrinogenemia, FDP interference with fibrin monomer polymerization, and thrombin interference with fibrin monomer polymerization. Additionally, plasmin-induced lysis of Factors $\mathrm{V}$ and $X$, to which the prothrombin time should be sensitive, is often present. In reality, the prothrombin time is prolonged in approximately $75 \%$ of patients with acute DIC and in $25 \%$ of patients the prothrombin time is normal or supernormal. The reasons for this are explained as follows: If there is the presence of a circulating activated clotting factor or factors, such as thrombin or Factor Xa, this may accelerate the formation of thrombin and the subsequent conversion of fibrinogen to fibrin in the test system and thus render a normal or supernormal result, even though some coagulation factors to which the prothrombin times are sensitive may be extremely low. In addition, early degradation products may be rapidly clottable by thrombin and quickly "gel" the test system, rendering a normal or supernormal prothrombin time. ${ }^{1,2,76}$ For these reasons, the prothrombin time is generally an unreliable and minimally useful test in DIC patients.

The activated partial thromboplastin time (APTT) should also be prolonged in acute DIC for multiple reasons. Finally, there is effective plasmin-induced biodegradation of many clotting factors to which the APTT is sensitive, including Factors V, VIII, IX, and $\mathrm{XI}$. The APTT, like the prothrombin time, is sensitive to (prolonged by) fibrinogen levels which are less than $100 \mathrm{mg} / \mathrm{dl}$. The prothrombin time or activated thromboplastin time begins to prolong at a fibrinogen level of approximately $100 \mathrm{mg} / \mathrm{dl}$ or less. Additionally, the APTT should (at least theoretically) be prolonged because of FDP inhibition of fibrin monomer polymerization. However, the APTT is prolonged in only 50 to $60 \%$ of patients with acute DIC and therefore a normal APTT can certainly not be used to rule out a diagnosis of acute DIC. The reasons for a supernormal or normal APTT in 40 to $50 \%$ of patients are as follows: firstly, early degradation products may be rapidly thrombin clottable and gel the test system, rendering a supernormal result; secondly, and perhaps more commonly, circulating activated clotting factor or factors are usually present in patients with acute DIC and activated clotting factors, especially circulating Factor $\mathrm{Xa}$ or circulating thrombin, may bypass the necessity of other clotting factors being measured in the APTT system, thus leading to rapid conversion of fibrinogen to fibrin and a supernormal test. ${ }^{1,2,76}$
Like the prothrombin time, the APTT is of marginal usefulness in patients with DIC.

The thrombin time and reptilase time are expected to be prolonged in patients with acute DIC. Both of these tests should be prolonged by the presence of circulating FDP and interference with fibrin monomer polymerization and from the hypofibrinogenemia commonly present in acute DIC. ${ }^{39,136,222,236-238}$ In fact, both of these tests are generally prolonged in patients with DIC; however, for reasons previously mentioned, they may be normal or supernormal in isolated cases. An additional bonus test may be derived from either one or both of these tests by observing the resultant clot for absence or presence of clot lysis. ${ }^{76}$ Since many small nonhospital laboratories do not have facilities for assessing the fibrinolytic system, this simple nonquantitative tool may provide significant clinical information. Thus, instead of throwing away the thrombin time or reptilase time derived clot, the tube can be set aside for 5 to 10 minutes and observed at the end of this time for evidence of clot dissolution. If the clot is not dissolving in 10 minutes, it may be assumed that the amount of plasmin circulating is not clinically significant; however, if the clot begins to lyse within this period, a clinically significant amount of plasmin is likely to be present.

The platelet count is usually significantly decreased in patients with acute DIC; however, the range may be quite variable and may be as low as 2000 to 3000 $\mathrm{mm}^{3}$ or may be greater than $100,000 \mathrm{~mm} .{ }^{3}$ However, in most patients with acute DIC the degree of thrombocytopenia is usually obvious by examination of a peripheral smear and averages around $60,000 \mathrm{~mm}^{3}$ Virtually all tests of platelet function, including the template bleeding time, platelet aggregation, and platelet lumiaggregation, will be abnormal in patients with DIC. This primarily occurs because of FDP coating of platelet membranes; there may be other potential reasons for platelet dysfunction as well, such as partial release of platelet procoagulant materials. Thus, there is no reason for performing tests of platelet function in patients with acute DIC, since abnormal results will invariably be found and add little to the diagnosis. It should be mentioned that no typical aggregation or lumiaggregation is noted in DIC and a wide variety of different types of aggregation and release defects may be seen in different patients. ${ }^{2,136,232}$

Coagulation factors assays will provide little, if any, clinical useful information in patients with DIC. In the majority of patients with acute DIC there is presence of systemically circulating activated clotting factor, especially Factors $\mathrm{Xa}$, IXa, and thrombin..$^{2,239,240}$ Thus, coagulation factor assays done by 
the standard APTT-derived or prothrombin timederived laboratory techniques using deficient substrates will render uninterpretable and meaningless results in patients with DIC. For example, if a Factor VIII assay were attempted in the presence of circulating Factor Xa in a patient with DIC, a high level of Factor VIII would be recorded, since Factor Xa "bypasses" the necessity for Factor VIII:C in the test system, ${ }^{2,76,241-243}$ and a rapid conversion of fibrinogen to fibrin will be noted. Thus, a rapid time will be recorded on the typical standard curve and this will be interpreted as a high Factor VIII level when there may, in fact, be no Factor VIII present. Thus, factor assays will render erroneous and meaningless results and are virtually uninterpretable and certainly add little or nothing to the diagnosis in patients with DIC. ${ }^{76}$

FDP are elevated in 85 to $100 \%$ of patients with acute DIC, depending on the series reported. ${ }^{2,136,232,244,245}$ It is a common misconception that elevated FDP titers are diagnostic of DIC, and it should be recalled that these degradation products are only "diagnostic" of plasmin biodegradation of fibrinogen or fibrin and FDP are therefore only indicative of the presence of plasmin. Their method of formation is depicted in Figure 7. The possibility of falsenegative results in some patients with DIC will be discussed subsequently.
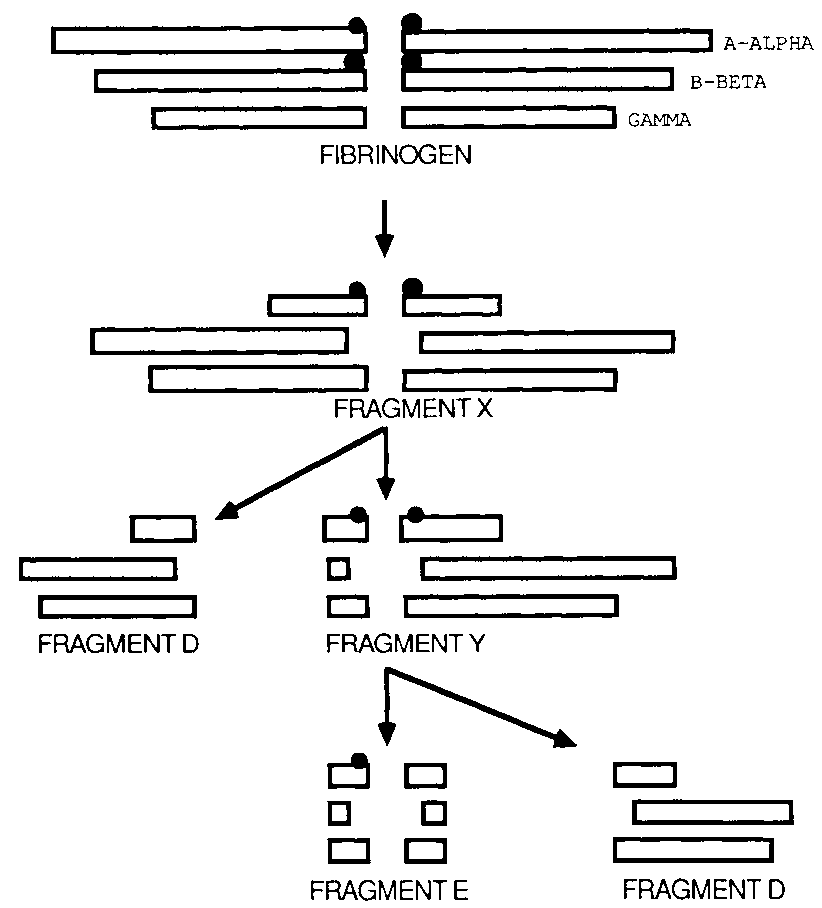

FIG. 7. A depiction of the method of formation of fibrin(ogen) degradation products.
The protamine sulfate test or ethanol gelatin test for circulating soluble fibrin monomer is almost always positive in acute and chronic DIC. 2,129,136,246-249 These are highly useful tests. Like the FDP, however, neither is diagnostic, since both elevated FDP and circulating soluble fibrin monomer can be noted in other clinical situations, including women using oral contraceptives, patients with pulmonary emboli, selected patients with myocardial infarction, patients with certain selected renal diseases, and patients with arterial or venous thrombotic or thromboembolic events. ${ }^{250,251}$ On occasion, the protamine sulfate test or ethanol gelation test may be negative for reasons to be discussed. In these rare instances, after successful therapy, the test may become positive for a short period of time and then revert to negative. ${ }^{2,76}$ The protamine sulfate test as described by Kidder et $\mathrm{al}^{252}$ appears to be the most sensitive and clinically applicable test for detecting circulating soluble fibrin and is the one used by my laboratory.

The antithrombin III (AT III) determination has become a key test for aiding in the diagnosis and monitoring of therapy in patients with acute and chronic DIC. ${ }^{253-255}$ In DIC there is almost always an overwhelming generation of activated clotting factors (serine proteases) during the activation (triggering) process as well as during the ongoing intravascular coagulation event. When this occurs, there is an irreversible complexing of some circulating activated clotting factor with AT III, thus leading to significant decreases of functional AT III in the majority of patients with acute and chronic DIC. ${ }^{254,256-260}$ In addition, as will be discussed in subsequent sections, the determination of an AT III assay provides one of the few reliable modalities for monitoring efficacy of anticoagulant therapy in patients with DIC. Several recent studies have compared the clinical applicability of various AT III methodologies, and, based on these studies synthetic substrate assay methods are clearly the methods of choice. ${ }^{261.263}$ Immunologic assays for AT III ignore biologic function and may be normal or low. Just because AT III is complexed with a serine protease does not necessarily mean the antigenic determinants, as measured by immunologic assays, are no longer present. Thus, immunologic assays for AT III in patients with DIC should not be used. ${ }^{2}$

Increased platelet turnover and decreased platelet survival will usually be seen in patients with DIC. ${ }^{264,265}$ However, since thrombocytopenia is often present, this method of following patients may be of questionable significance, especially in severely thrombocytopenic patients. It has been found that simple methods using automated electronic counting techniques have proved useful in monitoring efficacy of 
therapy in patients with chronic DIC provided the platelet count is greater than $80,000 / \mathrm{mm}^{3}{ }^{266}$ Platelet factor 4 levels and $\beta$-thromboglobulin levels are newer assay techniques that are markers of overall platelet reactivity and release. As such, several recent reports have suggested that either one of these two modalities may be highly useful in aiding in a diagnosis of DIC as well as in monitoring efficacy of therapy with respect to blunting or causing cessation of the intravascular clotting process. ${ }^{266-271}$ Both assays are now readily available for the clinical laboratory and each has its attendant advantages and disadvantages. Both platelet factor 4 and $\beta$-thromboglobulin are elevated in the vast majority of instances of DIC; however, it should be readily appreciated that neither of these modalities is diagnostic of DIC, since they may be elevated in a wide variety of intravascular coagulation disorders, including pulmonary emboli, acute myocardial infarction, deep vein thrombosis, and in many disorders associated with microvascular disease, such as diabetes and autoimmune disorders. ${ }^{272,273}$ However, if they are noted to be elevated in the patient with DIC and then decline after the institution of specific therapy, this may provide a useful sign that therapy has been successful in either blunting or stopping the intravascular clotting process.

Fibrinopeptide A is commonly elevated in patients with DIC and is an overall assessment of hemostasis, much like platelet factor 4 and $\beta$-thromboglobulin levels. The presence of fibrinopeptide $A$ is diagnostic of the presence of thrombin acting on fibrinogen. Fibrinopeptide A determinations may be of aid in assessing efficacy of therapy, as has been suggested in several studies. ${ }^{186,274-278}$ However, the determination of fibrinopeptide A is presently laborious for the routine clinical laboratory and is not diagnostic of DIC, since it may be elevated in a wide variety of other micro- or macrovascular thrombotic events, as previously discussed. Nonetheless, the noting of high fibrinopeptide A levels followed by a decline of these levels with the institution of therapy may be a good prognostic sign with respect to stopping or blunting the intravascular clotting process. A newer modality, also available by radioimmunoassay, is that of $\mathrm{B} \beta \quad 15-42$ and related peptide determinations. ${ }^{279-281}$ The noting of elevated $\mathrm{B} \beta \quad 15-42$ and related peptides may, when performed in conjunction with concomitant fibrinopeptide A levels, add greatly to the differential diagnosis of DIC versus primary lysis. As previously discussed, plasmin will rapidly cleave $\mathrm{B} \beta$ peptides at position 118 and position 42 , and 15 through 42 (after thrombin has cleaved fibrinopeptide B or amino acid sequence 1 through 14) off of the $B \beta$ chain of fibrinogen. Thus, the elevation of $\mathrm{B} \beta$ 15-42 related pep- tides in the absence of fibrinopeptide $\mathrm{A}$ is strong evidence for primary fibrinolysis, whereas the elevation of both fibrinopeptide $A$ and $B \beta \quad 15-42$ related peptides is strong evidence of DIC. Formation of $\mathrm{B} \beta$ 15-42 peptides is summarized in Figure 8.

Fibrinolytic system assays are now readily available in the clinical laboratory and provide highly useful information in patients with DIC. Typically there are decreased plasminogen levels and circulating plasmin present. ${ }^{1,2,14,145,282}$ The presence or absence of a secondary fibrinolytic response is of clinical value in predicting the degree of potential microvascular thrombosis and resultant irreversible end-organ damage in patients. If there is inadequate or absent activation of the fibrinolytic system, the degree of morbidity and mortality due to end-organ damage may be expected to be greater. The degree of fibrinolytic system activation can be assessed by measuring plasminogen and plasmin levels by currently available synthetic substrate techniques. ${ }^{283-287}$ In this regard, the euglobulin lysis time provides little or no clinical useful information with respect to assessing the fibrinolytic system in clinical disorders, including DIC. ${ }^{2,288,289}$ The preparation of a euglobulin fraction, by definition, destroys fibrinolytic inhibitors and thus a positive result is of questionable clinical meaning and may simply represent an artifact. Thus, this test should not be used in clinical medicine. The measurement of fibrinolytic inhibitors, including fast-acting alpha ${ }_{2}$ antiplasmin ${ }^{290-294}$ and slow-acting alpha ${ }_{2}$-macroglobulin, ${ }^{295-297}$ may also be of help in assessing the overall fibrinolytic system in DIC patients. If these two fibrinolytic system inhibitors are markedly elevated, there may be an inadequate fibrinolytic

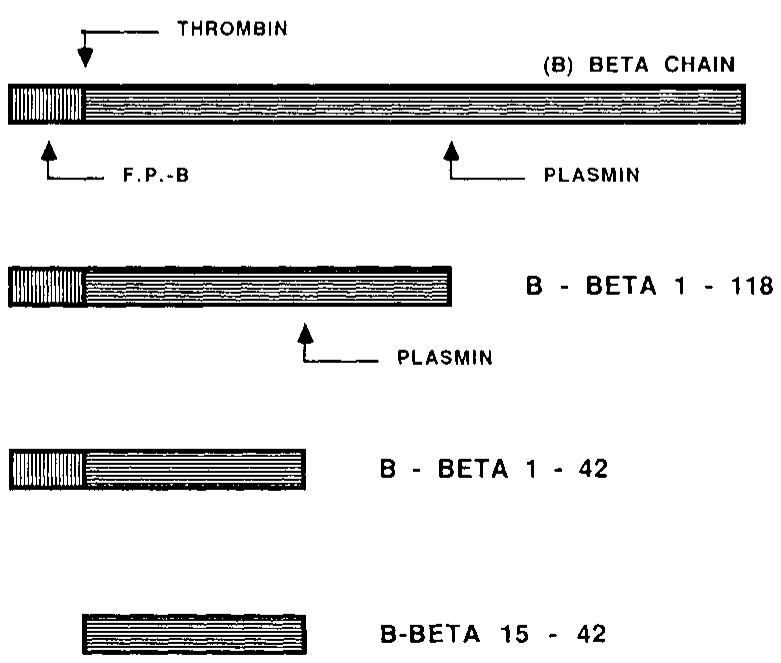

FIG. 8. Formation of $B \beta \quad 15-42$ and related peptides. 
response with resultant enhanced fibrin monomer precipitation, fibrin deposition, and microvascular or macrovascular thrombosis. Recently, assays for tissue (endothelial) plasminogen activator and tissue plasminogen activator inhibitor have become available; with experience, this determination may also become useful in patients with DIC.

Fibrinogen chromatography may provide a new and sensitive modality for assessing patients with DIC and may prove useful for both aiding in a diagnosis and allowing detailed monitoring of efficacy of therapy in these patients. ${ }^{282,298-301}$ Although this modality is currently only used in large centers specializing in thrombohemorrhagic disorders, it has provided quite impressive data and may become clinically applicable in the future, as will be discussed subsequently.

By understanding the pathophysiologic aspects of DIC, it is quite clear that hemostasis will be considerably altered and thus most common laboratory tests of hemostasis will be significantly abnormal. ${ }^{76,302-304}$ It is therefore useful to determine which tests are of practical significance with respect to providing a high degree of reliability as well as availability in assessing patients with DIC. In this regard, hospital laboratories must be equipped to offer assays that will quickly and reliably allow assessment of patients with DIC. If the laboratory is unable to meet this need, the hospital is providing substandard medical care by allowing admissions of patients with DIC or diseases associated with DIC. Tests useful for aiding in a diagnosis of DIC are depicted in Table 15. Tests that are routinely used by me for both aiding in a diagnosis of DIC and monitoring efficacy of therapy in these patients are indicated by an asterisk. ${ }^{2,76,238,239,305}$ In general, I do not indulge in "DIC panels" and prefer to let the particular clinical situation, in conjunction with clinical judgment, dictate which laboratory tests are to be obtained both initially and subsequent to therapy. However, if a true "DIC panel" were to be devised, those tests that are indicated by an asterisk would be the recommended current tests for aiding in a diagnosis and monitoring efficacy of therapy because they are readily available and reasonably reliable when evaluated together. However, it must be stressed that none of these tests is diagnostic of DIC and, as in all areas of clinical medicine, laboratory modalities must be evaluated in the appropriate clinical setting. In addition, most of these laboratory tests are certainly not specific. The presence of soluble monomer is one of the more specific tests but certainly not diagnostic. If circulating soluble fibrin monomer is present, as detected by the protamine sulfate test or ethanol gelation test, this is strong evidence that thrombin and plasmin have circulated. Since fibrin monomer is
TABLE 15. Laboratory Evaluation of Acute Disseminated Intravascular Coagulation

Prolonged prothrombin time
Prolonged partial thromboplastin time
Prolonged thrombin time
Prolonged reptilase time
Low clotting factors by assay
Elevated fibrin(ogen) degradation products*
Positive protamine sulfate test*
Decreased antithrombin III*
Thrombocytopenia*
Schistocytosis*
Leukocytosis
Elevated platelet factor $4^{*}$
Elevated $\beta$-thromboglobulin
Elevated fibrinopeptide A*
Elevated B- $\beta$ 15-42 related peptides*
Low plasminogen levels*
Circulating plasmin*
Abnormal fibrinogen chromatograms
D-dimer by monoclonal antibody*

*Most useful and reliable test at present.

created by the presence of thrombin and fibrin monomer has to then be solubilized by complexing with FDP created by plasmin, this test determines the presence of both enzymes.

A newer diagnostic test for the presence or absence of DIC is the D-dimer assay. D-dimer is a neoantigen formed when thrombin initiates the transition of fibrinogen to fibrin and also activates Factor XIII to cross-link the fibrin thus formed; this neoantigen is formed as a result of plasmin digestion of cross-linked fibrin. ${ }^{281,306}$ The D-dimer test is therefore specific for fibrin degradation products, whereas the formation of FDP, the $\mathrm{X}, \mathrm{Y}, \mathrm{D}$, and $\mathrm{E}$ fragments discussed previously, may be either fibrinogen or fibrin derived, following plasmin digestion. Recently, monoclonal antibodies have been harvested against the D-dimer neoantigen DD-3B6/22, and these have been found to be specific for cross-linked fibrin derivatives containing the D-dimer configuration. ${ }^{307,308}$ The formation of D-dimer is depicted in Figure 9.

After the harvesting of monoclonal antibodies, a latex agglutination procedure, utilizing latex particles coated with anti-DD-3B6/22 antibody has been developed into a commercially available test kit. Recent studies have shown the monoclonal antibody test, performed by enzyme immunoassay, to be essentially equivalent to the latex agglutination assay, thus mak- 


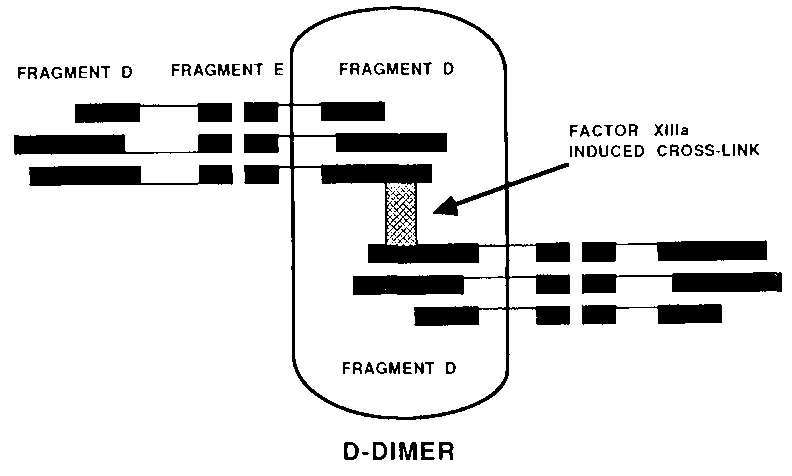

FIG. 9. Formation of D-dimer.

ing the latex agglutination assay applicable for measuring D-dimer in plasma, resulting in a clinically applicable and easily performed test in patients with DIC. ${ }^{309}$ We have recently used this assay as part of our laboratory battery of DIC tests to assess its efficacy in diagnosing patients with suspected or diagnosed DIC. ${ }^{310}$ In our studies we have noted that in patients with documented DIC the D-dimer assay was abnormally elevated (more than $200 \mathrm{ng} / \mathrm{ml}$ ) in $93.2 \%$ of patients, with the mean D-dimer level being 2047 $\mathrm{ng} / \mathrm{ml}$. In those patients in whom DIC was ruled out, the average $\mathrm{D}$-dimer assay was only abnormal in $6 \%$, with the mean level being $541 \mathrm{ng} / \mathrm{ml}$ (Table 16).

In addition, the D-dimer assay appears to be of use in patients with deep vein thrombosis. In our experience, the D-dimer assay is abnormally elevated in $42 \%$ of patients with deep vein thrombosis, with the average level being $325 \mathrm{ng} / \mathrm{ml}$. Based on our laboratory evaluation of the D-dimer assay performed by latex agglutination technique, it appears to be a highly useful assay for assessing the probability of DIC in appropriate clinical settings. Indeed, of the usual tests used in assessing patients with DIC, it appears to be the most reliable test with respect to probability of being abnormal in patients with confirmed DIC. In our hands with our battery of DIC tests, in the appropriate clinical setting, the reliability of tests used, in descending order of reliability are the D-dimer assay (abnormal in 93\%), the AT III level (abnormal in $89 \%$ ), the fibrinopeptide A level (abnormal in $88 \%$ ), and FDP titer, which is usually abnormal in $75 \%$ of patients. Lane and coworkers ${ }^{311}$ have studied the Ddimer fragment in nine patients with DIC and found the levels to be elevated in eight of the nine. In addition, Elms and coworkers ${ }^{312}$ have also performed Ddimer assays in DIC patients and found the D-dimer levels to be elevated in all patients with DIC so studied.

It seems reasonable to conclude that the D-dimer
TABLE 16. Assay Results (Mean) in All Patients

\begin{tabular}{lcccc}
\hline \hline & $\begin{array}{c}\text { DIC } \\
(n=44)\end{array}$ & $\begin{array}{c}\text { No DIC } \\
(n=17)\end{array}$ & $\begin{array}{c}\text { Deep Vein } \\
\text { Thrombosis } \\
(n=12)\end{array}$ & $\begin{array}{c}\text { Normal } \\
\text { Values }\end{array}$ \\
\hline D-dimer & 2047 & 541 & 325 & $<200 \mathrm{ng} / \mathrm{ml}$ \\
AT III & 61.7 & 108.6 & 77.5 & $>85 \% \mathrm{NHP}$ \\
Fibrinopeptide A & 24.4 & 22.8 & 6.4 & $<9 \mathrm{ng} / \mathrm{ml}$ \\
FDP & 221.6 & 23.5 & 23.5 & $<40 \mu \mathrm{g} / \mathrm{ml}$ \\
\hline
\end{tabular}

TABLE 17. Antithrombin III Levels in Disseminated Intravascular Coagulation

\begin{tabular}{ccc}
\hline Patient & Percent AT III & Type DIC \\
\hline 1 & 36 & Chronic \\
2 & 81 & Chronic \\
3 & 36 & Chronic \\
4 & 65 & Chronic \\
5 & 85 & Chronic \\
6 & 32 & Chronic \\
7 & 52 & Chronic \\
8 & 65 & Acute \\
9 & 50 & Acute \\
10 & 137 & Acute \\
11 & 75 & Acute \\
12 & 31 & Acute \\
13 & 85 & Acute \\
\hline
\end{tabular}

latex agglutination test, measuring the presence of the neoantigen DD-3B6/22, is becoming a highly useful test that is easily performed in a clinical laboratory and should be considered in the armamentarium of tests used to confirm or rule out DIC. Since the Ddimer test provides the same information as the combination of the FDP titer and the protamine sulfate or ethanol gelation test, it can easily replact both of these tests in the diagnostic work-up of a patient with suspected DIC, thus leading to cost effectiveness as well as enhanced efficacy.

Table 17 depicts biologic AT III levels in a series of patients with acute and chronic DIC. ${ }^{76,257}$ It will be noted that the vast majority of patients display significant decreases in AT III levels at the time of diagnosis. One exception to this are patients with disseminated malignancy and concomitant DIC. In some instances it appears that AT III, as an alpha ${ }_{2}-$ globulin, behaves as an acute phase reactant and may be consumed (complexed) to normal or near-normal levels in patients with disseminated malignancy and concomitant DIC. ${ }^{2,53,54,313,314}$ However, in most all other instances of acute or chronic DIC this serine protease inhibitor appears to be significantly and rapidly decreased. Also, protein $\mathrm{C}$, protein $\mathrm{S}$, and fibronectin levels are decreased in patients with DIC; however, their diagnostic efficacy as well as usefulness to 
monitor therapeutic efficacy remains to be established. ${ }^{315,316}$

Figure 7 depicts fibrinogen and its degradation products, the $\mathrm{X}, \mathrm{Y}, \mathrm{D}$, and $\mathrm{E}$ fragments. As previously discussed, fibrinogen is comprised of $\mathrm{A} \alpha, \mathrm{B} \beta$, and $\gamma$ chains and plasmin first digests along the carboxy-terminal of the A $\alpha$ chain, giving rise to fragment $\mathrm{X}$. Following this, there is asymmetric digestion by plasmin along the amino-terminal end of all three chains, giving rise to a fragment $Y$ and a fragment $D$. Subsequently, fragment $Y$ is further asymmetrically digested on the opposing amino-terminal portion, giving rise to another fragment $\mathrm{D}$ and a fragment $\mathrm{E}$, or so-called N-terminal disulfide knot. This Figure reveals that fragments $X$ and $Y$ still contain fibrinopeptides, and they are thus thrombin clottable. Understanding this and the method of plasmin-induced digestion allows an understanding as to why, in selected instances, in patients with acute or chronic DIC FDP titers may be negative. The currently available FDP determinations utilize latex particles that are antifibrinogen, and, since they are antifibrinogen, thrombin clot tubes are supplied to clot out fibrinogen so that latex particles will not react with fibrinogen and erroneously measure fibrinogen rather than its degradation products. ${ }^{317-319}$ However, fibrinogen and its degradation products have common antigenic determinants. ${ }^{320}$ When these thrombin clot tubes are used, not only is fibrinogen removed from the system, but also fragment $\mathrm{X}$ and fragment $\mathrm{Y}$. For this reason, currently available FDP methodologies measure fragments D and E. Thus, in some instances of DIC when there may be minimal secondary fibrinolytic response and minimal plasmin circulating, there may only be degradation to the $\mathrm{X}$ fragment stage or some intermediate between fibrin(ogen) and fragment $X$. In this instance there may be nothing for the test to measure, since fragment $X$ and its intermediates may be removed from the test system by the thrombin clot tubes used. Alternatively, in instances of acute DIC in which there is a massive secondary fibrinolytic activation and overwhelming amounts of plasmin circulating, there may be degradation past the $\mathrm{D}$ and $\mathrm{E}$ stages. Fragments $\mathrm{D}$ and $\mathrm{E}$ are the last degradation products that have antigenic determinants and that are capable of being detected by the currently available commercial FDP titer kits. An additional problem is that of massive release of granulocyte enzymes, collagenases and elastases, which may also degrade all available $\mathrm{D}$ and $\mathrm{E}$ fragments and again render negative FDP titers in patients with acute DIC. ${ }^{76,321}$ Thus, the presence of negative FDP titers cannot be used to rule out a diagnosis of acute or chronic DIC. Despite these difficulties, FDP titers are almost always elevated in patients with DIC.

Table 18 depicts those subspecies of fibrinogen and its degradation products that can be readily detected by fibrinogen chromatography. If there is an increase in high molecular weight fibrinogen complexes, the presence of thrombin can be assumed. Alternatively, when noticing an increase in concentration of early fibrinogen "first derivative," it can be assumed that plasmin is present. The concentrations of these two derivatives in conjunction with elevated FDP can lead to significant information with respect to aiding in a diagnosis and monitoring of therapy in DIC. For example, if thrombin plus plasmin are circulating in early DIC, both high molecular weight fibrinogen complexes and fibrinogen "first derivative" will be seen. As the thrombotic events begin to subside, high molecular weight polymerized complexes will begin to decrease, and as the fibrinolytic system becomes activated and plasmin begins to cleave fibrinogen into lysed fibrin deposited in the microcirculation, fibrinogen "first derivative" concentrations and FDP will begin to increase, providing a sensitive method for monitoring efficacy of therapy. Clinical information provided by fibrinogen chromatography is summarized in Table 19.

TABLE 18. Fibrinogen Chromatography: Subspecies Identification

Fibrin monomer: fibrinogen minus fibrinopeptides (molecular weight, $320,000 \mathrm{~d}$ )

Fibrinogen dimer: fibrinogen plus fibrin monomer (molecular weight, 650,000 d)

Fibrinogen polymer: fibrinogen plus various fibrin(ogen) fragments (molecular weight, 400,000 to $1,000,000 \mathrm{~d}$ )

Fibrinogen "first derivative": minimal cleavage by plasmin (molecular weight, 267,000 d)

Fibrin(ogen) degradation products (moderate cleavage by plasmin)

TABLE 19. Fibrinogen Chromatography: Clinical Information in Disseminated Intravascular Coagulation

Thrombus formation (thrombin generation) Increased fibrin monomer Increased fibrin(ogen) complexes Increased fibrin(ogen) polymer

Thrombus resolution (plasmin circulation) Increased fibrinogen "first derivative" Increased fibrin(ogen) degradation products Decreased fibrin monomer Decreased fibrin(ogen) complexes Decreased fibrin(ogen) polymer 
Typical laboratory findings of chronic DIC are significantly different from those seen in acute DIC; many usual tests of hemostasis are normal or near normal and typical findings in chronic DIC are depicted in Table 20 . The platelet count is usually within normal limits or borderline in the patient with chronic DIC; however, most of these patients develop decreased platelet survival and increased turnover of platelets due to platelet consumption, and this is often referred to as a "compensated state." Like the platelet count, fibrinogen levels are usually "compensated"; there is increased turnover and decreased survival of fibrinogen as well as Factor V, Factor VIII, and other coagulation proteins. Thus, fibrinogen levels are usually normal or elevated. Fibrinogen levels may be significantly elevated in chronic DIC because fibrinogen may behave as an acute phase reactant in many disorders associated with chronic DIC, including cancer, autoimmune disorders, and chronic inflammatory diseases. For similar reasons, Factor VIII and Factor V levels may be normal or elevated in patients with chronic DIC. Like platelets and fibrinogen, increased turnover and decreased survival of Factor VIII:C and Factor V may be seen in patients with chronic DIC. The prothrombin time is usually within normal limits or supernormal in the patient with chronic DIC for reasons previously discussed. Likewise, the APTT is commonly within normal limits or short (supernormal).

Red cell fragments, or schistocytes, are present in almost all patients with chronic DIC but are only present in $50 \%$ of patients with acute DIC. This is most likely because of the nature of the underlying disease processes giving rise to chronic DIC, such as

TABLE 20. Laboratory Evaluation of Chronic Disseminated Intravascular Coagulation

\begin{tabular}{ll}
\hline Platelet count & Usually normal/borderline \\
Fibrinogen & Normal or elevated \\
Factor VIII:C & Normal or elevated \\
Prothrombin time & Normal or fast \\
APTT & Normal or fast \\
Schistocytes & Present in $90 \%$ \\
FDP & Usually elevated \\
Protamine sulfate & Usually positive \\
Fibrinopeptide A & Usually elevated \\
Plasminogen & Usually decreased \\
Plasmin & Usually present \\
D-dimer & Usually elevated \\
\hline
\end{tabular}

cancer and related disorders. FDP are almost always elevated in patients with chronic DIC and are quite useful for aiding in a diagnosis. The elevation of these fragments accounts for much of the pathophysiologic findings and low-grade hemorrhage seen in patients with chronic DIC because of the platelet dysfunction that they induce. Soluble fibrin monomer is also commonly detected in patients with chronic DIC and, like the FDP titer, can be quite helpful and is a relatively specific finding. Often, there is also elevated fibrinopeptide A, $\beta$-thromboglobulin, platelet factor 4 , and $\mathrm{B} \beta$ 15-42 related peptides in patients with chronic DIC. Their diagnostic efficacy remains to be determined but looks promising. The use of these assays in monitoring efficacy of therapy also remains to be determined; however, they may prove quite helpful. Circulating plasmin associated with hypoplasminogenemia is also a common finding in patients with chronic DIC. In the appropriate clinical setting, the noting of elevated FDP, a positive protamine sulfate test, elevated fibrinopeptide A, elevated B $\beta$ 15-42 peptides, and hypoplasminogenemia is strongly suggestive of chronic DIC.

Table 21 reveals average laboratory values, using commonly available laboratory modalities, in a series of 48 patients with acute DIC. ${ }^{322}$ Both average values for pretreatment and post-treatment are given and post-treatment values were derived 4 to 6 hours after therapy that was thought to stop or significantly blunt the intravascular clotting process. It will be noted that the prothrombin time and APTT are borderline prolonged. It is also noted that in the vast majority of patients these two tests are corrected to well within normal limits after the delivery of effective therapy. The average platelet count was $64,600 / \mathrm{mm}^{3}$ at the time of making the diagnosis and $204,000 / \mathrm{mm}^{3}$ after effec-

\begin{tabular}{lcc}
$\begin{array}{l}\text { TABLE 21. Average Laboratory } \\
\text { Disseminated Intravascular }\end{array}$ & Coagulation \\
\hline & Pretherapy & Post-therapy \\
\hline Prothrombin time & 16.8 seconds & 13.6 seconds \\
APTT & 55.8 seconds & 42.4 seconds \\
Reptilase time & 26.8 seconds & 18.8 seconds \\
Thrombin time & 23.8 seconds & 15.6 seconds \\
FDP level & $>40$ & $>40$ \\
Platelets & 64,600 & 204,000 \\
Protamine sulfate & + & + \\
Fibrinogen & $129 \mathrm{mg} / \mathrm{dl}$ & $221 \mathrm{mg} / \mathrm{dl}$ \\
AT III & $57.8 \%$ & $101.4 \%$
\end{tabular}


tive therapy. The average fibrinogen level was 129 $\mathrm{mg} / \mathrm{dl}$ before therapy and $221 \mathrm{mg} / \mathrm{dl}$ after therapy.

Also of significance is the noting of AT III levels before and after therapy; this will be discussed in more detail subsequently. In this particular series of patients the average biologic AT III level was $58 \%$ at the time of making a diagnosis and well within normal range 4 to 6 hours after therapy, which was thought to cause cessation or significant blunting of the intravascular clotting process. Laboratory testing and the interpretation of the laboratory results with respect to aiding in a diagnosis and monitoring of therapy in patients with acute DIC remain highly confusing and, in fact, controversial because very few patient series have actually been published. The reliability of laboratory testing in patients with acute DIC is depicted in Table $22 .{ }^{322}$ The percentage of abnormal values pretreatment and the percentage of those remaining abnormal after treatment are depicted for each test in this Table. It will be noticed that in this series of patients, FDP were elevated in $100 \%$ of patients at the time of making a diagnosis but remained elevated in $25 \%$ of patients after effective therapy. Thus, FDP determinations are of significant diagnostic value but are of only limited value with respect to monitoring efficacy of therapy. The AT III level was noted to be decreased in $97 \%$ of patients at the time of making a diagnosis and was only decreased in $16 \%$ of patients after therapy, which was thought to be successful at stopping the intravascular clotting process. Thus, the AT III level appears to be quite useful for both aiding in a diagnosis and providing information regarding cessation of the intravascular clotting process.

It can be concluded that the most reliable commonly used laboratory tests for aiding in a diagnosis

TABLE 22. Reliability of Laboratory Tests in Acute Disseminated Intravascular Coagulation*

\begin{tabular}{lcc}
\hline \hline & $\begin{array}{c}\text { Pretherapy } \\
\text { (\% Abnormal) }\end{array}$ & $\begin{array}{c}\text { Post-Therapy } \\
\text { (\% Abnormal) }\end{array}$ \\
\hline FDP level & 100 & 24 \\
AT III & 97 & 16 \\
Platelets & 97 & 34 \\
Protamine sulfate & 92 & 18 \\
Thrombin time & 81 & 32 \\
Fibrinogen & 79 & 16 \\
Prothrombin time & 76 & 58 \\
APTT & 63 & 24 \\
Reptilase time & 58 & 8 \\
\hline
\end{tabular}

*Given in descending order of reliability. of DIC and for monitoring efficacy of therapy in acute DIC are the D-dimer assay, the FDP titer, the AT III level, the platelet count, the presence of soluble fibrin monomer and elevated fibrinopeptide A; these are followed by the thrombin time, fibrinogen level, prothrombin time, APTT, and reptilase time, all of which appear to be generally unreliable. It should be noted in this series of patients that the APTT was only prolonged in $63 \%$ of patients at the time of rendering a diagnosis of acute DIC, thus emphasizing that the APTT is not at all a reliable test for aiding in a diagnosis of DIC or for monitoring of therapy.

Table 23 summarizes average pretreatment and post-treatment values for commonly available laboratory modalities in a group of patients with chronic DIC. ${ }^{2,76,321,322}$ It will be noted that the prothrombin time and APTT are even less reliable as diagnostic aids in chronic DIC. The fibrinogen level and platelet count are also less useful than in acute DIC. In chronic DIC the average fibrinogen level was 231 $\mathrm{mg} / \mathrm{dl}$ at the time of making a diagnosis and 330 $\mathrm{mg} / \mathrm{dl}$ after therapy. The average platelet count was $190,000 / \mathrm{mm}^{3}$ at the time of making a diagnosis and increased to $254,000 / \mathrm{mm}^{3}$ after therapy. The AT III level is also less reliable in diagnosing chronic DIC; however, it appears to be almost as useful for monitoring efficacy of therapy as it is in acute DIC. Table 24 depicts the percentage of patients demonstrating an abnormal laboratory test at the time of making a diagnosis (pretherapy) and the percentage of those tests remaining abnormal after it was clinically deemed that the intravascular clotting process had been successfully stopped. It will be noticed that the FDP titer was elevated in all patients; however, the titer remained elevated in $50 \%$ of patients after therapy. Likewise, soluble fibrin monomers were present in $80 \%$ of patients with chronic DIC but remained circulating in $20 \%$ of patients after successful therapy

TABLE 23. Average Laboratory Values in Chronic Disseminated Intravascular Coagulation

\begin{tabular}{lcc}
\hline \hline \multicolumn{1}{c}{ Test } & Pretherapy & Post-Therapy \\
\hline Prothrombin time & 14.4 seconds & 12.6 seconds \\
APTT & 43.9 seconds & 34.5 seconds \\
Reptilase time & 27.8 seconds & 18.2 seconds \\
Thrombin time & 17.7 seconds & 11.9 seconds \\
FDP level & $>40$ & $>40$ \\
Platelet count & $190,000 / \mathrm{mm}^{3}$ & $254,000 / \mathrm{mm}^{3}$ \\
Protamine test & + & + \\
Fibrinogen level & $231 \mathrm{mg} / \mathrm{dl}$ & $333 \mathrm{mg} / \mathrm{dl}$ \\
AT III level & $83.9 \%$ & $116.8 \%$ \\
\hline
\end{tabular}


TABLE 24. Reliability of Laboratory Tests in Chronic Disseminated Intravascular Coagulation

\begin{tabular}{lcc}
\hline \hline Test & $\begin{array}{c}\text { Pretherapy } \\
(\% \text { Abnormal) }\end{array}$ & $\begin{array}{c}\text { Post-Therapy } \\
\text { (\% Abnormal) }\end{array}$ \\
\hline FDP level & 100 & 50 \\
Protamine test & 80 & 20 \\
Prothrombin time & 80 & 30 \\
AT III & 70 & 10 \\
Reptilase time & 70 & 0 \\
Platelet count & 50 & 30 \\
Fibrinogen & 30 & 0 \\
APTT & 30 & 10 \\
Thrombin time & 30 & 0 \\
\hline
\end{tabular}

had been delivered. The prothrombin time appears to be more useful in chronic DIC than in acute DIC. The AT III level is of less diagnostic value, being only decreased in $70 \%$ of patients with chronic DIC; however, after therapy it remained depressed in only $10 \%$, suggesting it to be a useful monitoring modality after therapy. The platelet count, fibrinogen level, APTT, and thrombin time do not appear to be of useful diagnostic significance in chronic DIC. Thus, the reliability of commonly available laboratory tests for aiding in a diagnosis and monitoring therapy in chronic DIC are the FDP product titer, the presence of soluble fibrin monomer, the prothrombin time, and the AT III determination. $2,76,238,239,322,323$ The reptilase time, platelet count, fibrinogen level, APTT, and thrombin time are of little diagnostic reliability in chronic DIC.

Table 25 depicts the probability of pretreatment and post-treatment coagulation abnormalities in all forms of DIC. It appears that the noting of elevated FDP, a depressed AT III level in conjunction with thrombocytopenia, and a positive protamine sulfate test or ethanol gelation test appear to be the most reliable laboratory indices for aiding in and confirming a diagnosis of DIC and for helping to determine the success of therapy. ${ }^{2,238,239,321-323}$ Likewise, other traditional tests including the prothrombin time, thrombin time, fibrinogen level, reptilase time, and APTT are less reliable as diagnostic or therapeutic indices. The D-dimer assay and the fibrinopeptide $\mathrm{A}$ assay are the most reliable newer tests available. Table 26 compares older and newer modalities that may be useful in diagnosing and monitoring therapy in DIC. ${ }^{2,76,232}$ Most newer methods are totally automated or at least automatable and may aid greatly in rendering laboratory data with respect to diagnosis as well as providing methods to monitor efficacy of therapy in DIC patients. Molecular marker profiling for DIC has now
TABLE 25. Reliability of Laboratory Tests in All Types of Disseminated Intravascular Coagulation

\begin{tabular}{lcc}
\hline \hline Test & $\begin{array}{c}\text { Pretherapy } \\
\text { (\% Abnormal) }\end{array}$ & $\begin{array}{c}\text { Post-Therapy } \\
\text { (\% Abnormal) }\end{array}$ \\
\hline Elevated FDP & 100 & 31 \\
Decreased AT III & 89 & 8 \\
Low platelets & 89 & 18 \\
Positive protamine test & 89 & 10 \\
Long prothrombin time & 82 & 47 \\
Long thrombin time & 76 & 18 \\
Low fibrinogen & 71 & 5 \\
Long reptilase time & 66 & 58 \\
Long activated PTT & 63 & 21 \\
\hline
\end{tabular}

${ }^{*}$ Given in descending order of reliability.

TABLE 26. Laboratory Modalities Available for the Evaluation of Disseminated Intravascular Coagulation

\begin{tabular}{|c|c|}
\hline $\begin{array}{l}\text { Old Methods } \\
\text { (Manual) }\end{array}$ & $\begin{array}{l}\text { New Methods } \\
\text { (Automated) }\end{array}$ \\
\hline Prothrombin time & AT III* \\
\hline APTT & Plasminogen* \\
\hline Thrombin time & Plasminogen activator* \\
\hline Reptilase time & Plasmin* \\
\hline Platelet count & Alpha $_{2}$-antiplasmin* \\
\hline Fibrinogen level & Fibrinogen \\
\hline \multirow{2}{*}{$\begin{array}{l}\text { Soluble fibrin monomer } \\
\text { (Protamine, ethanol) }\end{array}$} & Fibrinopeptide Af \\
\hline & Fibrinopeptide B $\ddagger$ \\
\hline \multirow{7}{*}{$\begin{array}{l}\text { FDP titer } \\
\text { Blood smear } \\
\text { Factor assays (not useful) }\end{array}$} & B- $\beta$ 15-42 peptides \\
\hline & Fibronectin $\dagger$ \\
\hline & Platelet survival \\
\hline & Platelet factor $4 \ddagger$ \\
\hline & $\beta$-thromboglobulin $\ddagger$ \\
\hline & Prostaglandin derivatives $\ddagger$ \\
\hline & D-dimer assay $\dagger$ \\
\hline
\end{tabular}

*Synthetic substrate.

†Immunoassay or enzyme-linked immunosorbent assay. $\ddagger$ Radioimmunoassay.

become available and is fully automatable..$^{324-326}$ These molecular markers are not only useful for diagnosing DIC, but are also useful for providing a differential diagnosis of DIC versus primary fibrinolysis or DIC versus TTP. The differential diagnosis of DIC versus TTP by molecular marker profiling is depicted in Table 27. The differential diagnosis of DIC versus primary fibrinolysis by automated molecular marker profiling is summarized in Table 28. In uncommon instances of an extremely difficult differential between 
TABLE 27. Molecular Markers for the Differential Diagnosis of Disseminated Intravascular Coagulation Versus Thrombotic Thrombocytopenic Purpura

\begin{tabular}{lll}
\hline \hline Marker & \multicolumn{1}{c}{ DIC } & \multicolumn{1}{c}{$T T P$} \\
\hline 6-keto-prostaglandin $\mathrm{F}_{1 \alpha}$ & Normal & Decreased \\
Thromboxanes & Increased & Increased \\
Platelet factor 4 & Increased & Increased \\
$\beta$-thromboglobulin & Increased & Increased \\
Plasminogen activator & Normal/increased & Decreased \\
B- $\beta$ 15-42 peptide & Increased & Normal \\
Fibrinopeptide A & Increased & Normal \\
Fibrinopeptide B & Increased & Normal \\
\hline
\end{tabular}

TABLE 28. Molecular Markers for the Differential Diagnosis of Disseminated Intravascular Coagulation Versus Primary Lysis

\begin{tabular}{lll}
\hline \hline Marker & DIC & Primary Lysis \\
\hline Fibrinopeptide A & Elevated & Normal \\
Fibrinopeptide B & Elevated & Normal \\
B- $\beta \quad 15-42$ peptide & Elevated & Normal \\
B- $\beta$ 1-42 peptide & Elevated & Elevated \\
B- $\beta \quad 1-118$ peptide & Elevated & Elevated \\
Platelet factor 4 & Elevated & Normal \\
$\beta$-thromboglobulin & Elevated & Normal \\
\hline
\end{tabular}

DIC, TTP, or primary fibrinolysis, use of these molecular markers may be quite helpful.

\section{TREATMENT OF DISSEMINATED INTRAVASCULAR COAGULATION}

\section{Acute Disseminated Intravascular Coagulation}

The treatment of acute and chronic DIC remains confusing to many and, indeed, controversial. Concomitant with this controversy and confusion is the general feeling that therapy is fruitless and most patients succumb to the disease process. However, most published comments about therapy are based on fiction rather than fact and emotion rather than clinical judgment. ${ }^{76}$ The reasons for this are because very few objective series of patients with DIC, with respect to therapy given, morbidity, mortality, and survival, have been published. Many argue vehemently against the use of heparin in acute or chronic DIC despite the amazing lack of published case
TABLE 29. Sequential Therapy of Acute Disseminated Intravascular Coagulation

Treat or remove the triggering process Evacuate uterus

Antibiotics

Control shock

Volume replacement

Maintain blood pressure

Steroids?

Antineoplastic therapy

Other indicated therapy

Stop intravascular clotting process

Subcutaneous heparin

Intravenous heparin?

Antiplatelet agents

AT III concentrate therapy

Component therapy as indicated

Platelet concentrates

Packed red cells (washed)

AT III concentrates

Fresh frozen plasma

Cryoprecipitate (fibrinogen)

Prothrombin complex

Inhibit residual fibrino(geno)lysis Aminocaproic acid

reports or series in the literature regarding the adverse effects of heparin in DIC. ${ }^{327-329}$ Likewise, many argue strongly in favor of the use of heparin in DIC; however, there is, likewise, a surprising lack of published reports demonstrating positive effects of heparin in patients with DIC. ${ }^{330-332}$ It is my experience that if logical aggressive and sequential therapy is undertaken in the patient with DIC, morbidity and mortality are not as dismal as suspected. ${ }^{2,76,238,239,322}$ Clinicians and investigators should develop judgment regarding therapy based on experience and published series of patients and documentation, rather than opinion and myth. It is hoped that the future will offer more guidelines than are available at the present time with respect to successes and failures with various forms of potential therapy.

My approach to therapy in acute DIC is somewhat vigorous and is summarized in Table 29. Although this approach is rather aggressive, it has been associated with a high survival rate $(76 \%)$ and low morbidity in patients with classic acute DIC. $2,76,238,239,322$ The most important therapeutic modality to be delivered to a patient with acute DIC is that of an aggressive but reasonable therapeutic approach to remove or treat the triggering disease process that is thought to be responsible for DIC. ${ }^{76,238,239,322,333,334}$ In some instances, this is impossible; however, successful therapy to remove or blunt the triggering event may, in some instances stop or at least significantly blunt the intravascular clotting process. If, however, there are 
no attempts to treat the triggering event and triggering pathophysiologic process, subsequent attempts at anticoagulant therapy, including heparin, will rarely, if ever, alleviate the disseminated intravascular clotting process. However, attempts to treat the underlying disease process do give the patient a reasonable chance of responding to therapy designed to stop the intravascular clotting process. In some instances it is impossible or highly unlikely that the underlying disease pathophysiologic event can be alleviated. However, in many instances the removal of the triggering pathophysiologic event will stop the disease process and the classic example of this is an obstetric accident. More commonly, however, therapy of the underlying process will at least blunt the process enough so that the patient may respond to anticoagulant therapy; however, in some instances this, too, will stop the intravascular clotting process, and another common situation in which this occurs is that of septicemia. The successful treatment of septicemia will blunt the process in many patients, thus giving them the opportunity to respond to anticoagulant therapy; in some instances of septicemia alleviating the triggering pathophysiologic event will actually stop the intravascular clotting process. In cases of obstetric accidents of any type, except amniotic fluid embolism, anticoagulant therapy, especially heparin, is rarely required. Simply evacuating the uterus, or in rare instances hysterectomy, will usually rapidly stop the intravascular clotting process. ${ }^{335,336}$ Although it is often difficult to convince the obstetrician or gynecologist to take a hemorrhaging hypofibrinogenemic patient to the operating room, the results are rewarding when this approach is pursued. The results are usually immediate and dramatic. In septicemia, specific antibiotic therapy, alleviation of shock, volume replacement, the potential use of steroids, and other specific therapy to maintain hemodynamics will often cause significant blunting of the intravascular clotting process and on some occasions may actually stop the DIC process. Each case must, of course, be evaluated on its own merits, depending on the clinical situation and what the clinician feels to be the significant dominant triggering event. However, the key point is that attempts to treat the triggering event are the most important therapeutic modality that may be delivered to the patient with DIC.

The majority of patients, except those with DIC secondary to obstetric accidents or massive liver failure, will subsequently require anticoagulant therapy of some form. The use of subcutaneous low-dose heparin appears to be highly effective in my experience and has been my choice of anticoagulant therapy for the last 9 years. ${ }^{2,76,238,239,322}$ Anticoagulant therapy is indicated if the patient continues to bleed or clot significantly for approximately 4 hours after the initiation of therapy to stop or blunt the triggering pathophysiologic event. This time period is somewhat empirical and depends on the sites and severity of bleeding. When the patient continues to bleed in this situation, the patient is given subcutaneous calcium heparin at $80 \mathrm{U} / \mathrm{kg}$ every 4 to 6 hours as the clinical situation, site and severity of bleeding and thrombosis, and patient size dictate. It has been noted that low-dose subcutaneous heparin appears to be as effective or possibly more effective than larger doses of intravenous heparin in DIC. $2,76,229,238,239,337,338$ With this approach, one often notes cessation of AT III consumption, lowering of FDP, and increases in fibrinogen levels and slow or rapid correction of other abnormal laboratory modalities of acute DIC in 3 to 4 hours, followed shortly thereafter by blunting or cessation of clinically significant hemorrhage and thrombosis. The use of subcutaneous low-dose heparin rather than intravenous heparin appears reasonable for several reasons: (1) If the patient fails to respond, larger doses of heparin can always be administered if deemed appropriate; (2) in contrast to what has been feared with larger intravenous doses of heparin, low-dose subcutaneous heparin therapy is associated with minimal chances of increasing the patient's risk of hemorrhage; and (3) most importantly, the use of low-dose subcutaneous heparin has been as efficacious as large-dose heparin therapy and is associated with a high percentage of patient survival when used in conjunction with other therapeutic modalities. ${ }^{76}$ In light of current understanding of the heparin-AT IIIserine protease-thrombin-fibrinogen axis low-dose subcutaneous heparin, from a theoretical standpoint as well as in published reports, is thought to be equal to or more effective than larger intravenous doses of USP heparin..$^{229,337,338}$ Other anticoagulant modalities that are available, depending on the clinicians experience, are intravenous heparin, the use of combination antiplatelet agents, or the use of AT III concentrates. Those clinicians using intravenous heparin therapy for acute DIC most commonly deliver between 20,000 and 30,000 U/24 hours by constant infusion, and this also may be associated with significant blunting or cessation of the intravascular clotting process. Combination antiplatelet agents are far less commonly effective in acute DIC, but on occasion may be called for as the specific clinical situation dictates and will be discussed under "Chronic Disseminated Intravascular Coagulation."

Acute DIC has been successfully treated with investigational AT III concentrates in small groups of patients by several investigators and preliminary expe- 
rience would suggest these to be quite effective for acute DIC..$^{2,254,339-341}$ From a theoretical standpoint, AT III concentrates should be highly effective in treating acute DIC and it is hoped that this therapeutic fraction may become available for such use in the near future and that the near future will provide for large-scale clinical trials using this investigational modality to treat this potentially catastrophic disease. With respect to heparin, it is my opinion that subcutaneous heparin, or heparin in any dose, is contraindicated in patients with acute DIC and central nervous system insults of any type, patients with acute DIC associated with fulminant liver failure, and in most instances of obstetric accidents. Approximately $75 \%$ of patients will respond to the two previously outlined sequential therapeutic steps. However, if patients continue to bleed after initiating reasonable attempts to treat the triggering pathophysiologic mechanism thought to be responsible for DIC and after initiating anticoagulant therapy, the most likely cause of continued bleeding is component depletion. In this instance, the exact components missing and clinically thought to be contributing to hemorrhage should be defined as precisely as possible. The delivery of certain components is associated with attendant hazards in patients with ongoing DIC and as a general guideline only concentrates and components that are void of fibrinogen should be delivered to a patient with ongoing DIC, ongoing DIC being manifested by continued severe depression of the AT III level. If, however, the AT III level, or other specific monitoring modality that the clinician chooses to use, is returning to normal and associated with a potential response, it can be assumed that the intravascular clotting process has been controlled, and in this instance any component or concentrate deemed necessary can safely be given. In general, the only components that are generally safe in patients with an active uncontrolled DIC process are washed packed red cells, platelet concentrates, AT III concentrates, and nonclotting protein containing volume expanders, such as plasma protein fraction, albumin, and hydroxyethyl starch.

If a patient continues to bleed after successful anticoagulant therapy and cessation of the DIC process, as manifested by correcting AT III levels, then any component deemed depleted to the point of contributing with a high degree of probability to continued hemorrhage is safe to give to the patient. However, it should be emphasized that components containing clotting factors or fibrinogen are, in general, not safe in patients with ongoing DIC, and the use of fresh frozen plasma and fresh whole blood may be associated with enhanced hemorrhage and thrombosis in a patient with active DIC to whom these components are unwisely delivered. ${ }^{2,238,239,342}$ Not only has this been seen clinically but would be expected from a theoretical standpoint when understanding the pathophysiologic mechanism of DIC. If whole blood, fresh frozen plasma, or cryoprecipitate is given to a patient with ongoing DIC, it is to be expected that plasmin will readily biodegrade most, if not all, of the coagulation factors supplied. This event in itself may not be particularly harmful but is certainly not helpful. Of more significance is that these components contain fibrinogen and are associated with a great potential for creation of even higher levels of FDP, which will further impair hemostasis by interference with fibrin monomer polymerization, further impair already compromised platelet function, and will lead to enhanced microvascular deposition and subsequent thrombocytopenia. Thus, a reasonable approach is to assess the patient after anticoagulant therapy and continued bleeding; if the AT III level, or other selected monitoring modality, has returned to normal or near normal, any component deemed significantly depleted and likely to be contributing to continued hemorrhage is reasonable to use. Alternatively, if the patient continues to bleed after anticoagulant therapy has been delivered and the AT III level and other modalities used to monitor the patient remain abnormal, it is highly likely in this situation that the intravascular clotting process has not been controlled and continues. In this instance the component should be restricted to packed red cells, platelets, volume expanders, and, if available, AT III. By adhering to the three sequential aggressive steps just given, greater than $95 \%$ of patients will stop hemorrhaging if they are, in fact, going to survive.

The potentially disastrous consequences of using fibrinogen-containing components, in this case plas$\mathrm{ma}$, in a patient with acute ongoing DIC are summarized in Figure 10. Although the clotting factors initially improved, hemorrhage became worse and the patient exsanguinated. In those rare instances in which bleeding continues after the aforementioned three sequential steps are initiated, the fourth step in the therapy of acute DIC is to consider inhibition of the fibrinolytic system. This step is rarely needed and, in fact, is needed in approximately $3 \%$ of patients only. In some rare instances, even though the intravascular coagulation process has been alleviated, the patient may continue to bleed because, for unexplained reasons, secondary fibrinolysis has continued with the concomitant biodegradation of the usual plasma protein targets of plasmin. In this rare instance, and it must be emphasized that this is necessary in less than 3 to $5 \%$ of all patients with acute DIC, antifibrinolytic therapy may be indicated. However, it should be 


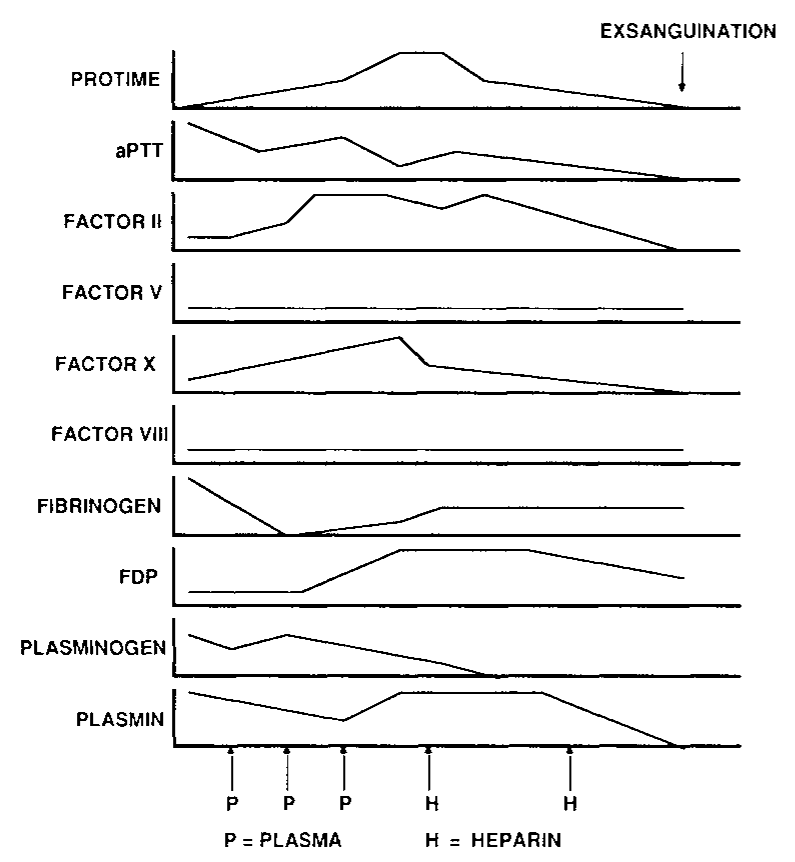

FIG. 10. Consequences of plasma therapy in ongoing disseminated intravascular coagulation.

emphasized that antifibrinolytic therapy should never be delivered to patients with ongoing DIC because such patients desperately need the fibrinolytic system to keep the microcirculation as clear of microthrombi as possible. ${ }^{76}$ Thus, antifibrinolytic therapy should never be delivered unless the first three sequential steps already delineated have been resorted to and it has been well documented from the laboratory and clinical standpoint that the intravascular coagulation process has been terminated by noting correction of biologic AT III levels or other modalities used by the clinician to monitor the event. In addition, antifibrinolytic therapy should never be used unless not only is the cessation of DIC documented, but also the presence of significant amounts of plasmin is documented in the laboratory.

In those rare instances in which antifibrinolytic therapy is indicated, $\epsilon$-aminocaproic acid is given as an initial 5 to $10 \mathrm{gm}$ slow intravenous push followed by 2 to $4 \mathrm{gm} /$ hour for 24 hours or until bleeding ceases. This agent should be used with great caution because it may cause ventricular arrhythmias, severe hypotension, and severe hypokalemia. ${ }^{343-345}$ In addition, it should be realized that if $\epsilon$-aminocaproic acid, or any fibrinolytic inhibitor, is used in a patient with ongoing DIC, it may cause enhanced precipitation of fibrin in the microcirculation and macrocirculation and lead to often fatal disseminated thrombosis.
TABLE 30. Pre- and Post-Therapy AT III Values in Acute Disseminated Intravascular Coagulation (38 Patients)

\begin{tabular}{ccc}
\hline \hline Pretherapy & Post-Therapy & Normal \\
\hline $66.3 \%( \pm 27)$ & $115 \%( \pm 30.2)$ & $85-116 \%$
\end{tabular}

Percent of

patients abnormal $\quad 89 \% \quad 19 \%$

Table 30 depicts a series of patients with chronic and acute DIC to demonstrate how AT III levels may be used as an aid in the diagnosis and may be used to monitor potential efficacy of therapy. ${ }^{2,238,239,346}$ It will be noted that in the vast majority of patients depicted, the biologic AT III levels are significantly depressed at the time of making a diagnosis. The exceptions noted in Table 30 are patients with disseminated malignancy. Thus, in a patient with acute or chronic DIC and normal or high AT III levels, disseminated underlying malignancy should be seriously considered and searched for. ${ }^{54,76}$ However, in almost all patients receiving successful therapy there is an associated rapid return to normal or near-normal biologic AT III levels. Even in those instances when the AT III levels are normal or elevated in association with cancer, the delivery of effective therapy is associated with significant further increases in the AT III level. When the AT III level increases to normal or near-normal levels after the delivery of therapy, it can be assumed with reasonable certainty that the intravascular coagulation process has undergone cessation or significant blunting. More clinical experience may demonstrate that a drastic decrease of previously elevated fibrinopeptide $\mathrm{A}, \beta$-thromboglobulin, or platelet factor 4 levels may be of equal efficacy in assessing response to therapeutic manipulation in patients with DIC.

Table 31 depicts a patient with acute DIC treated with miniheparin. ${ }^{2,239}$ The pretherapy and post-therapy laboratory values are depicted; within 4 hours there was general correction of laboratory modalities and this was associated with cessation of clinical hemorrhage. Table 32 depicts a patient treated with an investigational AT III concentrate and in this instance the patient not only stopped bleeding and thrombosing but also survived the DIC process with minimal morbidity. ${ }^{339}$

\section{Chronic Disseminated Intravascular Coagulation}

Therapy of chronic DIC is approached much differently than that for acute DIC and is summarized 
TABLE 31. Low-Dose Heparin Therapy in Disseminated Intravascular Coagulation*

\begin{tabular}{llll}
\hline & & \multicolumn{2}{c}{ Post-Therapy } \\
\cline { 3 - 4 } Test & Pretherapy & \multicolumn{1}{c}{4 Hours } & 8 Hours \\
\hline Fibrinogen & $68 \mathrm{mg} / \mathrm{dl}$ & $104 \mathrm{mg} / \mathrm{dl}$ & $450 \mathrm{mg} / \mathrm{dl}$ \\
Platelets & 48,000 & 270,000 & 270,000 \\
Thrombin time & 22 seconds & 22 seconds & 20 seconds \\
Reptilase time & 20 seconds & 16 seconds & 24 seconds \\
Prothrombin time & 16 seconds & 14.8 seconds & 12 seconds \\
APTT & 48 seconds & 36 seconds & 36 seconds \\
FDP titer & $>40$ & $>40$ & $<10$ \\
Protamine test & + & + & Negative \\
AT III level & $60 \%$ & $76 \%$ & $185 \%$ \\
\hline
\end{tabular}

*Typical response.

TABLE 32. Antithrombin III Concentrate Therapy in Disseminated Intravascular Coagulation*

\begin{tabular}{llll}
\hline \hline & & \multicolumn{2}{c}{ Post-Therapy } \\
\cline { 3 - 4 } Test & Pretherapy & 12 Hours & 24 Hours \\
\hline Fibrinogen & $30 \mathrm{mg} / \mathrm{dl}$ & $110 \mathrm{mg} / \mathrm{dl}$ & $150 \mathrm{mg} / \mathrm{dl}$ \\
Platelets & 62,000 & 90,000 & 128,000 \\
Thrombin time & 30 seconds & 18 seconds & 16 seconds \\
Reptilase time & 38 seconds & 18 seconds & 18 seconds \\
Prothrombin time & 18 seconds & 13 seconds & 12 seconds \\
APTT & 62 seconds & 59 seconds & 38 seconds \\
FDP level & $>40$ & $>10$ & $<10$ \\
Protamine test & + & + & Negative \\
AT III level & $48 \%$ & $102 \%$ & $115 \%$ \\
\hline
\end{tabular}

*Typical response.

TABLE 33. Sequential Therapy of Chronic Disseminated Intravascular Coagulation

Therapy for the triggering disease process Any therapy clinically indicated

Anticoagulant therapy when indicated Antiplatelet agents

Low-dose calcium heparin No warfarin

Component therapy

Only rarely indicated or necessary

Inhibit fibrinolysis Almost never indicated

in Table 33. The majority of patients with chronic DIC do not have life-threatening hemorrhage but rather have bothersome hemorrhages, which are often associated with diffuse superficial or deep vein throm- bosis and thromboembolism. ${ }^{231,347}$ As with acute DIC, the most important therapeutic modality for a patient with chronic DIC is therapy for the underlying disease process; in many instances this will cause cessation of the intravascular clotting process and alleviation of hemorrhage and thrombosis. If treatment for the triggering disease process thought responsible for the intravascular coagulation process does not stop the event, at least it will often significantly blunt the process to a degree where bothersome bleeding or thrombosis may cease to be a clinical problem. If this first step is vigorously attempted and hemorrhage or thrombosis or thromboembolism continues, then anticoagulant therapy is indicated. However, since patients with chronic DIC usually do not have life-threatening hemorrhage, anticoagulant therapy need not be vigorous in many instances. In fact, vigorous anticoagulant therapy may be contraindicated, in selected instances of cancer, especially those with intracranial metastases. ${ }^{2,76,348,349}$ Combination antiplatelet therapy is often successful in stopping a chronic DIC process provided that attempts to treat the triggering pathophysiologic events have also been instituted. A combination of two antiplatelet agents with independent mechanisms of action are often needed. A combination of acetylsalicylic acid, $600 \mathrm{mg}$ orally twice daily to be taken in conjunction with $30 \mathrm{ml}$ of liquid antacid plus dipyridamole, $50 \mathrm{mg}$ orally four times daily, will stop a chronic intravascular coagulation process within 24 to 30 hours, as demonstrated by generalized correction of laboratory parameters and the cessation of bleeding or thrombosis, or both. Alternatively, the use of sulfinpyrazone, $200 \mathrm{mg}$ orally three times daily, to be taken in conjunction with $30 \mathrm{ml}$ of liquid antacid plus dipyridamole, $50 \mathrm{mg}$ orally four times daily, may be substituted. ${ }^{350,351}$ Both acetylsalicylic acid and sulfinpyrazone are cyclooxygenase inhibitors leading to a decreased synthesis of thromboxane $\mathrm{A}_{2}$; it is often without avail to use both of these agents in combination, since they have the same mechanism of action. ${ }^{352}$ Dipyridamole, however, is an inhibitor of phosphodiesterase, leading to increased concentrations of intraplatelet cyclic adenosine monophosphate, ${ }^{111}$ and therefore the ideal combination appears to be acetylsalicylic acid plus dipyridamole or sulfinpyrazone plus dipyridamole.

Miniheparin, or intravenous heparin is rarely indicated in patients with chronic DIC; however, lowdose subcutaneous heparin therapy should be considered in patients with chronic DIC who appear to be evolving into a more subacute or acute DIC process or who are developing active thrombotic or thromboembolic problems. Replacement therapy is rarely, if ever, indicated in the patient with chronic DIC un- 
less the patient demonstrates component depletion from other triggering mechanisms, such as the patient with chronic DIC and cancer who also demonstrates thrombocytopenia because of therapy, bone marrow replacement, hypersplenism, or other mechanisms. Inhibition of the fibrinolytic system with $\epsilon$-aminocaproic acid is also rarely, if ever, indicated in patients with chronic DIC.

\section{THERAPY OF DISSEMINATED INTRAVASCULAR COAGULATION IN THE PATIENT WITH CANCER}

Successful therapy of DIC in the patient with cancer represents a major clinical challenge and is summarized in Table 34. Effective therapy is multiphasic and must be approached in a sequential and logical manner if the process is to be controlled. The first and most important modality to be given is to treat the cancer itself, since this is providing the trigger or triggers for the intravascular coagulation process. Therapy may be surgical, radiotherapeutic, or chemotherapeutic, as the clinical situation warrants. Treatment of the specific tumor is often associated with cessation or significant improvement in DIC and until attempts at antineoplastic therapy are instituted, subsequent therapy of bleedings or thrombosis is often unsuccessful. ${ }^{2,53,54,239,348}$ A classic example of response to antineoplastics is seen in the patient with prostatic carcinoma. ${ }^{353,354}$ These patients will often show a marked improvement of their hemorrhagic or thrombotic or thromboembolic problems with the institution of diethylstilbesterol therapy or cytotoxic

TABLE 34. Therapy of Intravascular Coagulation in Malignancy

Treat the malignancy (trigger)

Surgery as indicated

Radiation as indicated

Chemotherapy or hormonal therapy as indicated

Stop intravascular clotting process

Antiplatelet agents

Low-dose heparin*

Intravenous heparin*

No warfarint

Component therapy as indicated

Platelet concentrates

Packed red cells (washed)

Fresh frozen plasma

AT III concentrates

Inhibit residual fibrinolysis

Rarely needed or indicated

* Contraindicated if CNS metastases.

$\dagger$ Rarely, if ever, indicated and usually ineffective. chemotherapy, as clinically indicated; this phenomenon may be noted in other tumors as well when antineoplastic therapy is started. In addition, the use of antiplatelet agents, especially in the form of aspirin plus dipyridamole, as previously outlined, has been associated with correction of altered laboratory tests suggestive of DIC, including normalization of fibrinogen and platelet survival in patients with cancer and chronic DIC. However, patients with cancer are also notoriously resistant to anticoagulant therapy with respect to stopping minor to moderate bleedings and thrombotic episodes as well as major thrombotic and thromboembolic episodes, all of which are commonly due to a chronic DIC-type process. . $^{2,53,54,348}$

Table 35 depicts a series of 48 patients to exemplify the incidence of hemorrhages or clinical thrombosis in acute and chronic DIC. ${ }^{2,322}$ This particular series of patients was chosen because the laboratory testing was done by one person and thought to be reasonably uniform. In patients with acute DIC slightly more than $50 \%$ had clinical or laboratory evidence of microvascular and macrovascular thrombosis and all patients had clinical hemorrhages. In those ten patients with chronic DIC, eight had clinical or laboratory evidence of thrombosis and all patients had hemorrhages. In this same group survival in patients with chronic DIC was $100 \%$ with respect to the DIC process. In addition, patients with acute DIC in this series treated with aggressive therapy as previously outlined demonstrated an overall survival of $76 \%$. Thus, the syndrome of DIC need not be universally associated with a high mortality rate, as has previously been generally believed.

\section{SUMMARY}

Current concepts of the cause, pathophysiologic mechanisms, diagnosis, and management of acute and chronic DIC have been discussed. Considerable attention has been devoted to interrelationships that have remained confusing. Only by clearly understanding these pathophysiologic interrelationships can the cli-

TABLE 35. Hemorrhages, Thrombosis, and Survival in 48 Patients with Disseminated Intravascular Coagulation

\begin{tabular}{lccc}
\hline \hline Type DIC & $\begin{array}{c}\text { Hemorrhages } \\
(\%)\end{array}$ & $\begin{array}{c}\text { Thrombosis } \\
(\%)\end{array}$ & $\begin{array}{c}\text { Survival } \\
(\%)\end{array}$ \\
\hline Acute & 100 & 53 & 74 \\
Chronic & 100 & 80 & 100 \\
Total & 100 & 58 & 79 \\
\hline
\end{tabular}


TABLE 36. Conditions Similar to Disseminated Intravascular Coagulation

Thrombotic thrombocytopenic purpura

Pediatric respiratory distress syndrome

Adult "shock lung" syndrome

Hemolytic uremic syndrome

Malignant hypertension

Preeclampsia or frank eclampsia

Glomerulonephritis

Collagen vascular disorders

Circulating immune complex diseases

Serum sickness

Cavernous hemangiomas

Hemangio(endothelio)sarcoma

Traumatic arteriovenous fistulas

Vasculitis

Rocky Mountain spotted fever

Mycoplasma infections

"Waring blender" syndrome

nician and laboratorian appreciate the divergent and wide clinical spectrum of often confusing clinical and laboratory findings in patients with DIC. Many of the therapeutic decisions to be made in these patients remain controversial and will remain so until more series of patients are published with respect to specific therapeutic modalities and survival patterns. Many syndromes that remain organ specific share common pathophysiologic properties with DIC but are identified as an independent disease entity, such as HUS, adult shock lung syndrome, eclampsia, and many other isolated organ-specific disorders. Many of these similar disorders, some systemic and some organ specific or multiorgan specific, are listed in Table 36.

\section{REFERENCES}

1. Bick RL, T Adams: Disseminated intravascular coagulation: Etiology, pathophysiology, diagnosis, and management. Med Counterpoint 6:38, 1974.

2. Bick RL: Disseminated Intravascular Coagulation. CRC Press, Boca Raton, FL, 1983, p 31.

3. Lasch HG, DL Heene, K Huth, W Sandritter: Pathophysiology, clinical manifestations, and therapy of consumptive-coagulopathy. Am J Cardiol 20:381, 1967.

4. Rodriquez-Erdmann F: Bleeding due to increased intravascular blood coagulation: hemorrhagic syndromes caused by consumption of blood-clotting factors (consumption coagulopathies). N Engl J Med 273:1370, 1965.

5. Dubber AHC, GP McNicol, AS Douglas: Acquired hypofibrin- ogenemia; the "defibrination syndrome." A study of seven patients. Scott Med J 12:138, 1967.

6. Mersky C, AJ Johnson, GJ Kleiner, H Wohl: The defibrination syndrome: Clinical features and laboratory diagnosis. $\mathrm{Br} \mathrm{J}$ Haematol 13:528, 1967.

7. Bick RL: Hypercoagulability and thrombosis. In: Murano G, RL Bick, Eds: Basic Concepts of Hemostasis and Thrombosis. CRC Press, Boca Raton, FL, 1980, p 237.

8. Seegers WH: Factors in the control of bleeding. Cincinnati J Med 31:395, 1950.

9. Seegers WH, CL Schneider: The nature of the blood coagulation mechanism and its relationship to some unsolved problems in obstetrics and gynecology. Transactions of the International and 4th American Congress Obstetrics and Gynecology 61 A: $469,1951$.

10. Seegers WH: Coagulation of the blood. Harvey Lect 47:180, 1952.

11. Johnson JF, WH Seegers, RG Braden: Plasma Ac-globulin changes in placenta abruptio. Am J Clin Pathol 22:322, 1952.

12. Stevenson CS, RG Braden, CL Schneider, JF Johnson, WH Seegers: Hemorrhagic diathesis in abruptio placentae with particular reference to the indications for caesarean section. Am J Obstet Gynecol 65:88, 1953.

13. Ratnoff OD, JA Pritchard, JA Colopy: Hemorrhagic states during pregnancy. I. N Engl J Med 253:63, 1955.

14. Ratnoff OD, JA Pritchard, JA Colopy: Hemorrhagic states during pregnancy. II. N Engl J Med 253:97, 1955.

15. Ratnoff $O D, W G$ Nebehay: Multiple coagulative defects in a patient with the Waterhouse-Friderichsen syndrome. Ann Intern Med 56:627, 1962.

16. Cohen E, CA Ballard: Consumptive coagulopathy associated with intra-amniotic saline instillation and the effect of oxytocin. Obstet Gynecol 43:300, 1974.

17. Malofiejew M: Kallikrein-like activity in human myometrium, placenta, and amniotic fluid. Biochem Pharmacol 22:123, 1973.

18. Steiner PE, CC Lushbaugh: Maternal pulmonary embolism by amniotic fluid as a cause of shock and unexplained deaths in obstetrics. JAMA 117:1245, 1941.

19. Sperry K: Amniotic fluid embolism: To understand an enigma. JAMA 225:2183, 1986.

20. Graeff N, W Kuhn: The amniotic infection syndrome. In: Coagulation Disorders in Obstetrics. WB Saunders, 1980, p 91.

21. Fiana, S: Maternal mortality in Sweden: 1955-74. Acta Obstet Gynecol Scand 57:129, 1978.

22. Peterson EP, HB Taylor: Amniotic fluid embolism: An analysis of 40 cases. Obstet Gynecol 35:787, 1970.

23. Aguillon A, T Andrus, A Grayson, GJ Race: Amniotic fluid embolism: A review. Obstet Gynecol Surv 17:619, 1962.

24. Cortney, LD: Amniotic fluid embolism. Obstet Gynecol Surv 29:169, 1974.

25. Morgan, M: Amniotic fluid embolism. Anesthesia 34:20, 1979.

26. Price T, VV Baker, RL Cefalo: Amniotic fluid embolism, three case reports with a review of the literature. Obstet Gynecol Surv 40:462, 1985.

27. Albrechtsen OK: Hemorrhagic disorders following amniotic fluid embolism. Clin Obstet Gynecol 7:361, 1964.

28. Russel WS, WH Jones: Amniotic fluid embolism: A review of the syndrome with a report of 4 cases. Obstet Gynecol 26:476, 1965 .

29. Atwood HD: The histological diagnosis of amniotic fluid embolism. J Pathol Bacteriol 76:211, 1958.

30. Yaffe H, A Eldor, E Hornstein, E Sadovsky: Thromboplastic activity in amniotic fluid during pregnancy. Obstet Gynecol 50: $454,1977$. 
31. Yaffe H, E Hay-am, E Sadovsky: Thromboplastic activity of amniotic fluid in term and postmature gestations. Obstet Gynecol 57:490, 1981 .

32. Hafter R, H Graeff: Molecular aspects of defibrination in a reptilase-treated case of "dead-fetus syndrome." Thromb Res $7: 391,1975$

33. Steichele DF: Consumptive coagulopathy in obstetrics and gynecology: Thromb Diath Haemorrh 36(Suppl): 177, 1969.

34. Egeberg $\mathrm{O}$ : Blood coagulation and intravascular hemolysis. Scand J Clin Lab Invest 14:217, 1962.

35. Krevins JR, DP Jackson, CL Cowley, RC Hartman: The nature of the hemorrhagic disorder accompanying hemolytic transfusion reactions in man. Blood 12:834, 1957.

36. Langdell RD, EM Hedgpeth: A study of the role of hemolysis in the hemostatic defect of transfusion reactions. Thromb Diath Haemorrh 3:566, 1959.

37. Quick AJ, JG Georgatsos, CV Hussey: The clotting activity of human erythrocytes: Theoretic and clinical implications. Am J Med 228:207, 1954.

38. Surgenor DM: Erythrocytes and blood coagulation. Thromb Diath Haemorrh 32:247, 1974.

39. Abildgaard CF, JJ Corrigan, RA Seeler, JV Simone, I Schulman: Meningococcemia associated with intravascular coagula. tion. Pediatrics 40:78, 1967.

40. McGehee WG, SI Rapaport, PF Hjort: Intravascular coagulation in fulminant meningococcaemia. Ann Intern Med 67:250, 1967.

41. Winkelstein A, CL Songster, TS Caras: Fulminant meningococcemia and disseminated intravascular coagulation. Arch Intern Med 124:55, 1969.

42. Corrigan JJ: Changes in the blood coagulation system associated with septicemia. N Engl J Med 279:851, 1968.

43. Yoshikawa $T, R$ Tanaka, LB Guze: Infection and disseminated intravascular coagulation. Medicine (Baltimore) 50:237, 1971.

44. Cline MJ, KL Melmon, WC Davis, HE Williams: Mechanism of endotoxin interaction with leukocytes. $\mathrm{Br} \mathrm{J}$ Haematol 15 : $539,1968$.

45. McKay DG, SS Shaprio: Alterations in the blood coagulation system induced by bacterial endotoxin. I: In vitro (generalized Schwartzman reaction). J Exp Med 107:353, 1958.

46. Cronberg S, P Skansberg, K Nivenios-Larsson: Disseminated intravascular coagulation in septicemia caused by beta-hemolytic streptococci. Thromb Res 3:405, 1973.

47. Rubenberg WL, LR Baker, JA McBride, JA Sevitt, WL Brain: Intravascular coagulation in a case of Clostridium perfringens septicemia: Treatment by exchange transfusion and heparin. $\mathrm{Br}$ Med J 3:271, 1967.

48. Gagel C, M Linder, G Müller-Berghaus, $H$ Lasch: Virus infection and blood coagulation. Thromb Diath Haemorrh 23:1, 1970.

49. McKay DG, W Margaretten: Disseminted intravascular coagulation in virus diseases. Arch Intern Med 120:129, 1967.

50. Niewiarowski S, E Bandowski, I Rogowicka: Studies in the absorption and activation of Hageman Factor (Factor XII) by collagen and elastin. Thromb Diath Haemorrh 24:387, 1965.

51. Robbins JE, CA Stetson: An effect of antibody-antigen interaction in blood coagulation. J Exp Med 109:1, 1959.

52. Salmon SJ, PH Lambert, J Louis: Pathogenesis of the intravascular coagulation syndrome induced by immunological reactions. Thromb Diath Haemorrh 45:161, 1971.

53. Bick RL: Alterations of hemostasis associated with malignancy. In: Murano G, RL Bick, Eds: Basic Concepts of Hemostasis and Thrombosis. CRC Press, Boca Raton, FL, 1980, p 213.

54. Bick RL: Alterations of hemostasis associated with malignancy:
Etiology, pathophysiology, diagnosis, and management. Semin Thromb Hemost 5:1, 1978.

55. Mersky C: Altered blood coagulability in patients with malignant tumors. Ann NY Acad Sci 23:289, 1974.

56. Sun NC, EJW Bowie, FJ Kazemier, LR Elueback, CA Owen: Blood coagulation studies in patients with cancer. Mayo Clin Proc 49:636, 1974.

57. Folkman J: Tumor angiogenesis: Therapeutic implications. N Engl J Med 285:1182, 1971.

58. Folkman J, RS Coltran: Relation of capillary proliferation to tumor growth. In: Richter GW, Ed: Int Rev Exp Pathol Vol 16, Williams \& Wilkins, Baltimore, 1976, p 16.

59. Semeraro N, MB Donati: Pathways of blood clotting initiation by cancer cells. In: Donati MB, JF Davidson, S Garattini, Eds: Malignancy and the Hemostatic System. Raven Press, New York, 1981, p 65.

60. Wilson WL: Malignancy and anticoagulation. In: Murano G, RL Bick, Eds: Basic Concepts of Hemostasis and Thrombosis. CRC Press, Boca Raton, FL, 1980, p 227.

61. Pineo GF, E Regoeczi, MW Haton, ML Brain: The activation of coagulation by extracts of mucin: A possible pathway of intravascular coagulation accompanying adenocarcinoma. J Lab Clin Med 82:255, 1976.

62. Pineo GF, MC Brain, AS Gallus, J Hirsh, MW Hatton, E Regoeczi: Tumors, mucus production, and hypercoagulability. Ann NY Acad Sci 230:262, 1974.

63. Rapaport SI, CG Chapman: Coexistant hypercoagulability and hypofibrinogenemia in a patient with prostatic carcinoma. Am J Med 27:144, 1959.

64. Dobbs RM, JA Barber, JW Weigel, JE Bergin: Clotting predisposition in carcinoma of the prostate. $J$ Urol 123:706, 1980.

65. Pergament ML, WR Swaim, CE Blackard: Disseminated intravascular coagulation in the urologic patient. J Urol 116:1, 1976.

66. Mertins BF, LF Greene, EJW Bowie, LR Elueback, CA Owen: Fibrinolytic split products and ethanol gelation test in preoperative evaluation of patients with prostatic disease. Mayo Clin Proc 49:642, 1974.

67. Gore I: Thrombin and pancreatic carcinoma. Am J Pathol 29: $1093,1953$.

68. Innerfield 1, A Angrist, JW Benjamin: Plasma antithrombin patterns in disturbances of the pancreas. Gastroenterology 19: $843,1951$.

69. Gralnick HR, HK Tan: Acute promyelocytic leukemia: A model for understanding the role of the malignant cell in hemostasis. Human Pathol 5:661, 1974.

70. Gralnick, HR: Cancer cell procoagulant activity. In: Donati $\mathrm{MB}, \mathrm{JF}$ Davidson, S Garattini, Eds: Malignancy and the $\mathrm{He}$ mostatic System. Raven Press, New York, 1981, p 57.

71. Lisiewicz. J: Mechanisms of hemorrhage in leukemias. Semin Thromb Hemost 4:241, 1978.

72. Lisiewicz J: Acute leukemias. In: Hemorrhage in Leukemias. Polish Medical Publishers, Warsaw, 1976, p 51.

73. Rand JJ, WE Moloney, HS Sise: Coagulation defects in acute promyelocytic leukemia. Arch Intern Med 123:39, 1969.

74. Gralnick HR, J Bagley, E Abrell: Heparin treatment for the hemorrhagic diathesis of acute promyelocytic leukemia. Am J Med 52:167, 1974.

75. Bennett RM: Proc Tutorial in Hematopathology. City of Hope, Dept. Pathol., Pasadena, 1980.

76. Bick RL: Disseminated intravascular coagulation and related syndromes. In: Bick RL, Ed: Disorders of Hemostasis \& Thrombosis: Principles of Clinical Practice. Thieme, New York, 1985, p 157. 
77. Perry S: Coagulation defects in leukemia. J Lab Clin Med 50: 229, 1957.

78. Beller FK: Experimental animal models for the production of disseminated intravascular coagulation. In: Bang $\mathrm{N}, \mathrm{FK}$ Beller, E Deutsch, EF Mammen, Eds: Thrombosis and Bleeding Disorders. Academic Press, New York, 1971, p 514.

79. McKay DG: Progress in disseminated intravascular coagulation. Calif Med 111:186, 1969.

80. Mersky C: Defibrination syndrome. In: Biggs R, Ed: Human Blood Coagulation. Blackwell Scientific, London, 1976, p 492.

81. Holder LA, LL Malin, CL Fox: Hypercoagulability after thermal injuries. Surgery 54:316, 1963.

82. Saliba MJ, WL Demsey, JL Kruggel: Large burns in humans: Treatment with heparin. JAMA 225:261, 1973.

83. Bick RL: Vascular disorders associated with thrombo-hemorrhagic phenomena. Semin Thromb Hemost 5:167, 1979.

84. Bick RL: Hereditary hemorrhagic telangiectasia and disseminated intravascular coagulation: A new clinical syndrome. Ann NY Acad Sci 370:851, 1981.

85. Inceman $\mathrm{S}, \mathrm{Y}$ Tangun: Chronic defibrination syndrome due to a giant hemangioma associated with microangiopathic hemolytic anemia. Am J Med 46:997, 1969.

86. Kasabach HH, KK Merritt: Capillary hemangioma with extensive purpura-report of a case. Am J Dis Child 59:1063, 1940.

87. Bick RL: Vascular disorders. In: Murano G, RL Bick, Eds: Basic Concepts of Hemostasis and Thrombosis. CRC Press, Boca Raton, FL, 1980, p 89.

88. Bick RL: Hereditary hemorrhagic telangiectasia and disseminated intravascular coagulation: A new clinical syndrome. Vasc Surg 15:394, 1981.

89. Kazemier FJ, P Didisheim, VK Fairbanks, J Ludwig, WS Payne, EJW Bowie: Intravascular coagulation and arterial discase. Thromb Diath Haemorrh 36(Suppl):295, 1969.

90. Bick RL: Alterations of hemostasis associated with surgery, cardiopulmonary bypass surgery, and prosthetic devices. In: Ratnoff OD, C Forbes, Eds: Disorders of Hemostasis. Grune \& Stratton, New York, 1984.

91. Owen CA, H Oels, EJW Bowie, P Didisheim, JH Thompson: Chronic intravascular coagulation syndrome. Thromb Diath Haemorrh 36(Suppl): 197, 1969.

92. Pritchard A, G Cunningham, MA Mason: Coagulation changes in eclampsia; their frequency and pathogenesis. Am J Obstet Gynecol 124:855, 1970.

93. Bonnar J, GP McNicol, AS Douglas: Coagulation and fibrinolytic systems in pre-eclampsia and eclampsia. Br Med J 1: 12,1971 .

94. Roberts JM, WJ May: Consumption coagulopathy in severe preeclampsia. Obstet Gynecol 48:163, 1976.

95. Spivack JL, DB Sprangler, WR Bell: Defibrination after intraamniotic injection of hypertonic saline. N Engl J Med 287: $321,1972$.

96. Owen CA, EJW Bowie: Chronic intravascular coagulation fibrinolysis (ICF) syndromes (DIC). Semin Thromb Hemost 3: $268,1977$.

97. Collins GJ, RL Heymann, R Zajtchuk: Hypercoagulability in patients with peripheral vascular disease. Am J Surg 130:2, 1975.

98. Schnetzer GW, JA Penner: Chronic intravascular coagulation syndrome associated with atherosclerotic aortic aneurysm. South Med J 66:264, 1973.

99. Rohner RF, JT Prior, JH Sipple: Mucinous malignancies, venous thrombosis, and terminal endocarditis with emboli: A syndrome. Cancer 19:1805, 1966.

100. Amundsen MA, JA Spittell, JH Thompson: Hypercoagulabil- ity associated with malignant disease and with the postoperative state. Ann Intern Med 58:608, 1963.

101. Davis RB, A Theologides, BJ Kennedy: Comparative studies of blood coagulation and platelet aggregation in patients with cancer and nonmalignant disease. Ann Intern Med 71:67, 1969.

102. Slichter SJ, LA Harker: Hemostasis in malignancy. Ann NY Acad Sci 230:252, 1974.

103. DeVries WI, MAJ Braat-van Straaten, E Muller, M Wettermark: Antiplasmin deficiency in polycythaemia: A form of thrombopathy. Thromb Diath Haemorrh 6:445, 1961.

104. Silverstein MH: Agnogenic Myeloid Metaplasia. Publishing Sciences Group, Action, Mass, 1975, p 10.

105. Hartman RC, DE Jenkins: Proxysmal nocturnal hemoglobinuria: Current concepts of certain pathophysiological features. Blood 25:850, 1965.

106. McKay DG: Disseminated Intravascular Coagulation: An Intermediary Mechanism of Disease. Harper \& Row, New York, 1965.

107. Ryan TJ: Coagulation and fibrinolysis. In: Ryan TJ, Ed: Microvascular Injury. WB Saunders, Philadelphia, 1976, p 221.

108. Katz J, S Krawitz, PV Sachs, SE Levin, P Thompson, J Levin, J Metz: Platelets, erythrocytes, and fibrinogen kinetics in the hemolytic-uremic syndrome of infancy. J Pediatr 83: $739,1973$.

109. Kisker CT, R Rush: Detection of intravascular coagulation. J Clin Invest 50:2235, 1971 .

110. Fareed $\mathrm{J}$ : New methods in hemostatic testing. In: Fareed J, HL Messmore, J Fenton, KM Brinkhous, Eds: Perspectives in Hemostasis. Pergamon Press, New York, 1981, p 310.

111. Henry RL: Platelet function in hemostasis. In: Murano G, RL Bick, Eds: Basic Concepts of Hemostasis and Thrombosis. CRC Press, Boca Raton, FL, 1980, p 17.

112. Heyes H, W Kohle, B Slijerpcevic: The appearance of schistocytes in the peripheral blood in correlation to degree of disseminated intravascular coagulation. Haemostasis 5:66, 1976.

113. Bull B, IN Kuhn: The production of schistocytes by fibrin strands (a scanning electron microscope study). Blood 35:104, 1970.

114. Backman $\mathrm{F}$ : The paradoxes of disseminated intravascular co. agulation. Hosp Pract 6:113, 1971.

115. Deykin D: The clinical challenge of disseminated intravascular coagulation. $N$ Engl J Med 283:636, 1970.

116. Evanson SA, RF Elgjo, D Shepro: Platelets, endothelium, and the triggering mechanisms of intravascular coagulation. Thromb Diath Haemorrh 24:207, 1973.

117. Flute PT: Intravascular coagulation. Postgrad Med J 48:346, 1972.

118. Haragawa N, N Watanabe, H Nagata, M Murao: Analysis of the disappearance curve of labeled fibrinogen at the time of hypofibrinogenemia in rabbits with acute or chronic intravascular coagulation. Thromb Haemost 50:49, 1976.

119. Heyes H, P Hilgard, W Theiss: Induction of disseminated intravascular coagulation by endotoxin and saline loading in rats. I. The influence on fibrinogen turnover and plasma parameters. Thromb Res 7:37, 1975.

120. McKay DG, D Gitlin, JM Graig: Immunochemical demonstration of fibrin in the generalized Schwartzman reaction. Arch Pathol 67:270, 1969.

121. McKay DG, W Margaretten, I Csavossy: An electron microscope study of the effects of bacterial endotoxin on the bloodvascular system. Lab Invest. 15:1815, 1966.

122. Müller-Berghaus G, L Roka, HG Lasch: Induction of glomer- 
ular microclot formation of fibrin monomer infusion. Thromb Diath Haemorrh 29:375, 1973.

123. Lee D, D Brown, L Baker, D Littlejohns, D Roberts: Hematological complications of chlorate poisoning. Br Med J 2:31, 1970.

124. Owen CA, EJW Bowie, HA Cooper: Turnover of fibrinogen and platelets in dogs undergoing induced intravascular coagulation. Thromb Res 2:251, 1973.

125. Latallo ZS: Products of fibrin(ogen) proteolysis. Thromb Diath Haemorrh 24(Suppl):145, 1973.

126. Marder VJ, HR Shulman, WR Carroll: High molecular weight derivatives of human fibrinogen produced by plasmin. I. Physico-chemical and immunological characterization. J Biol Chem 244:2111, 1969.

127. Marder VJ, AZ Budzynski, HL James: High molecular weight derivatives of human fibrinogen produced by plasmin. Ill. Their $\mathrm{NH}_{2}$-terminal amino acids and comparison of the " $\mathrm{NH}_{2}$-terminal amino disulfide knot." J Biol Chem 247:4775, 1972.

128. Plow EF, C Hougie, TS Edgington: Immunochemical and molecular investigations of fibrinogen cleavage fragments. In: Pollar L, Ed: Recent Advances in Thrombosis. Churchill Livingstone, London, 1973, p 203.

129. Bang NU, M Chang: Soluble fibrin complexes. Semin Thromb Hemost 1:91, 1974.

130. Fletcher AP, N Alkjaersig, S Fisher, S Sherry: The proteolysis of fibrinogen by plasmin: the identification of thrombinclottable fibrinogen derivatives which polymerize abnormally. J Lab Clin Med 68:780, 1966.

131. Jacobson E, B Ly, P Kieulf: Incorporation of fibrinogen with soluble fibrin complexes. Thromb Res 4:499, 1974.

132. Shainoff JR, IH Page: Significance of cryoprofibrin in fibrinogen-fibrin conversion. J Exp Med 116:687, 1962.

133. Breen FA, JZ Tullis: Ethanol gelation, a rapid screening test for intravascular coagulation. Ann Intern Med 69:1197, 1968.

134. Derechin M, S Szuchet: Gelation phenomena in degraded fibrinogen and fibrin. Arch Biochem Biophys 87:100, 1960.

135. Gurewich V, E Hutchinson: Detection of intravascular coagulation by protamine sulfate and ethanol gelation tests. Thromb Res 2:539, 1973.

136. Bick RL: The clinical significance of fibrinogen degradation products. Semin Thromb Hemost 8:302, 1982.

137. Kopec M, Z Wegrzynowiczy, A Budzynski, Z Latallo, B Lipinski, E Kowalski: Interaction of fibrinogen degradation products with platelets. Exp Biol Med 3:73, 1968.

138. Niewiarowski S, E Regoeczi, G Stewart, A Senyi, J Mustard: Platelet interaction with polymerizing fibrin. J Clin lnvest 51 : 685, 1972.

139. Pechet L: Fibrinolysis. N Engl J Med 273:96, 1965.

140. Sharp AA: Pathological fibrinolysis. Br Med Bull 20:240, 1964.

141. Chesterman $\mathrm{CN}$ : The fibrinolytic system and haemostasis. Throm Diath Haemorrh 34:308, 1975.

142. Donaldson V: Effect of plasmin in vitro on clotting factors in plasma. J Lab Clin Med 56:644, 1960.

143. Nilsson IM: Local fibrinolysis as a mechanism for haemorrhage. Thromb Diath Haemorrh 34:623, 1975.

144. Stormorken H: Relation of the fibrinolytic to other biological systems. Thromb Diath Haemorrh 34:378, 1975.

145. Ratnoff OD, GB Haff: The conversion of Cils to $\mathrm{Cl}^{\prime}$ esterase by plasmin and trypsin. J Exp Med 125:337, 1961 .

146. Schreiber AD, KF Austen: Interrelationships of the fibrinolytic, coagulation, kinin generation, and complement systems. Semin Hematol 6:593, 1973.
147. Ward PA: A plasmin split fragment of C-3 as a new chemotactic factor. J Exp Med 126:189, 1967.

148. Kaplan A, H Meier, R Mandel: The Hageman factor dependent pathways of coagulation, fibrinolysis, and kinin generation. Semin Thromb Hemost 3:6, 1976.

149. Sherry S: The kallikrein system: A basic defense mechanism. Hosp Pract 5:75, 1970.

150. Ulevich R, C Cochran, S Revak, D Morrison, A Johnson: The structural and enzymatic properties of the Hageman Factoractivated pathways. In: Reich E, D Rifkin, E Shaw, Eds: Proteases and Biological Control. Cold Spring Habor Symposiums, Cold Spring Harbor, NY, 1975, p 85.

151. Webster ME: Human plasma kallikrein, its activation and pathological role. Fed Proc 27:84, 1968.

152. Beller FK, W Theiss: Fibrin derivitives, plasma hemoglobin and glomerular fibrin deposition in experimental intravascular coagulation. Thromb Diath Haemorrh 29:363, 1973.

153. McKay DG, MM Linder, VK Cruse: Mechanisms of thrombosis of the microcirculation. Am J Pathol 63:231, 1971.

154. Penick GD, HR Roberts, WP Webster, KM Brinkhous: Hemorrhagic states secondary to intravascular clotting. Arch Pathol 66:708, 1958.

155. Penick GD, HR Roberts: Intravascular clotting: Focal and systemic. Int Rev Exp Pathol 3:269, 1964.

156. Seegers WH: Use and regulation of blood clotting mechanisms. In: Seegers WH, Ed: Blood Clotting Enzymology. Academic Press, New York, 1971, p 1.

157. Brown DL, PJ Lachmann: The behavior of complement and platelets in lethal endotoxin shock in rabbits. Int Arch Allergy Appl Immunol 45:193, 1973.

158. Davey MG, EF Lüscher: Release reactions of human platelets induced by thrombin and other agents. Biochem Biophys Acta 165:490, 1968.

159. Des Prez RM, HI Horowitz, EW Hook: Effects of bacterial endotoxin on rabbit platelets. I. Platelet aggregation and release of platelet factors in vitro. J Exp Med 114:857, 1961.

160. Evenson SA, M Jeremic: Platelets and the triggering mechanism of intravascular coagulation. Br J Haematol 19:33, 1970.

161. Apitz K: A study of the generalized Schwartzman phenomenon. J Immunol 29:255, 1935.

162. Hjort PF, SI Rapaport: The Schwartzman reaction: Pathogenetic mechanism and clinical manifestations. Annu Rev Med 16:135, 1965.

163. McKay DG, W Margaretten, I Cszvossy: An electron microscopic study of endotoxin shock in rhesus monkeys. Surg Gynecol Obstet 125:825, 1967.

164. Müller-Berghaus G, M Hocke: Effect of endotoxin on the formation of microthrombi from circulating fibrin monomer complexes in the absence of thrombin generation. Thromb Res 1:541, 1972.

165. Shen SM, SI Rapaport, DI Feinstein: Intravascular clotting after endotoxin in rabbits with impaired intrinsic clotting produced by a factor VIII antibody. Blood 42:523, 1973.

166. Wong TC: A study on the generalized Schwartzman reaction in pregnant rats induced by bacterial endotoxin. Am J Obstet Gynecol 84:786, 1962.

167. Coleman RW, M Shapira, CF Scott: Regulation of the formation and inhibition of human plasma kallikrein. Ann NY Acad Sci 370:261, 1981.

168. Kaplan AP, M Silverberg, JT Dunn, G Miller: Mechanisms for Hageman Factor activation and role of HMW kininogen as a coagulation cofactor. Ann NY Acad Sci 370:253, 1981.

169. Kaplan AP: The Hageman Factor dependent pathways of human plasma. Microvasc Res 8:97, 1974. 
170. Murano G: "The Hageman Connection": Interrelationships between complement, kinins, and coagulation. Am J Hematol $4: 409,1978$.

171. Stormorken $\mathrm{H}$ : Interrelationships between the coagulation, the fibrinolytic, and the kallikrein-kinin systems. In: Meri-Sernari GG, CRM Prentice, Eds: Haemostasis and Thrombosis. Academic Press, London, 1979, p 203.

172. Henson PM: The adherence of leukocytes and platelets induced by fixed $\operatorname{lgG}$ antibody or complement. Immunology 16 : $107,1969$.

173. Henson PM: Complement-dependent platelet and polymorphonuclear leukocyte reactions. Transplant Proc 6:27, 1963.

174. Dennis LH, BE Reisberg, J Crosbie, D Crozier, ME Conrad: The original haemorrhagic fever: Yellow fever. $\mathrm{Br} \mathrm{J}$ Haematol 17:455, 1969.

175. Heene D, G Hoffmann-Fezer, R Hoffmann, E Weiss, G Müller-Berghaus, HG Lasch: Coagulation disorders in acute hog cholera. Beitr Pathol 144:259, 1931.

176. Sohal RS, SC Sun, HL Colcolough, GE Burch: Heat stroke: An electron microscopic study of endothelial cell damage and disseminated intravascular coagulation. Arch Intern Med 122: 43, 1968.

177. Starzl TE, NJ Boehmig, N Amemiya, CB Wilson, FJ Dixon, GR Giles, KM Simpson, CG Halgrimson: Clotting changes including disseminated intravascular coagulation during rapid renal-allograft rejection. $\mathrm{N}$ Engl J Med 283:383, 1970.

178. Wilner GD, HL Nossell, El Leroy: Activation of Hageman factor by collagen. J Clin Invest 47:2608, 1968.

179. Bick RL: Desseminated Intravascular Coagulation and Related Syndromes. Manual 5570. American Society of Clinical Pathologists, Chicago, 1979, p 14.

180. Bick RL: Difficult Diagnostic Problems in Hemostasis and Thrombosis. Manual 5549. American Society of Clinical Pathology, Chicago, 1980, p 1.

181. Hardaway $R$ : Disseminated intravascular coagulation in shock. Thromb Diath Haemorrh 36(Suppl):159, 1967.

182. Lerner RG: The defibrination syndrome. Med Clin North Am 60:871, 1976.

183. McKay DG: Tissue damage in disseminated intravascular coagulation: Mechanisms of localization of thrombi in the microcirculation. Thromb Diath Haemorrh 36(Suppl):67, 1969.

184. Pitner W: Disseminated intravascular coagulation. Semin Hematol 8:65, 1971.

185. Robboy SJ, RW Coleman, JD Minna: Pathology of disseminated intravascular coagulation (DIC). Analysis of 26 cases. Human Pathol 3:327, 1972.

186. Mombelli G, A Roux, AW Haelberli, PW Straub: Comparison of 125-I fibrinogen kinetics and fibrinopeptide A in patients with disseminated neoplasia. Thromb Haemost 46:9, 1981.

187. Sandritter W, HG Lasch: Pathologic aspects of shock. Arch Exp Pathol 3:86, 1967.

188. Müller-Berghaus G: Pathophysiology of generalized intravascular coagulation. Semin Thromb Hemost 3:209, 1977.

189. Nalbandian RM, RL Henry, RL Bick: Thrombotic thrombocytopenic purpura. Semin Thromb Hemost 5:216, 1979.

190. Bleyl U: Morphologic diagnosis of disseminated intravascular coagulation: Histologic, histochemical, and electron-microscopic studies. Semin Thromb Hemost 3:247, 1977.

191. Skjorten F: Hyaline microthrombi in an autopsy material. A quantitative study with discussion of the relationship to small vessel thrombosis. Acta Pathol Microbiol Scand 76:361, 1969.

192. Morris JA, RW Smith, NS Assali: Hemodynamic action of vaso-pressor and vaso-depressor agents in endotoxin shock. Am J Obstet Gynecol 91:491, 1965.

193. Bleyl U, W Kuhn, H Graeff: Reticuloendotheliale Clearance Intravasculärer. Fibrinmonere in der Milz. Thromb Diath Haemorrh 22:87, 1969.

194. Boyd JF: Disseminated fibrin-thromboembolism among neonates dying within 48 hours of birth. Arch Dis Child 42 : $401,1967$.

195. Lendrum AC, DC Fraser, W Slidders, R Henderson: Studies on the character and staining of fibrin. J Clin Pathol 15:401, 1962.

196. Bleyl U, CM Busing, B Kremplen: Pulmonale hyaline Membranen und perinataler Kreislaufschock. Virchows Arch Pathol Anat Physiol 348:187, 1969.

197. Busing CM, U Bleyl, G Dohnert: Pulmonary hyaline membranes in the rabbit after thrombin infusion. IVth International Congress on Haemostasis, Vienna, 1973.

198. Bull B, MC Brain: Experimental models of microangiopathic hemolytic anemia. Proc R Soc Med 61:1134, 1968

199. Baker LR, ML Rubenberg, JV Dacie, MC Brain: Fibrinogen catabolism in microangiopathic hemolytic anemia. Br J Haematol 14:617, 1968.

200. Bull B, M Rubenberg, J Dacie, MC Brain: Microangiopathic hemolytic anemia: Mechanisms of red-cell fragmentation. $\mathrm{Br}$ J Haematol 14:643, 1968

201. Rubenberg M, E Regoeczi, B Bull, J Dacie, MC Brain: Microangiopathic hemolytic anemia: The experimental production of hemolysis and red-cell fragmentation by defibrination in vivo. Br J Haematol 74:627, 1968.

202. Harker L, S Slichter: Platelet and fibrinogen consumption in man. N Engl J Med 287:999, 1972.

203. Slaastad RA, NC Godal: Coagulation profile and ethanol gelation test with special reference to components consumed during coagulation. Scand J Haematol 16:25, 1976.

204. Karpatkin S, Q Khan, M Freedman: Heterogeneity of platelet function Correlation with platelet volume. Am J Med 64: 542,1978

205. Karpatkin S: Heterogeneity of human platelets. VI. Correlation of platelet function with platelet volume. Blood 51:307, 1978.

206. Eckhardt T, G Müller-Berghaus: The role of blood platelets in the precipitation of soluble fibrin endotoxin. Scand $\mathrm{J}$ Haematol 14:181, 1975.

207. Skjorten F: Bilateral renal cortical necrosis and the generalized Schwartzman reaction. Acta Pathol Microbiol Scand 65: 405, 1964.

208. Brozovic M: Acquired disorders of blood coagulation. In: Bloom A, DP Thomas, Eds: Hemostasis and Thrombosis. Churchill Livingston, New York, 1981, p 411.

209. Müller-Berghaus G, HG Lasch: Consumption of Hageman factor activity in the generalized Schwartzman reaction induced by liquid. Its prevention by inhibition of Hageman factor activation. Thromb Diath Haemorrh 23:386, 1970.

210. Mustard JF, MA Packham, RL Kinlough-Rathbone: Mechanisms in thrombosis In: Bloom AL, DP Thomas, Eds: Haemostasis and Thrombosis. Churchill Livingston, New York, $1981, \mathrm{p} 503$.

211. Blaisdell FW, RJ Stallone: The mechanism of pulmonary damage following traumatic shock. Surg Gynecol Obstet 130: $15,1970$.

212. Gitlin D, JM Graig: The nature of the hyaline membrane in asphyxia of the newborn. Pediatrics 17:64, 1956.

213. Van Breeman VL, HB Heustein, PD Bruns: Pulmonary hy- 
aline membranes studied with the electron microscopy. Am J Pathol 33:769, 1957.

214. Martin AM, HB Soloway, RL Simmons: Pathologic anatomy of the lungs following shock and trauma. J Trauma 8:687, 1968.

215. Soloway HB, Y Castillo, AM Martin: Adult hyaline membrane disease. Ann Surg 168:937, 1968.

216. Hardaway RM: Acute respiratory distress syndrome and disseminated intravascular coagulation. South Med J 71:596, 1978.

217. Killough J: Protective mechanisms of the lungs: Pulmonary diseases, pleural diseases. In: Sodeman WA, TM Sodeman, Eds: Mechanisms of Disease. WB Saunders, Philadelphia, 1979, p 459.

218. Ambrus CM, TS Choi, DH Weintraub, B Eisonberg, HP Staub, NG Courey, RJ Foote, D Goperlund, RV Moesch, M Ray, I Bross, OS Jung, IB Mink, JL Ambrus: Studies on the prevention of respiratory distress syndrome of infants due to hyaline membrane disease with plasminogen. Semin Thromb Hemost 2:42, 1975.

219. Ambrus CM, AH Weintraub, D Dunphy, JE Dowd, JW Pickren, KR Niswander, JL Ambrus: Studies on hyaline membrane disease. I. The fibrinolysis system in pathogenesis and therapy. Pediatrics 32:10, 1963.

220. Ambrus CM, JW Pickren, DH Weintraub, KR Niswander, JL Ambrus, D Robard, JL Levy: Studies on hyaline membrane disease: oxygen induced hyaline membrane disease in guinea pigs. Biol Neonate 12:246, 1968.

221. Ambrus CM, JL Ambrus, DH Weintraub, RJ Foote, NG Courey, KR Niswander: Thrombolytic therapy in hyaline membrane disease. Thromb Diath Haemorrh. 47(Suppl):269, 1971 .

222. Cohen MM, DS Weintraub, AM Lilienfeld: The relationship of pulmonary hyaline membrane to certain factors in pregnancy and delivery. Pediatrics 26:42, 1960.

223. Weintraub DB, JL Ambrus, CM Ambrus: Studies on hyaline membrane disease: Diagnostic and prognostic problems. Pediatrics 38:244, 1966.

224. Hardaway RM: Syndromes of Disseminated Intravascular Coagulation With Special Reference to Shock and Hemorrhage. Charles C Thomas, Springfield, IL, 1966.

225. Müller-Berghaus G, B Mann: Precipitation of ancrod-induced soluble fibrin by aprotinin and norepinephrine. Thromb Res 2:305, 1973 .

226. Latour JG, JB Prejean, W Margaretten: Corticosteroids and the generalized Schwartzman reaction. Mechanisms of sensitization in the rabbit. Am J Pathol 65:189, 1971.

227. Lee L: Reticuloendothelial clearance of circulating fibrin in the pathogenesis of the generalized Schwartzman reaction. J Exp Med 115:1065, 1962.

228. McKay DG, G Müller-Berghaus: Therapeutic implications of disseminated intravascular coagulation. Am J Cardiol 20:392, 1967.

229. Bentley PG, VV Kakkar, MF Scully, IR MacGregor, P Webb, $P$ Chan, H Jones: An objective study of alternative methods of heparin administration. Thromb Res 18:177, 1980.

230. Cooper HA, EJW Bowie, P Didisheim: Paradoxic changes in platelets and fibrinogen in chronically induced intravascular coagulation. Mayo Clin Proc 46:521, 1971.

231. Owen CA, EJW Bowie: Chronic intravascular syndromes. Mayo Clin Proc 49:673, 1974.

232. Bick RL: Clinical hemostasis practice: The major impact of laboratory automation. Semin Thromb Hemost 9:139, 1983.
233. Fareed J, HL Messmore, EW Bermes: New perspectives in coagulation testing. Clin Chem 26:1380, 1980.

234. Messmore HL, J Fareed, J Kniffin, G Squillacia, J Walenga: Synthetic substrate assays of the coagulation enzymes and their inhibitors. Comparison with clotting and immunologic method for clinical and experimental usage. Ann NY Acad Sci 370:785, 1981

235. Messmore HL: Automation in coagulation testing: Clinical applications. Semin Thromb Hemost 9:335, 1983.

236. Bick RL: Disseminated intravascular coagulation: Pathophysiology and diagnosis. Pract Cardiol 7:145, 1981 .

237. Bick RL: Clinical significance of fibrino(geno)lytic degradation product (FDP) testing. Lab Lore 9:683, 1981.

238. Bick RL: Disseminated intravascular coagulation. In: Fareed J, HL Messmore, J Fenton, KM Brinkhous, Eds: Perspectives in Hemostasis. Pergamon Press, New York, 1981, p 121.

239. Bick RL: Disseminated intravascular coagulation and related syndromes. In: Murano G, RL Bick, Eds: Basic Concepts of Hemostasis and Thrombosis. CRC Press, Boca Raton, FL, 1980, p 163.

240. Bick RL: Pathophysiology of disseminated intravascular coagulation. In: Clinical Significance of FDP Testing. Health Sciences Consortium Press, Chapel Hill, NC, 1981.

241. Kurcznski EM, JA Penner: Activated prothrombin concentrate for patients with Factor VIII inhibitors. N Engl J Med 291:164, 1974.

242. Penner JA, PE Kelly: Management of patients with Factor VIII or IX inhibitors. Semin Thromb Hemost 1:386, 1975.

243. Seegers WH, E Marceniak: Autoprothrombin C in irregular blood clotting. Thromb Diath Haemorrh 8:81, 1962.

244. Marder VJ, MO Matchett, S Sherry: Detection of serum fibrinogen and fibrin degradation products: Comparison of six techniques using purified products and application in clinical studies. Am J Med 51:71, 1971.

245. Myers AR, KJ Bloch, RW Coleman: A comparative study of four methods for detecting fibrinogen degradation products in patients with various diseases. $\mathrm{N}$ Engl $\mathrm{J}$ Med 283:663, 1970.

246. Gurewich V, B Lipinsky, I Lipinska: A comparative study of precipitation and paracoagulation by protamine sulfate and ethanol gelation tests. Thromb Res 2:539, 1973.

247. Hedner U, IM Nilsson: Parallel determinations of FDP and fibrin monomers with various methods. Thromb Diath Haemorrh 28:268, 1972.

248. Phillips L, V Skrodelis: Intravascular coagulation in obstetric complications: Fibrin monomer and fibrin split products. In: Neri-Sernari GG, CRM Prentice, Eds: Haemostasis and Thrombosis. Academic Press, New York, 1979, p 551.

249. Zirlinsky A, R Aitman, J Rouvier: Comparison between a modified ethanol gelation test and protamine sulfate test: Experimental studies. Thromb Haemost 36:165, 1976.

250. Pindyck J, NC Lichtman, SG Kohl: Cryofibrinogenemia in women using oral contraceptives. Lancet 1:51, 1970.

251. Sonnabend D, D Cooper, P Fiddes, R Penny: Fibrin degradation products in thromboembolic disease. Pathology $4: 47$, 1972.

252. Kidder WR, LJ Logan, SI Rapaport, MJ Patch: The plasma protamine paracoagulation test: Clinical and laboratory evaluation. Am J Clin Pathol 58:675, 1972.

253. Bick RL, ML Dukes, WL Wilson, L Fekete: Antithrombin III (AT-III) as a diagnostic aid in disseminated intravascular coagulation. Thromb Res 10:721, 1977.

254. Bick RL: Clinical relevance of antithrombin III. Semin Thromb Hemost 8:276, 1982. 
255. Huseby RM, RE Smith: Synthetic oligopeptide substrates: Their diagnostic application in blood coagulation, fibrinolysis, and other pathological states. Semin Thromb Hemost 6: $173,1980$.

256. Abildgaard U, K Graven, HC Godal: Assay of progressive antithrombin in plasma. Thromb Diath Haemorrh 24:224, 1970.

257. Bick RL, I Kovacs, LF Fekete: A new two-stage functional assay for antithrombin-III: Clinical and laboratory evaluation. Thromb Res 8:745, 1976.

258. Harpel PC, RD Rosenberg: Alpha-2-macroglobulin and antithrombin-heparin cofactor: Modulators of hemostasis and inflammatory reactions. Prog Hemost Thromb 3:145, 1976.

259. Ødegard OR, M Lie, U Abildgaard: Heparin cofactor activity measured with an amidolytic method. Thromb Res 6:287, 1975.

260. Seegers WH: Antithrombin III: Theory and clinical applications. Am J Clin Pathol 69:367, 1968.

261. Bick RL, BJ McClain: A clinical comparison of chromogenic, fluorometric, and natural (fibrinogen) substrates for determination of antithrombin-III. Thromb Haemost 46:364, 1981 .

262. Bishop RC, PM Hudson, G Mitchell, SP Pochron: Use of fluorogenic substrates for the assay of antithrombin III and heparin. Ann NY Acad Sci 370:720, 1981.

263. Farred J, HL Messmore, JM Walenga, EW Bermes, RL Bick: Laboratory evaluation of antithrombin III: A critical overview of currently available methods for antithrombin III measurements. Semin Thromb Hemost 8:288, 1982.

264. Kraytman M: Platelet size in thrombocytopenias and thrombocytosis of various origin. Blood 41:587, 1973.

265. Zieve PM, J Levin: Disseminated intravascular coagulation. In: Zieve PD, J Levin, Eds: Disorders of Hemostasis. WB Saunders, Philadelphia, 1976, p 71.

266. Bick RL, BJ McClain: Sequential platelet size distribution profiling for assessing platelet survival and response to antiplatelet drugs. Blood 58:230, 1981.

267. Farrel RJ, MJ Duffy, GJ Duffy: Elevated plasma beta-thromboglobulin in patients with malignancy. Thromb Haemost 42: $143,1979$.

268. Lundham CA, JD Cash: B-thromboglobulin: A new tool for the diagnosis of hypercoagulability. In: Neri-Sernari GG, CRM Prentice, Eds: Hemostasis and Thrombosis. Academic Press, London, 1979, p 159.

269. Matsuda T, T Seki, M Ogawara, R Miura, M Yokouchi, M Murakami: Comparison between plasma levels of B-thromboglobulin and platelet factor 4 in various diseases. Thromb Haemost 42:288, 1979.

270. Zahavi J, VV Kakkar: B-thromboglobulin - a specific marker of in vivo platelet release reaction. Thromb Haemost 44:23, 1980.

271. Zieman M, I Friedrich, HK Breddin: Activated platelets and platelet function in traumatic septic and haemorrhagic preshock conditions. Thromb Haemost 42:410, 1979.

272. Lundham CA, N Allen, RB Bradford, R Dowdle, N Bentley, AL Bloom: B-thromboglobulin and platelet survival in patients with rheumatic diseases and prosthetic heart valves and their treatment with sulfinpyrazone. Thromb Haemost 42 : $329,1979$.

273. Niewiarowski S, J Guzzo, AK Rav, I Berman, P James: Increased levels of low-affinity platelet factor 4 in plasma and urine of patients with chronic renal failure. Thromb Haemost 42:416, 1979.

274. Budzynski AZ, VJ Marder: Determination of human fibrino- peptide A by radioimmunoassay in purified systems and in the blood. Thromb Diath Haemorrh. 34:709, 1975.

275. Cronlund M, J Hardin, J Burton, L Lee, I Haber, KJ Bloch: Fibrinopeptide-A in plasma of normal subjects and patients with disseminated intravascular coagulation and systemic lupus erythematosus. J Clin Invest 58:142, 1976.

276. Douglas JT, M Shah, GDO Lowe, CRM Prentice: Fibrinopeptide-A and beta-thromboglobulin levels in pre-eclampsia and hypertensive pregnancy. Thromb Haemost 46:8, 1981.

277. Kockum C: Radioimmunoassay of fibrinopeptide-A-clinical applications. Thromb Res 8:225, 1976.

278. Nossel HL, M Ti, KL Kaplan, K Spandonis, T Soland, VD Butler: The generation of fibrinopeptide-A in clinical blood samples-evidence for thrombin activity. J Clin Invest 58: $1136,1976$.

279. Fareed J, RL Bick, J Walenga, HL Messmore, EW Bermes: Clinical and experimental studies using a modified radioimmunoassay for B-beta $15-42$ related peptides. Thromb Haemost 50:300, 1983.

280. Fareed J, RL Bick, G Squillaci, J Walenga, HL Messmore. EW Bermes: Clinical and experimental utilization of a modified radioimmunoassay for B-beta 15-42 related peptides. Clin Chem 29:1161, 1983.

281. Plow EF, TS Edgington: Surface markers of fibrinogen and its physiologic derivatives related by antibody probes. Semin Thromb Hemost 8:36, 1982.

282. Alkjaersig N, L Roy, AP Fletcher: Analysis of gel exclusion chromatographic data by plasma fibrinogen chromatography. Thromb Res 3:525, 1973.

283. Clavin SA, JL Bobbitt, RT Shuman, EL Smithwick: Use of peptidyl-4-methoxy-2-naphthylamides to assay plasmin. Anal Biochem 80:355, 1977.

284. Gaffney PJ, RD Philo: A commentary of new methodology in haemostasis using chromogenic substrates. In: Fareed J, JL Messmore, J Fenton, KM Brinkhous, Eds: Perspectives in Hemostasis. Pergamon Press, New York, 1981, p 405.

285. Latallo ZS, E Teisseyre, S Lopaciuk: Evaluation of a fibrinolytic profile of plasma using chromogenic substrates. In: Scully MF, VV Kakkar, Eds: Chromogenic Peptide Substrates. Churchill Livingston, London, 1979, p 262.

286. Soria CS, M Samama: A plasminogen assay using a chromogenic synthetic substrate: Results from clinical work and from studies of thrombolysis. In: Davidson JF, RM Rowan, MM Samama, PC Desnoyers, Eds: Progress in Chemical Fibrinolysis and Thrombolysis. Raven Press, New York, 1978, 337.

287. Triplett DA, C Harms, L Hermelin, RM Huseby, GA Mitchell, SP Pochron: Clinical studies of the use of fluorogenic substrate assay method for the determination of plasminogen. Thromb Haemost 42:50, 1979.

288. Kowalski E, M Kopec, S Niewiarowski: An evaluation of the euglobulin method for the determination of fibrinolysis. J Clin Pathol 12:215, 1959.

289. Menon IS: A study of the possible correlation of euglobulin lysis time and dilute blood clot lysis time in the determination of fibrinolytic activity. Lab Pract 17:334, 1968.

290. Collen D, F DeCock, M Verstraete: Immunological distinction between anti-plasmin and alpha -1-antitrypsin. Thromb Res $7: 245,1975$

291. Collen P: Identification and some properties of a new fastacting plasmin inhibitor in human plasma. Eur J Biochem 69: 209, 1976.

292. Edy J, D Collen, M Verstraete: Quantitation of the plasma protease inhibitor antiplasmin with the chromogenic substrate 
(S-2251). In: Davidson JF, RM Rowan, MM Samama, PC Desnoyers, Eds: Chemical Fibrinolysis and Thrombolysis. Raven Press, New York, 1978, p 315.

293. Gyzander E, P Friberger, H Myrwold, H Noppa, R Olsson, AC Teger-Nilsson, L Walmo: Antiplasmin determination by means of the plasmin specific substrate S-2251: Methodology studies and some clinical applications. In: Witt I, Ed: New Methods for the Analysis of Coagulation Using Chromogenic Substrates. Walter De Gruyter, Berlin, 1977, p 229.

294. Teger-Nilsson AC, E Gryzander, U Hedner, H Myrwold, H Noppa, R Olsson, L Walmo: Antiplasmin and other natural inhibitors of fibrinolysis in clinical material. In: Davidson FJ, RM Rowan, MM Samama, PC Desnoyers, Eds: Progress in Chemical Fibrinolysis and Thrombolysis. Raven Press, New York, 1978, p 327.

295. Harpel PC, MW Mosesson, NR Cooper: Studies on the structure and function of $\alpha$-2-macroglobulin and $\mathrm{C} 1$ inactivator. In: Reich E, DB Rifkin, E Shaw, Eds: Proteases and Biological Control. Cold Spring Habor Symposium, Cold Spring Habor, New York, 1975, p 387.

296. Murano G: Plasma protein function in hemostasis. In: Murano G, RL Bick, Eds: Basic Concepts of Hemostasis and Thrombosis. CRC Press, Boca Raton, FL, 1980, p 43.

297. Parvez Z, R Moncada: Immunological vs functional methods for the evaluation of serine protease inhibitors. $I n$ : Fareed $\mathrm{J}$, HL Messmore, J Fenton, KM Brinkhous, Eds: Perspectives in Hemostasis. Pergamon Press, New York, 1981, p 355.

298. Arneson H: Characterization of fibrinogen and fibrin degradation products by isoelectric focusing in polyacrylamide gel. Thromb Res 4:861, 1974.

299. Fletcher AP, N Alkjaersig: Blood hypercoagulability, intravascular coagulation, and thrombosis: New diagnostic concepts. Thromb Diath Haemorrh 45(Suppl):389, 1974.

300. Fletcher AP, NK Alkjaersig: Gel chromatography of fibrinogen in the diagnosis of prethrombotic states. In: Neri-Sernari GG, CRM Prentice, Eds: Haemostasis and Thrombosis. Academic Press, London, 1979, p 113.

301. Neri-Sernari GG, GF Gensini, R Abbate: High molecular weight fibrinogen complexes in the assessment of hypercoagulability. In: Neri-Sernari GG, CRM Prentice, Eds: Hemostasis and Thrombosis. Academic Press, London, 1979, p 123.

302. Kwaan HC: Disseminated intravascular coagulation. Med Clin North Am 56:177, 1972.

303. Maki M, K Sasaki, S Sato: Methods for differential diagnosis of consumptive coagulopathy. Tohoku J Exp Med 99:347, 1969.

304. Simpson JG, AL Stalker: The concept of disseminated intravascular coagulation. Clin Haematol 2:189, 1973.

305. Bick RL: Disseminated intravascular coagulation and related syndromes. II. Pract Cardiol 7:152, 1981.

306. Francis CW, VJ Marder: A molecular model of plasmic degradation of cross-linked fibrin. Semin Thromb Hemost 8:25, 1982.

307. Matsumoto T, Y Nishijima, Y Teramura, K Fujino, M Hibino, $M$ Hirata: Monoclonal antibodies to fibrinogen-fibrin degradation products which contain D-domain. Thromb Res $38: 279,1985$.

308. Rylatt DB, AS Blake, LE Cottis, DA Massingham, WA Fletcher, PP Masci, AN Whitaker, M Elms, I Bunce, AJ Weber, D Wyatt, PG Bundesen: An immunoassay for human D-dimer using monoclonal antibodies. Thromb Res 31:767, 1983.

309. Elms MJ, IH Bunce, PG Bundesen, DB Rylatt, AJ Webber,
PP Masci, AN Whitaker: Rapid detection of cross-linked fibrin degradation products in plasma using monoclonal antibody-coated latex particles. Am J Clin Pathol 85:360, 1986.

310. Bick RL, W Baker, R Patel: Diagnostic efficacy of the Ddimer assay in DIC and related disorders (D-dimer assay). Blood: 68:329, 1986.

311. Lane DA, FE Preston, ME Van Ross, VV Kakkar: Characterization of serum fibrinogen and fibrin fragments produced during disseminated intravascular coagulation. $\mathrm{Br} \mathrm{J}$ Haematol 40:609, 1978.

312. Elms MJ, IH Bunce, PG Bundesen, DB Rylatt, AJ Webber, PP Masci, AN Whitaker: Measurement of cross-linked fibrin degradation products - an immunoassay using monoclonal antibodies. Thromb Haemost 50:591, 1983.

313. Bick RL: Acquired circulating anticoagulants and defective hemostasis in malignant paraprotein disorders. In: Murano G, RL Bick, Eds: Basic Concepts of Hemostasis and Thrombosis. CRC Press, Boca Raton, FL, 1980, p 205.

314. Bick RL: Malignancy's effect on hemostasis: complex questions finding answers. Diagn Dialog 2:1, 1980.

315. Esmon CT: Protein-C: Biochemistry, physiology, and clinical implications. Blood 62:1155, 1983.

316. Griffin JH: Clinical studies of protein C. Semin Thromb Hemost 10:162, 1984.

317. Fibrin(ogen) Degradation Products (FDP) Detection Set. A product of the Data-Fi System, Product Circular. American Dade Corporation, Miami, September, 1980, p 1.

318. Murakami M: A new method of fibrinolysis measurement. Acta Haematol Jpn 28:341, 1965.

319. Wellcome FDP Kit. Detection of fibrinogen degradation products and fibrinogen. Burroughs Wellcome Company, Research Triangle Park, NC, 1977, p 39.

320. Murano G: The molecular structure of fibrinogen. Semin Thromb Hemost 1:1, 1974.

321. Bick RL: Disseminated intravascular coagulation and related syndromes. Am J Hematol 5:265, 1978.

322. Bick RL: Disseminated intravascular coagulation: A clinical/laboratory study of 48 patients. Ann NY Acad Sci 370: 843,1981

323. Bick RL: Disseminated intravascular coagulation: Clinical/laboratory correlations. Am J Clin Pathol 77:244, 1982.

324. Bick RL, J Fareed, G Squillaci, J Walenga, EW Bermes, HL Messmore: Molecular markers of hemostatic processes. Implications in diagnostic and therapeutic management of thrombotic and hemorrhagic disorders. Fed Proc 42:1031, 1983.

325. Bick RL, J Fareed, J Walenga, EW Bermes: Automation in coagulation testing. Clin Chem 29:1196, 1983

326. Fareed J, J Walenga, RL Bick, EW Bermes, HL Messmore: Impact of automation on the quantitation of low molecular weight markers of hemostatic defects. Semin Thromb Hemost 9:355, 1983.

327. Heene DL: Blood coagulation mechanism and endotoxins: Hemostatic defect in septic shock. In: Urbaschek B, Ed: Gram-Negative Bacterial Infections and Mode of Endotoxin Actions. Springer-Verlag, Vienna, 1975, p 367.

328. Leroy J, JD Lamagnere, C Mercier: La coagulopathic de consommation au cours des purpuras fulminans et son traitment (10 observations). Sem Hop Paris 50:843, 1974.

329. Lo SS, WH Hitzig, PG Frick: Clinical experience with anticoagulant therapy in the management of disseminated intravascular coagulation in children. Acta Haematol (Basel) 45: $1,1971$.

330. Corrigan JJ, CM Jordan: Heparin therapy in septicemia with 
disseminated intravascular coagulation. Effect on mortality and correction of hemostatic defects. N Engl J Med 283:778, 1970.

331. Good RA, L Thomas: Studies on the generalized Schwartzman reaction: Prevention of the local and generalized Schwartzman reactions with heparin. J Exp Med 97:871, 1953.

332. Heene DL: Disseminated intravascular coagulation: Evaluation of therapeutic approaches. Semin Thromb Hemost 3:291, 1977.

333. Al-Mondhiry $\mathrm{H}$ : Disseminated intravascular coagulation: Experience in a major cancer center. Thromb Diath Haemorrh 34:181, 1975.

334. Minna JD, S Robboy, RW Coleman: Clinical approach to a patient with suspected DIC. In: Minna JD, S Robboy, RW Coleman, Eds: Disseminated Intravascular Coagulation. Charles C Thomas, Springfield, IL, 1974, p 167.

335. Bonnar $\mathrm{J}$ : Blood coagulation and fibrinolysis in obstetrics. Clin Hematol 2:213, 1973.

336. Kuhn W, H Graeft: Gerinnungsstörungen in der Geburtshilfe. Thieme Verlag, Stuttgart, 1977, p 90.

337. Bick RL: Monitoring heparin therapy. Diagn Dialog 1:1, 1979.

338. Jacques LB: The premises involved in the clinical use of heparin. Semin Thromb Hemost 4:275, 1978.

339. Bick RL, LF Fekete, WL Wilson: Treatment of disseminated intravascular coagulation with antithrombin III. Trans Am Soc Hematol, 1976, p 167.

340. Kakkar VV: The clinical use of antithrombin III. Thromb Haemost 42:265, 1979.

341. Thaler E, K Lechner: Antithrombin III deficiency and thromboembolism. Clin Haematol 10:369, 1981.

342. Bick RL, WR Schmalhorst, LF Fekete: Disseminated intravascular coagulation and blood component therapy. Transfusion $16: 361,1976$.
343. Gralnick HR, P Greipp: Thrombosis with epsilon-aminocaproic acid therapy. Am J Clin Pathol 56:151, 1971.

344. McNicol GP, AS Douglas: Thrombolytic therapy and fibrinolytic inhibitors. In: Biggs R, Ed: Human Blood Coagulation, Haemostasis, and Thrombosis. Oxford Press, London, 1972, p 393.

345. Naeye RL: Thrombolytic state after hemorrhagic diathesis, possible complications of therapy with epsilon-aminocaproic acid. Blood 19:694, 1962.

346. Bick RL, MB Bick, LF Fekete: Antithrombin III patterns in disseminated intravascular coagulation. Am J Clin Pathol 73: 577, 1980.

347. Edwards EA: Migrating thrombophlebitis associated with carcinoma. N Engl J Med 240:1031, 1949.

348. Bick RL: Treatment of bleeding and thrombosis in the patient with cancer. In: Nealon T, Ed: Management of the Patient with Cancer. WB Saunders, Philadelphia, 1976, p 48.

349. Goodnight $\mathrm{SH}$ : Bleeding and intravascular clotting in malignancy: A review. Ann NY Acad Sci 230:271, 1974.

350. Harker LA, J Hirsh, M Gent, E Genton: Critical evaluation of platelet inhibiting drugs in thrombotic disease. Prog Hematol. 9:229, 1975.

351. Weiss HJ: The pharmacology of platelet inhibition. Prog Hemost Thromb 1:199, 1972.

352. Nalbandian RM, RL Henry: Platelet-endothelial cell interactions: Metabolic maps of structures and actions of prostaglandins, prostacyclin, thromboxane, and cyclic AMP. Semin Thromb Hemost 5:87, 1978.

353. Brown RC, DC Campbell, JH Thompson: Increased fibrinolysis with malignant disease. Arch Intern Med 109:129, 1962.

354. Omar JB, H Saxena, HS Mitel: Fibrinolytic activity in malignant diseases. J Assoc Physicians India 19:293, 1971. 